\title{
Proton export drives the Warburg Effect
}

Shonagh Russell1,2, Liping Xu1, Yoonseok Kam1, Dominique Abrahams1, Bryce Ordway1,2, Alex S. Lopex1, Marilyn Bui1, Joseph Johnson 1 , Tamir Epstein1, Epifanio Ruiz1, Mark C. Lloyd1, Pawel Swietach3, Daniel Verduzco1,, Jonathan Wojtkowiak1, \& Robert J. Gillies1* 1Moffitt Cancer Center, 12902 USF Magnolia Dr, Tampa, 33612, FL, USA

${ }_{2}$ Graduate School, University of South Florida, 4202 E Fowler Ave, Tampa, 33620, FL, USA

3Department of Physiology, Anatomy and Genetics, University of Oxford, Parks Road, Oxford, OX1 3PT, UK

RJG is supported by a grant from Helix, Biopharma. The authors declare no other potential conflicts of interest.

6 Figures

1 Table

86 References

2 Supplemental Tables

24 supplemental Figures

Acknowledgements: NIH U54 CA193489 (RJG); NIH R01 CA 077575-17 (RJG); NIH F99 CA234942 (SR); NIH P30 CA076292 (core grant); ERC Consolidator Award SURVIVE \#723997 (PS) 


\begin{abstract}
Aggressive cancers commonly ferment glucose to lactic acid at high rates, even in the presence of oxygen. This is known as aerobic glycolysis, or the "Warburg Effect". It is widely assumed that this is a consequence of the upregulation of glycolytic enzymes. Oncogenic drivers can increase the expression of most proteins in the glycolytic pathway, including the terminal step of exporting $\mathrm{H}^{+}$equivalents from the cytoplasm. Proton exporters maintain an alkaline cytoplasmic $\mathrm{pH}$, which can enhance all glycolytic enzyme activities, even in the absence of oncogene-related expression changes. Based on this observation, we hypothesized that increased uptake and fermentative metabolism of glucose could be driven by the expulsion of $\mathrm{H}^{+}$ equivalents from the cell. To test this hypothesis, we stably transfected lowly-glycolytic MCF7, U2-OS, and glycolytic HEK293 cells to express proton exporting systems: either PMA1 (yeast $\mathrm{H}^{+}$-ATPase) or CAIX (carbonic anhydrase 9). The expression of either exporter in vitro enhanced aerobic glycolysis as measured by glucose consumption, lactate production, and extracellular acidification rate. This resulted in an increased intracellular $\mathrm{pH}$, and metabolomic analyses indicated that this was associated with an increased flux of all glycolytic enzymes upstream of pyruvate kinase. These cells also demonstrated increased migratory and invasive phenotypes in vitro, and these were recapitulated in vivo by more aggressive behavior, whereby the acid-producing cells formed higher grade tumors with higher rates of metastases. Neutralizing tumor acidity with oral buffers reduced the metastatic burden. Therefore, cancer cells with increased $\mathrm{H}^{+}$export increase intracellular alkalization, even without oncogenic driver mutations, and this is sufficient to alter cancer metabolism towards a Warburg phenotype.
\end{abstract}




\section{Introduction}

In 1924, Otto Warburg and colleagues demonstrated that cancer, even in the presence of oxygen, ferments glucose to lactic acid at high rates (Warburg et al., 1924), and this was contemporaneously confirmed by the Coris (Cori and Cori, 1925). Aerobic glycolysis, commonly termed the "Warburg Effect" in cancer (DeBerardninis and Chandel, 2020; Vaupel and Multhoff, 2020), is undeniably a hallmark of primary tumors and aggressive invasive disease (Hanahan and Weinberg, 2011). This preference of tumors for aerobic glycolysis is exploited in diagnostic PET imaging of fluorodeoxyglucose ( $\left.{ }^{18} \mathrm{~F}-\mathrm{FDG}\right)$ uptake (Kunkel et al., 2003). It is commonly believed that this increased fermentative glycolysis, and thus proton flux, is driven by oncogenes, such as RAS, MYC, HIF, and AKT (Kim et al., 2007; Wonsey et al., 2002), and that this augmented flux out-competes the ability of mitochondria to oxidize pyruvate, leading to the net production and export of lactic acid and reconversion of NADH to $\mathrm{NAD}^{+}$to maintain redox balance. Hence, the Warburg Effect could solely be an epiphenomenon of oncogene activation, which is consistent with the observation that fermentation under aerobic conditions is energetically unfavorable and does not confer any clear evolutionary benefits (Vander Heiden et al., 2009).

We propose an alternative to this canonical view, building on principles of evolutionary dynamics (Gatenby and Gillies, 2004b). Aerobic glycolysis is such a commonly observed phenotype of aggressive cancers (Rizwan et al., 2013; Yu et al., 2015), we argue that it MUST confer some selective advantage for tumor growth (Damaghi et al., 2021). An inherent consequence of glycolysis is lactic acid production, and we propose that acid secretion per se renders cells more competitive, despite the energetic cost (Gatenby et al., 2006b; Gillies et al., 2008). Indeed, oncogenic drivers upregulate expression of proton exporting systems, e.g., sodium hydrogen antiporters, NHEs (Cardone et al., 2015; Cheng et al., 2019), carbonic anhydrase 9, CA-IX (Kopacek et al., 2005; Mahon et al., 2016; Takacova et al., 2010), and sodium-bicarbonate co-transporters, NBCs (Boedtkjer, 2019). Such activities will exacerbate the intra- to extracellular $\mathrm{pH}$ gradient, raising the intracellular $\mathrm{pH}(\mathrm{pHi})$ and acidifying the extracellular $\mathrm{pH}(\mathrm{pHe})$. These transporters have been associated with breast cancer aggressiveness (Beketic-Oreskovic et al., 2010). Additionally, glycolytic enzymes all exhibit 
significant pH-dependence (Persi et al., 2018), and thus maintenance of an alkaline pHi would directly promote increased glycolytic flux.

Simultaneously, lowering pHe provides invading cancer cells competitive benefits that can enhance colonization, invasion, and metastasis. These benefits include extracellular matrix remodeling via release and activation of proteases to increase invasion (Kato et al., 2005; Stock and Schwab, 2009; Webb et al., 2011b), inhibition of immune surveillance (Brand et al., 2016), promotion of an epithelial-to-mesenchymal transition (EMT) (Nieto et al., 2016; Pastushenko et al., 2018; Puisieux et al., 2014; Riemann et al., 2019), and anchorage-independent growth (Damaghi et al., 2015; Jin et al., 2018; Paoli et al., 2013; Peppicelli et al., 2019). This is further supported by the observation that neutralization of $\mathrm{pHe}$ acidity can inhibit invasion and metastases (Estrella et al., 2013; Robey et al., 2009).

The current study investigates whether aerobic glycolysis can be driven by protonexport, and further investigates the impact of this on cancer aggressiveness. We demonstrate that over-expression of proton exporters is sufficient to increase aerobic glycolysis, through enhanced glucose uptake and lactate production. We further observed that proton export increased intracellular $\mathrm{pH}$ and increased metabolic flux at most steps in glycolysis. Finally, we observed in vivo that these proton-exporting cell lines were more aggressive, generating higher-grade tumors and increased metastases. There is a known association between acid production, aerobic glycolysis, and metastatic potential. Further, experimental metastases can be inhibited with acidneutralizing buffers. The current work adds to this literature by demonstrating that acid production per se can be sufficient to drive the Warburg Effect and promote metastasis.

\section{RESULTS}

10 Overexpression of CA-IX in cancer cells increases glycolytic metabolism

CA-IX hydrates extracellular $\mathrm{CO}_{2}$ to $\mathrm{H}^{+}+\mathrm{HCO}_{3}{ }^{-}$. This facilitates $\mathrm{CO}_{2}$ diffusion away

12 from the cell reducing $\mathrm{pH}$ gradients across tissues. The bicarbonate generated from $\mathrm{CO}_{2}$

13 hydration, a reaction that occurs either spontaneously or is sped up by carbonic anhydrases, can

14 then reenter the cell via $\mathrm{Na}^{+}+\mathrm{HCO}_{3}{ }^{-}$co-transporter (Boedtkjer, 2019; Svastova et al., 2012).

15 Numerous studies in, e.g., breast, ovarian (Choschzick et al., 2011), and astrocytoma

16 (Nordfors et al., 2013) cancers have shown that CA-IX expression correlates with poor prognosis 
17 and reduced survival. Figure 1A shows the overall survival of ER+ breast cancer patients with

18 low and high (median cutoff) CA-IX expression was 143 and 69.4 months, respectively, p=9.32

19 e-7. Although the sample size was smaller, a similar pattern was seen for metastasis-free

20 survival in patients with low and high CA-IX expression, 130 vs. 50 months, respectively,

$21 \mathrm{p}=0.0012$. Metastasis-free survival is also reduced in other cancers with high CA-IX expression,

22 including cervical and colorectal (van Kuijk et al., 2016). CA-IX's role in outcome makes it a

23 clinically significant target warranting further investigation.

To test the hypothesis that proton export can drive aerobic glycolysis, we established models which over-expressed proton exporters. We transfected MCF-7 cells with a CA-IX expression vector and isolated two individual clones (M1 and M6) and confirmed CA-IX protein expression (Fig. 1B). MCF-7 cells do not express CA-IX under normoxic conditions, but do express other carbonic anhydrases, CA-II and CA-XII (Fig. 1B). CA-IX is distinct among exofacial CA's (CA-IV, CA-XII), as it contains a proteoglycan domain, which enables it to maintain enzymatic activity at lower pHe (Li et al., 2011). In tissues, CA-IX can function as a "pH-stat", which tumors hijack to maintain an acidic pHe (Lee et al., 2018). We also transfected MCF-7 cells with an empty pcmv6 vector hereafter referred to as MOCK-2. Additionally, we confirmed by ICC that CA-IX, an exofacial membrane-bound protein, was expressed on the plasma membrane in both CA-IX clones (Fig. 1C).

To test our hypothesis that proton export can drive aerobic glycolysis, we interrogated the metabolism of our CA-IX expressing clones using a Seahorse XFe96 Extracellular Flux (XF) Analyzer, enzymatic, and radiochemical assays to assess both glycolytic and mitochondrial metabolism. Specifically, the Seahorse glycolytic stress tests (GST) showed that both CA-IX clones exhibited higher proton production rates (PPR) upon glucose stimulation compared to

40 MOCK-2 or parental clones (Fig. 1D). Using glucose, and $\left[{ }^{3} \mathrm{H}\right]$-2-deoxyglucose (2DG) uptake

41 assays (Fig. 1E \& Supplementary Fig. 1), and lactate production rate assays (Fig. 1F \&

42 Supplementary Fig. 2), we further confirmed CA-IX expressing clones had increased glycolysis

43 in normoxic conditions. Mitochondrial metabolism in these clones, as measured by Seahorse

44 mitochondrial stress test (MST), exhibited a decreased reliance on oxidative phosphorylation. In

45 the CA-IX clones, both basal oxygen consumption rates (Fig. 1G) and reduced ATP-linked

46 oxygen consumption rates (Supplementary Fig. 3) were decreased compared to MOCK-2 or 
parental cells. CA-IX expressing clones also had hyperpolarized mitochondria (Supplementary

A.

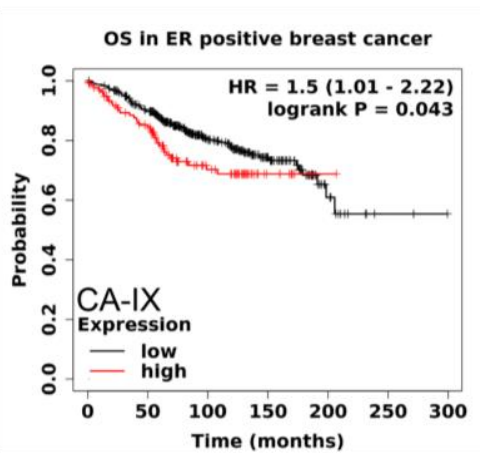

B.

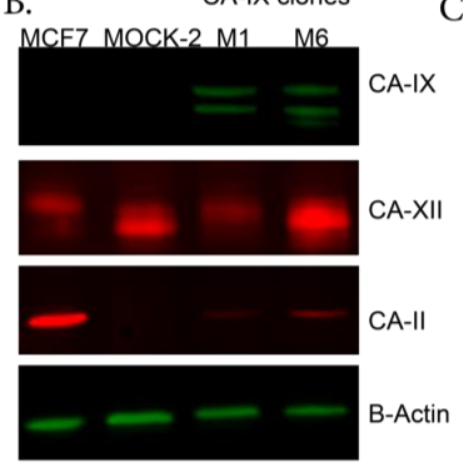

C.

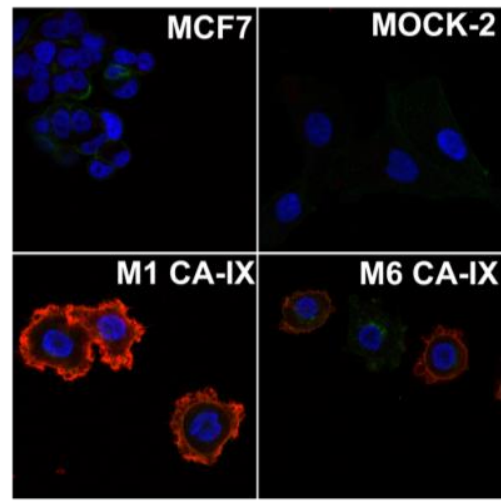

F.

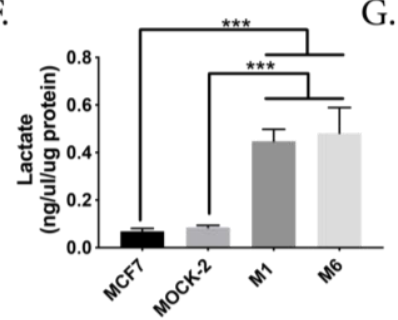

G.

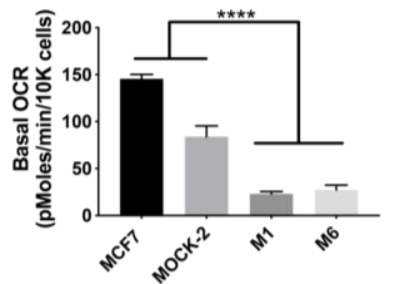

D.

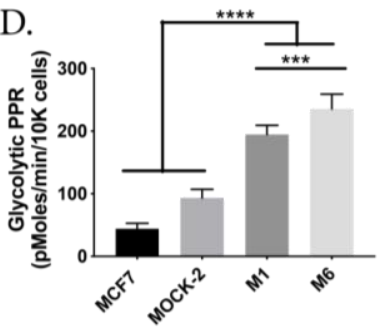

E.

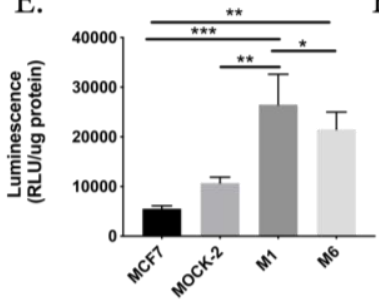

Figure 1: Over-expression of CA-IX in MCF-7 breast cancer cells increases glycolytic metabolism in vitro A: Overall survival Kaplan-Meier Curve in ER-positive breast cancer comparing low and high CA9 gene expression $n=1402$ (kmplot.com). Statistical analysis using Log rank P test $\mathrm{p}=0.0024$. B: Immunoblotting of protein lysates from MCF-7 cells transfected with empty vector (MOCK-2) or Ca9 vector (M1 and M6). Proteins from total cell extracts were immunoblotted for CA-IX, CA-II, CA-XII, and B-actin (loading control). C: Representative immunocytochemistry images of CA-IX protein expression in MCF-7, MOCK-2, and CA-IX clones M1 and M6. CA-IX clones (M1 \& M6) exhibit CA-IX membrane staining, whereas MOCK-2 and parental MCF-7 cells do not. DAPI nuclear stain (blue), Wheat germ agglutinin membrane stain (green), and CA-IX stain (red). D: Glycolysis associated proton production rate (PPR) using the Seahorse extracellular flux analyzer, measured post glucose injection. Data are shown as mean $\pm \mathrm{SD}, \mathrm{N}=8$ biological replicates per group, statistical analysis using ordinary one-way ANOVA. E: Glucose uptake of cells in each group over $24 \mathrm{hr}$, measured as luminescence generated using Glucose Uptake-Glo assay (Promega). N=3, statistical analysis using ordinary one-way ANOVA. F: Lactate measured in extracellular media after $24 \mathrm{hr}$ using Sigma kit. N=3 biological replicated per group, statistical analysis using ordinary one-way ANOVA. G: Basal oxygen consumption rate (OCR) measured using the Seahorse extracellular flux analyzer in $5.8 \mathrm{mM}$ glucose concentration. Data are shown as mean $\pm \mathrm{SD}, \mathrm{N}=8$ biological replicates per group, statistical analysis using ordinary one-way ANOVA. $* \mathrm{p}<0.05, * * \mathrm{p}<0.01, * * * \mathrm{p}<0.001, * * * * \mathrm{p}<0.0001$ tested other cell lines. CA-IX was over-expressed in U2-OS osteosarcoma human cells and HEK 293 human embryonic kidney cells. CA-IX expression upregulated glycolysis in both cell lines, 
73 cells, which have higher basal glycolysis than the other cell lines tested, over-expression of the

74 proton exporting CA-IX still enhanced their rate of aerobic glycolysis.

75 To delineate which steps in glycolysis were being impacted by acid export, we analyzed

76 the intracellular metabolites using mass spectrometry and a library of known metabolites (see

77 methods). Principal component analysis (PCA) showed a statistically significant separation of

78 MOCK-2 and parental MCF-7 from the CA-IX clones (Fig. 2A). Notably, PCA also showed that

79 the parental and MOCK-2 cells had distinct metabolic profiles, but neither overlapped with the

80 CA-IX clones. Consistent with this, heatmap visualization of the top 50 most significantly

81 altered metabolites showed that the two CA-IX clones exhibited similar metabolic profiles (Fig.

82 2B) but were considerably different from the MOCK-2 and parental clones. MOCK-2 cells grow

83 more rapidly in vitro compared to the parental MCF-7 or the CA-IX clones which is likely why

84 they exhibit a different metabolic profile from the parental line (Supplementary Fig. 7). We

85 note later, however, that this difference in growth rate was not maintained in vivo when grown as

86 primary tumors (Fig.4A). Out of all metabolites assessed, the glycolytic intermediates were

87 consistently altered in the CA-IX clones compared to parental or MOCK-2.

The CA-IX clones exhibited increased levels of all glycolytic intermediates upstream of

89 pyruvate kinase, PK (Fig. 2C-J), which catalyzes the penultimate step of glycolysis: the

90 conversion of phosphoenolpyruvate (PEP) + ADP $\rightarrow$ pyruvate +ATP. Thus, it appears that the

91 activities of the upstream enzymes have increased, leading PK to now become rate-limiting for

92 glycolytic flux in the CA-IX expressing cells (Fig. 2J). As the CA-IX cells have higher

93 glycolytic flux (Fig. 1D-F), the most straightforward interpretation is that CA-IX expression de-

94 inhibited all of the enzymatic steps upstream of PK. Overall, CA-IX expression enhances

95 glycolytic intermediates' flux, resulting in enhanced lactate and acid production. 
A.

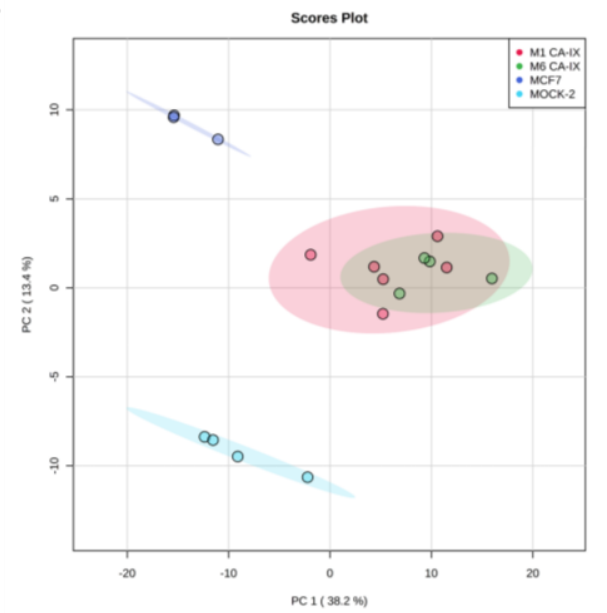

C.

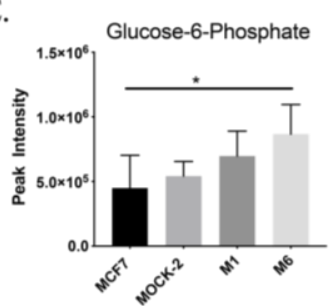

E. Fructose-1,6-Bisphosphate F.

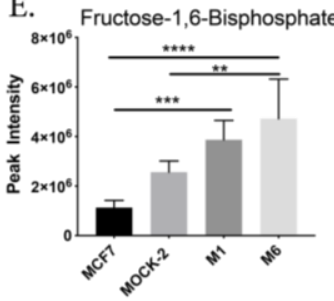

G.

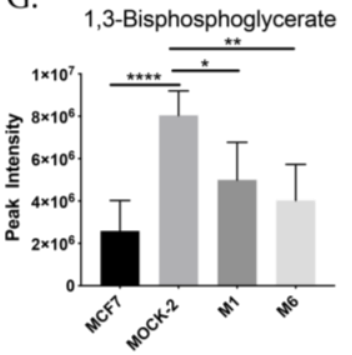

D.

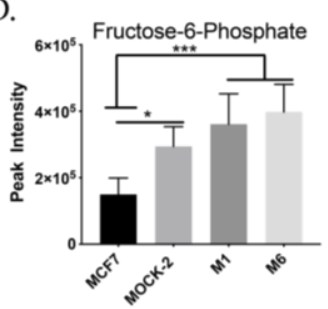

F.

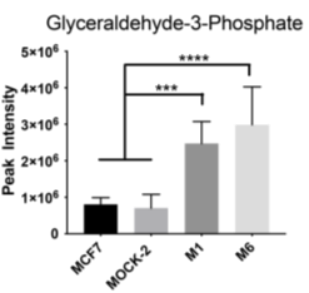

H.

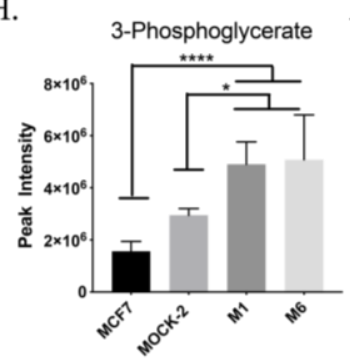

B.

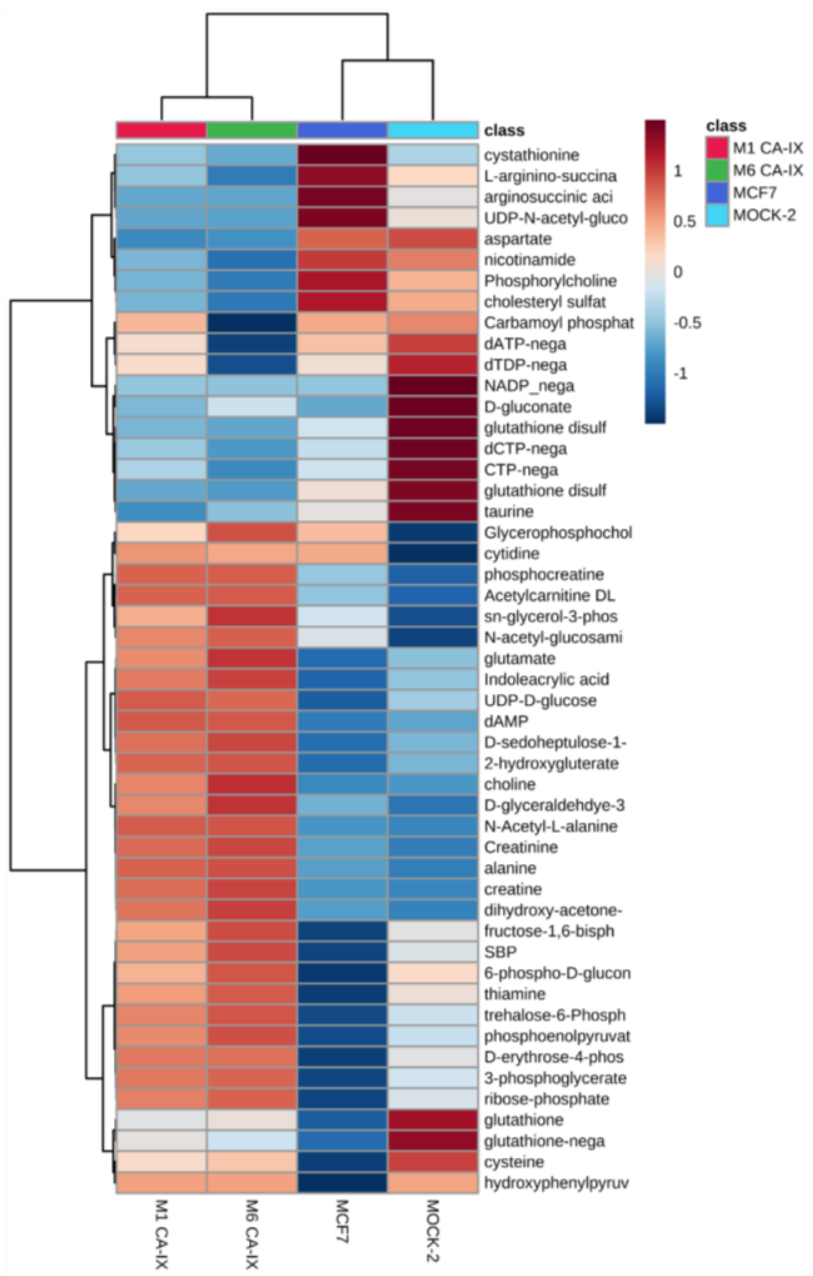

I.

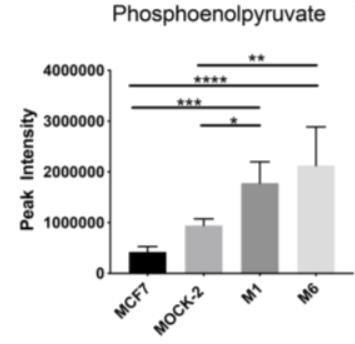

J.

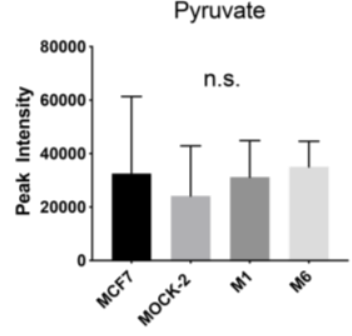

Figure 2: Unlabeled metabolic profiling of CA-IX expressing MCF-7 cells intracellular metabolites and analysis of the glycolytic metabolites A: Principal component analysis of intracellular metabolites in CA-IX expressing, MOCK-2, and Parental MCF-7 cells. B: Heatmap (hierarchical clustering) of the fifty most significant fold changes of intracellular metabolites between CA-IX expressing clones, MOCK-2, and Parental cells. Numerous glycolytic intermediates were significantly higher in CA-IX expressing cells compared to MOCK-2 and Parental. C-F: Average peak intensity of each glycolytic intermediate in CA-IX expressing, MOCK-2 and Parental MCF-7 Cells. N=5-6 biological replicates per group, statistical analysis using ordinary one-way ANOVA. G-J: Average peak intensity of each glycolytic intermediate in CA-IX expressing, MOCK2 and Parental MCF-7 Cells. N=5-6 biological replicates per group, statistical analysis using ordinary one-way ANOVA. $* \mathrm{p}<0.05, * * \mathrm{p}<0.01, * * * \mathrm{p}<0.001, * * * * \mathrm{p}<0.0001$ 
Our metabolomics studies suggest multiple glycolytic enzymes were impacted, we

110 therefore hypothesized that CA-IX expression might raise the intracellular $\mathrm{pH}$ of cells, which

111 could pleiotropically increase glycolytic enzyme rates. Most glycolytic enzymes have ionizable

112 residues that can alter their enzyme activity. Recently, these residues have been characterized for

113 all glycolytic enzymes through homology modelling, which predicted glycolytic enzyme

114 activities generally increase with pHi above neutral (Persi et al., 2018). We tested the PPR in

115 MCF-7 parental cells after altering pHi in a range of pHe media 6.6-7.4, expecting that the PPR

116 rate would increase with increasing pHi. Cells were incubated with either a chloride-containing

117 solution or an iso-osmotic low-chloride formulation which replaced chloride salts with gluconate

118 equivalents. Low-chloride solutions alter the driving force for $\mathrm{Cl}^{-} / \mathrm{HCO}_{3}{ }^{-}$exchangers, effectively

119 loading cells with $\mathrm{HCO}_{3}{ }^{-}$ions and raising $\mathrm{pHi}$ at the same pHe (Sasaki and Yoshiyama, 1988;

120 Wu et al., 2020). At all values of pHe from 6.6-7.2, cells in gluconate media exhibited

121 significantly higher glycolytic rates compared to those in chloride-containing media (Fig. 3A \&

122 Supplementary Fig. 8), indicating that the increased glycolytic rate is strongly dependant on 123 pHi.

124 CA-IX overexpression has been shown to increase pHi in other systems (Morgan et al.,

125 2007), leading us to probe pHi in our CA-IX expressing cells. We used a pHi reporter dye,

126 cSNARF1 to measure the effects of CA-IX expression on intracellular $\mathrm{pH}$ (pHi). A cSNARF1

127 calibration curve was generated using nigericin/K+ $\mathrm{K}^{+}$buffers (Supplementary Fig. 9). We then

128 loaded MCF7 parental or the CA-IX expressing clones with cSNARF1 and used fluorescence

129 imaging to measure pHi. MOCK-2 cells were unsuccessfully loaded with cSNARF1, possibly

130 due to reduction or loss of esterase activity from the integration of the MOCK-2 plasmid into the

131 MCF-7 DNA; therefore, they are not included in these analyses. We equilibrated the cells in

132 media at pHe 6.6, 6.8, 7.1, and 7.4 and co-loaded them with cSNARF1 and nuclear dye Hoechst

133 33342. The inclusion of a nuclear dye allowed post-processing to mask the nucleus, ensuring

134 measurement of cytoplasmic $\mathrm{pH}$ only. At the intermediate pHe values of 6.8 and 7.1, the CA-IX

135 expressing clones had significantly higher pHi compared to parental (Fig. 3C, D \&

136 Supplementary Table 1). The enzymatic activity of CA-IX is optimal at $\mathrm{pH} 6.8$ and drops 
137 precipitously as the $\mathrm{pH}$ is lowered to 6.0 (Li et al., 2011)(McIntyre et al., 2012). Consistent with 138 this, at an acidic pHe of 6.4, we observed that the MCF7 parental cells had a higher intracellular

139 pH compared to CA-IX clones (Fig. 3B \& Supplementary Table 1), suggesting CA-IX

140 enzymatic function was strongly reduced resulting in reduced $\mathrm{CO}_{2}$ venting. There were no

141 significant differences in pHi at pHe 7.4 (Fig. 3E \& Supplementary Table 1). These data show

142 that CA-IX expression can raise the $\mathrm{pHi}$ at intermediate $\mathrm{pHe}$ values and that thus increasing $\mathrm{pHi}$

143 likely results in increased glycolytic flux by globally enhancing glycolytic enzyme activity.

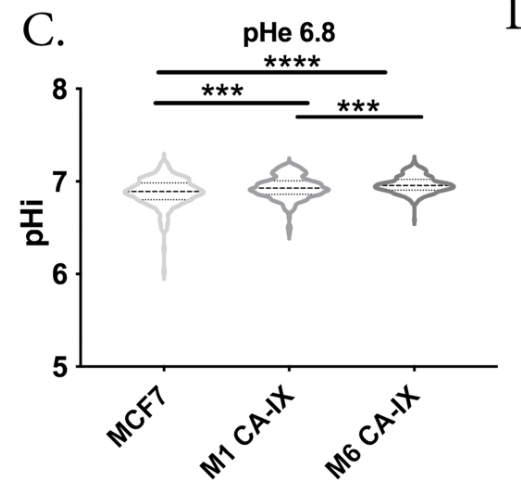
$* * * \mathrm{p}<0.001, * * * * \mathrm{p}<0.0001$
A.

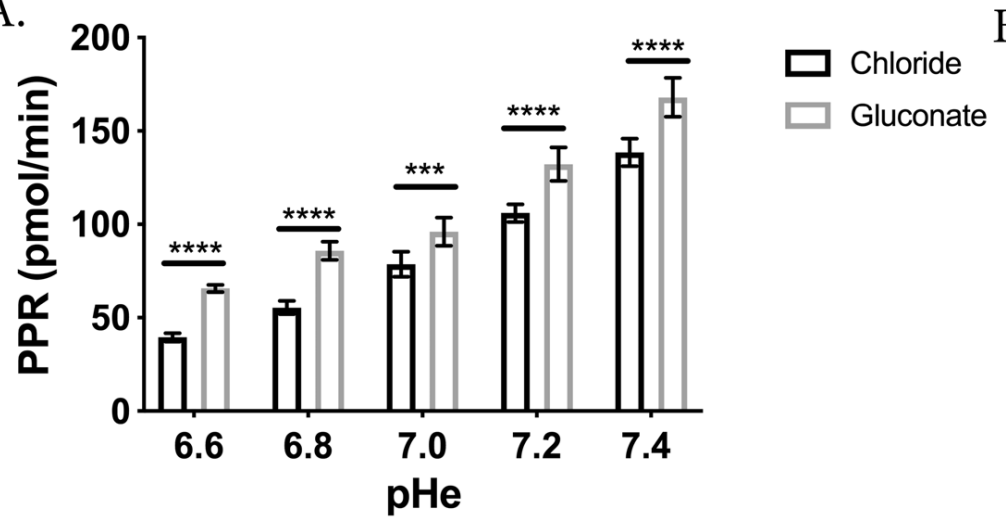

B.

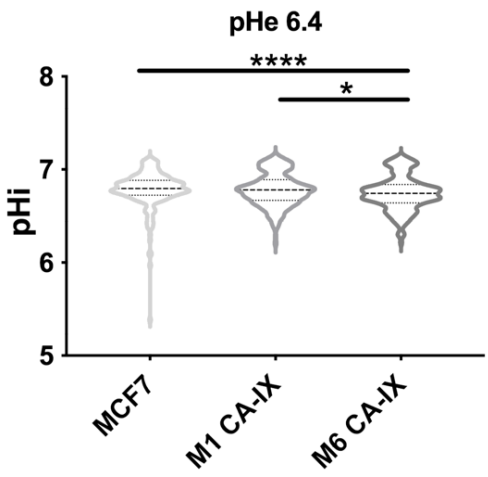

D.

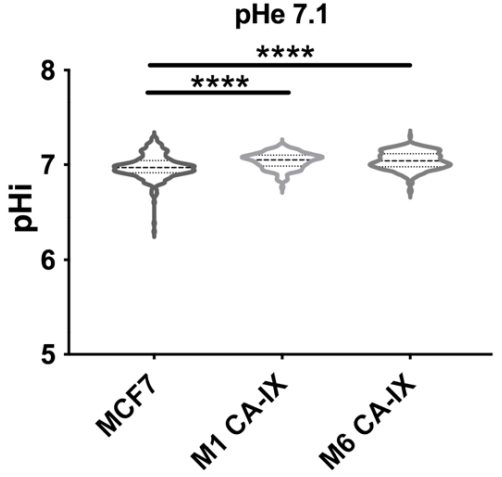

E.

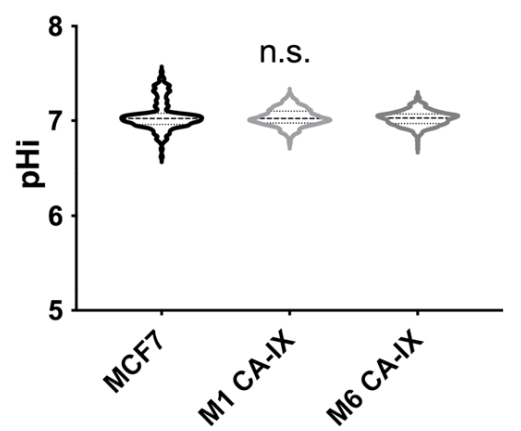

Figure 3: Increased intracellular pH enhances glycolysis in breast cancer cells. A: Increased intracellular $\mathrm{pH}$, using gluconate substituted media, increases the glycolytic rate in MCF7 cells irrespective of $\mathrm{pHe}$. N=8 per group, statistical analysis using Welch's T-test; B-E: Intracellular $\mathrm{pH}$ as measured using cSNARF1 in varying extracellular $\mathrm{pH}, \mathrm{n}=158-438$ cells analyzed per group, statistical analysis using Kruskal-Wallis test. *p $<0.05$, 
We then investigated the effect of CA-IX expression on migration, invasion, and metastasis, as there are reported correlations between increased glycolytic flux, reduced extracellular pH, and metastasis (Birchmeier et al., 2003; Estrella et al., 2013; Hiraga et al., 2013; Kato et al., 2004). Additionally, CA-IX has been associated with increased invasion and metastasis in several systems (Swayampakula et al., 2017; Ward et al., 2015).

In vitro, we utilized scratch assays and gel escape to measure migration and invasion in the CA-IX clones. Scratch assays showed that clone M1 had increased migratory ability

162 (Supplementary Fig. 10), closing the wound significantly more rapidly than controls. However, 163 this was not observed in the M6 CA-IX clone. In the gel escape assay, expansion out of the gel

164 is due to a combination of proliferation, invasion, and migration. Both CA-IX clones invaded

165 the area surrounding the gel drop substantially quicker than the parental MCF-7 clone

166 (Supplementary Fig. 11). Compared to the MOCK-2 cells, however, only the M6 clone was

167 significantly more invasive. The apparent increased invasion rate by MOCK-2 compared to

168 parental is likely due to their increased proliferation rate as correcting for proliferation eliminates

169 the difference between MOCK-2 and parental (Supplementary Fig. 7). It is important to note

170 that these assays were carried out at neutral $\mathrm{pH}$ and that the invasive behavior might be further

171 enhanced by low pH, as we have shown previously for melanoma cells (Moellering et al., 2008).

172 Together, these studies suggest that CA-IX expression can enhance cell motility, increasing

173 migration and local invasion.

$174 \quad$ Furthermore, aggressive cancers with stem-like properties can resist anoikis, which can

175 be measured in vitro by cells' ability to form spheroids independent of attachment to a basement

176 membrane. Utilizing the hanging droplet technique, we observed that CA- IX expression enabled

177 robust, compact spheroid formation, compared to the MOCK-2 and parental MCF-7 clones,

178 which could not (Supplementary Fig. 12). This spheroid forming ability suggests CA-IX not

179 only enhances cell:cell adhesion but also suggests that increased proton export can contribute to

180 anoikis resistance when detached from the basement membrane.

181 Although the phenotype of our proton exporting CA-IX clones appeared to be more

182 aggressive, this could be an in vitro only phenomenon. We thus investigated the clones in vivo.

183 We studied the effect of CA-IX expression on primary tumor growth, as well as the ability of

184 these clones to form both spontaneous (from the mammary fat pad) and experimental (tail vein 
185 injected) metastasis. For primary and spontaneous metastasis models, MOCK-2, M1 or M6 CA-

186 IX MCF-7 cells were implanted in the mammary fat pads of mice, and growth was monitored by

187 caliper measurement. Although in vitro, mock cells proliferated faster (Supplementary Fig. 7),

188 this was not observed in vivo, as the tumors from CA-IX expressing clones grew significantly

189 faster. At all of the time points measured, primary tumor volume was significantly increased in

190 the CA-IX expressing clones, compared to controls (Fig. 4A \& Supplementary Fig. 13).

191 Regression-based analysis determined the growth rate of tumors was significantly different

192 between the groups, $\mathrm{p}<0.0001$. After resection, the primary tumors were sectioned, stained with

193 H \& E, and blindly graded by a board-certified pathologist (M.B.), who identified increased

194 stromal invasion in the CA-IX expressing tumors (Fig. 4B). The mice were monitored for an

195 additional 12 weeks post-resection, at which time the animals were sacrificed, and lungs stained

196 for evidence of micro and macro metastases, scored blindly by a board-certified pathologist

197 (M.B.). As shown in Table 1, 6/21 mice developed spontaneous metastasis from the M6 clone,

198 whereas no spontaneous metastases were formed form the M1 clone and 1/10 were formed in the

199 MOCK clones.

Table 1: Effect of CA-IX expression on metastasis of MCF-7 cells. (Two-tailed Fisher's exact t-test p $\left.<0.05^{*}\right)$

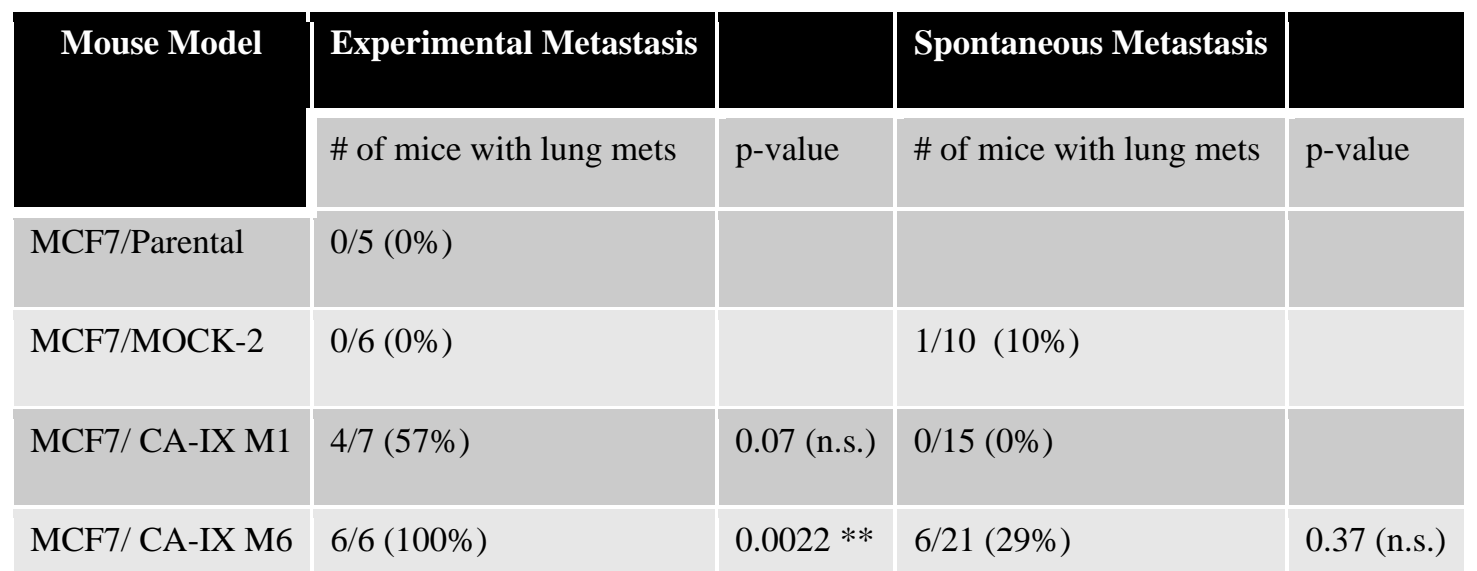

Because formation of spontaneous metastases is a multi-step, time-consuming, and

204 complex process, we also investigated the ability of these clones to form experimental metastases

205 following tail-vein injection, which only involves the final steps of extravasation and 
206 colonization. Metastases to the lung were scored blindly by a board-certified pathologist (M.B.),

207 who observed that neither of the control groups developed metastases, and that both CA-IX

208 clones had significant macrometastases (Table 1). Consistent with the spontaneous model, the

209 M1 formed fewer metastases compared to the M6, however both CA-IX clones exhibited gross

210 metastasis to the lungs (Fig. 4C), which were confirmed histologically (Fig. 4D). The resulting

211 macrometastases significantly reduced overall survival of the mice (Fig. 4E). Additional IHC

212 staining confirmed the lung metastasis expressed both CA-IX and human estrogen receptor,

213 which we used as a marker for MCF7 cells (Fig. 4F).

214 Prior studies have shown that neutralization of acidity using oral buffers inhibits

215 metastasis (Ibrahim-Hashim et al., 2017; Ibrahim-Hashim et al., 2012). As we hypothesized that

216 our M6 CA-IX clones were metastatic by virtue of increased acid production (Fig. 1D, E), we

217 asked whether buffer therapy would reduce the metastatic burden. Using the experimental

218 metastasis model, we compared untreated to buffer-treated M6 or MOCK-2 mice. As in the first

219 experimental metastasis study, all mice injected with M6 developed macrometastases, and these

220 were significantly reduced by bicarbonate (Fig. 4G \& H). Two out of ten MOCK-2 mice

221 developed very small micrometastasis, and no metastases were found in the buffer therapy

222 MOCK-2 group (Fig. 4G). 

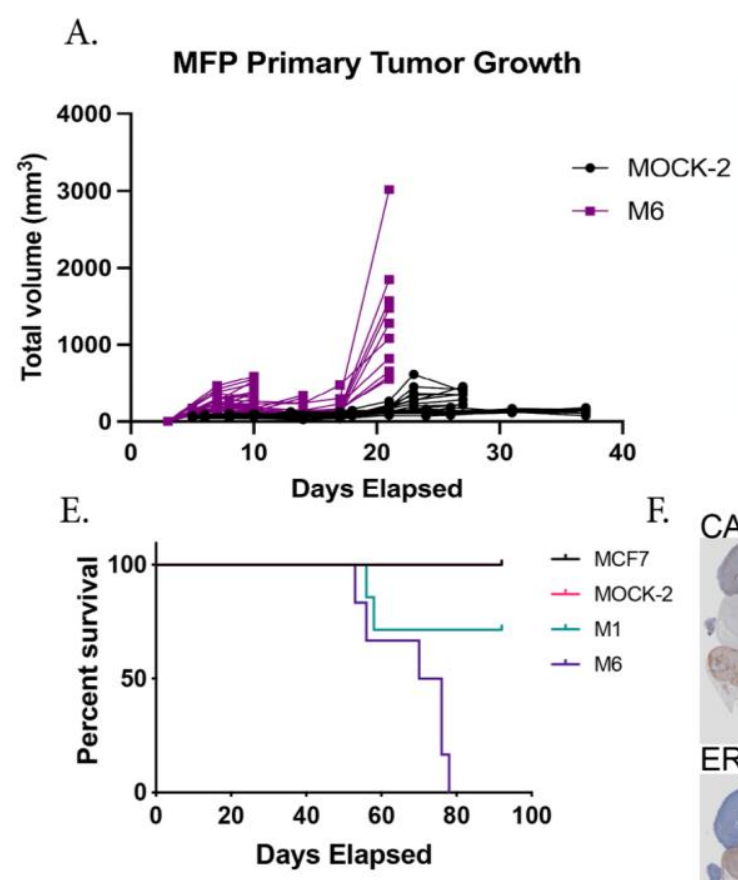

B.

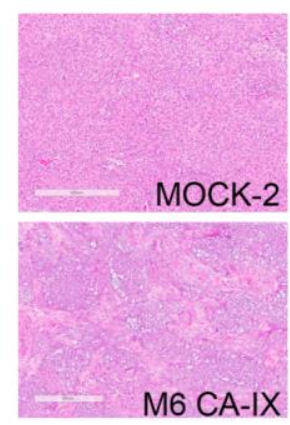

F.

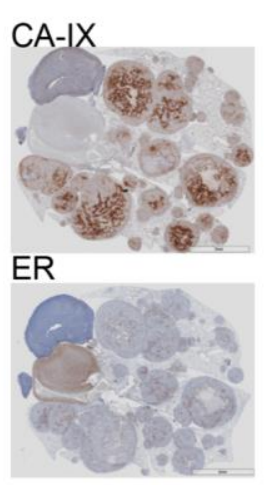

$\mathrm{G}$.
C.
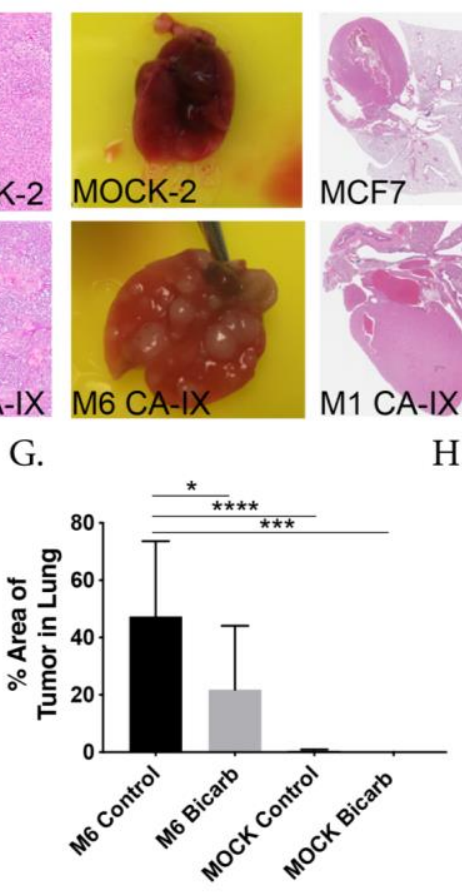

D.

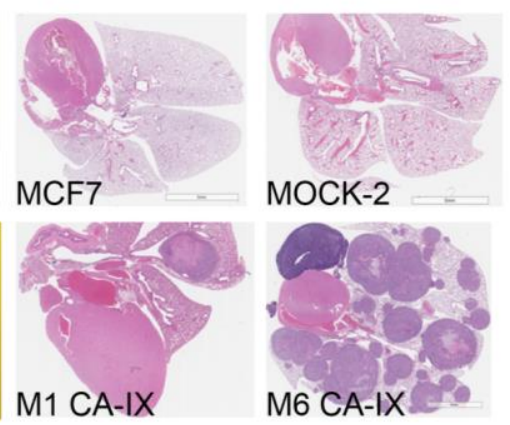

$\mathrm{H}$.

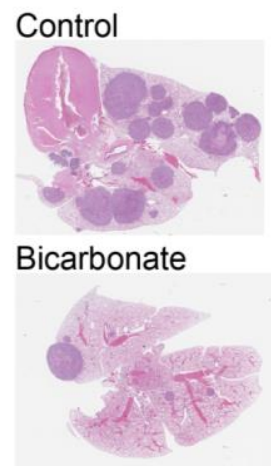

Figure 4: In vivo studies of CA-IX expressing cells and the effect on tumor growth, metastasis, and buffer therapy A: Primary tumor volume of control or CA-IX cells implanted in the mammary fat pad, $n=10$ mice per group, statistical analysis using Welch's T-test. Statistical analysis of the tumor volume was carried out to determine if tumor growth rate was different between the Mock-2 and M6 groups. Linear regression analysis showed the differences between the slopes were extremely significant. $\mathrm{F}=21.03$. $\mathrm{DFn}=1, \mathrm{DFd}=116, \mathrm{P}<0.0001$ B: Representative H\&E staining of resected primary tumors. M6 CA-IX group showed high infiltration of stromal cells compared to MOCK-2. C: Representative whole lung images from MOCK-2 and M6 experimental metastasis model showing the extent of metastasis visible. D: Representative immunohistochemistry of H\&E staining in the lungs of the experimental metastasis groups, showing gross metastasis of the lungs. E: KaplanMeier Survival curve of experimental metastasis study in SCID beige mice, 90-day endpoint after tail vein injection of cells. Log-rank test performed $\mathrm{p}=0.0062, \mathrm{df}=3$. N=5(MCF-7), 6(MOCK-2), 7(M1), 7(M6) mice. F: Representative immunohistochemistry of M6 lungs with antibodies towards CA-IX and ER, to confirm the generated M6 clone were the cells forming tumors in the lungs. MCF-7 cells are ER-positive. G: Effect of buffer therapy on experimental metastasis of CA-IX clone M6 and MOCK-2 cells in SCID beige mice and the \% of tumor burden in the lungs, 77days after IV injection of cells. Data are shown as average $\% \pm S D, N=6(M 6)$, 9(M6 Bicarb), 9(MOCK-2), 7(MOCK-2 Bicarb) mice, statistical analysis using ordinary one-way ANOVA. H: Immunohistochemistry of $\mathrm{H} \& \mathrm{E}$ staining in the lungs of the M6 control and bicarb treated experimental metastasis study groups, showing gross metastasis of the lungs. ${ }^{*} \mathrm{p}<0.05,{ }^{*} \mathrm{p}<0.01, * * * \mathrm{p}<0.001,{ }^{*} * * * \mathrm{p}<0.0001$

\section{Over-expression of yeast proton pump PMA1 increases motility and metabolism}

While we hypothesize that CA-IX is acting as a proton equivalent exporting system, there are many other activities of this protein, including non-enzymatic activities, that could be activating glycolysis and promoting metastasis. To test whether the observed effects on 
248 glycolysis could be due to increased proton export, we utilized another model, PMA1, which

249 electrogenically pumps $\mathrm{H}^{+}$out of cells at the expense of ATP (Ferreira et al., 2001). Prior work

250 has shown ectopic expression of PMA1 in murine 3T3 fibroblasts led to tumorigenesis (Perona

251 and Serrano, 1988) and to increased aerobic glycolysis with elevated intracellular pH (Gillies,

252 1990; Martinez et al., 1994). We engineered MCF-7 cells to express PMA1 and selected two

253 clones following zeocin selection (PMA1-C1 and PMA1-C5) as well as an empty vector

254 transfected control (MOCK-1). PMA1 over-expression in C1 and C5 was confirmed, by qRT-

255 PCR (Supplementary Fig. 14) and western blot (Fig. 5A). Moreover, using

256 immunocytochemistry of non-permeabilized cells (Fig. 5B \& Supplementary Fig. 15) or

257 permeabilized cells (Supplementary Fig. 16), we verified PMA1 protein expression on the

258 plasma membrane and in the cytoplasm of both PMA1 clones. 
A.

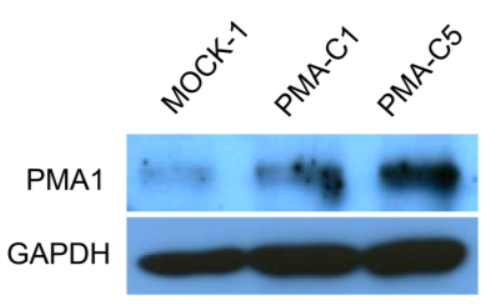

D.

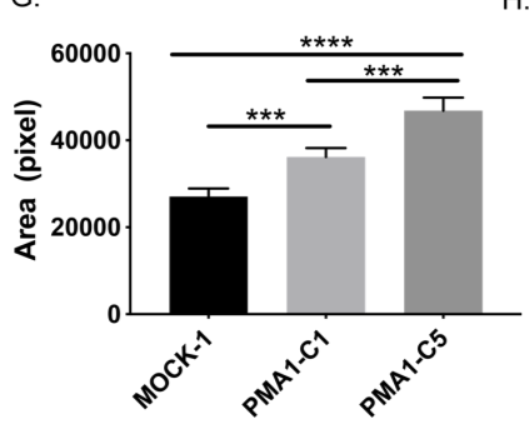

E.

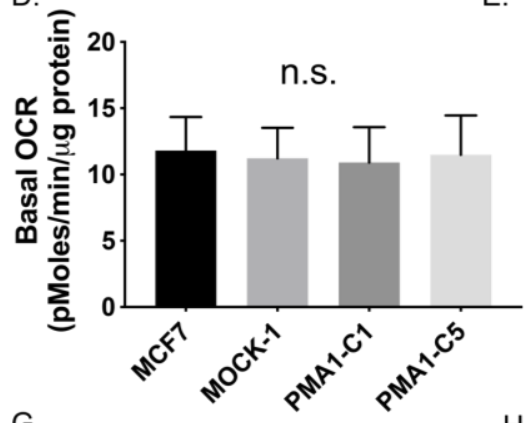

$\mathrm{H}$.
B.
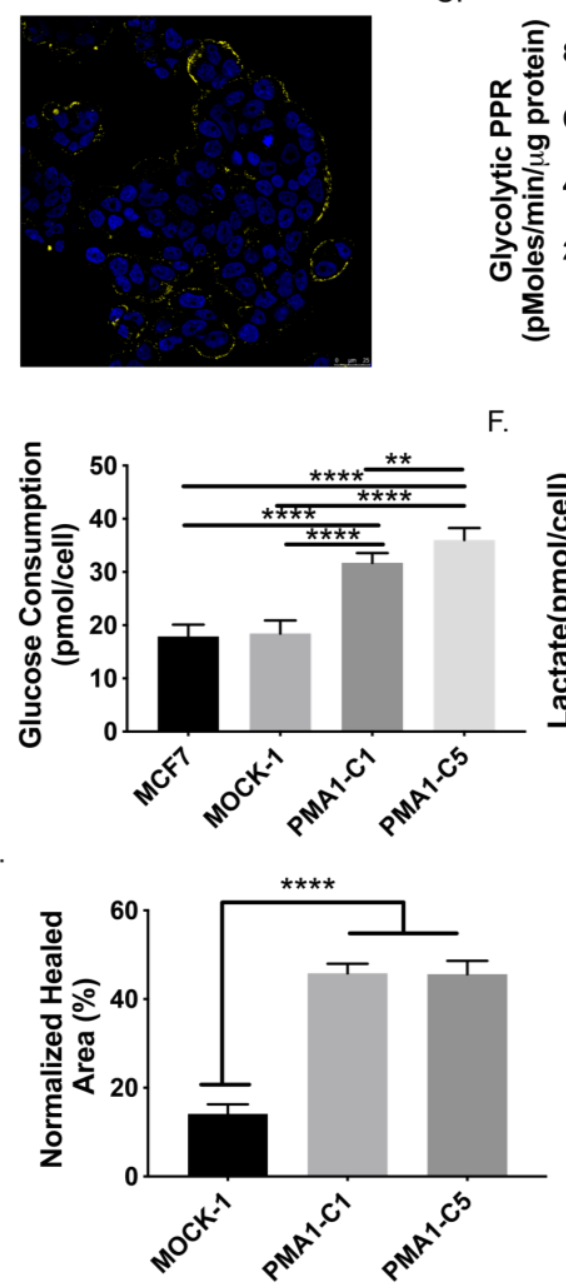

C.
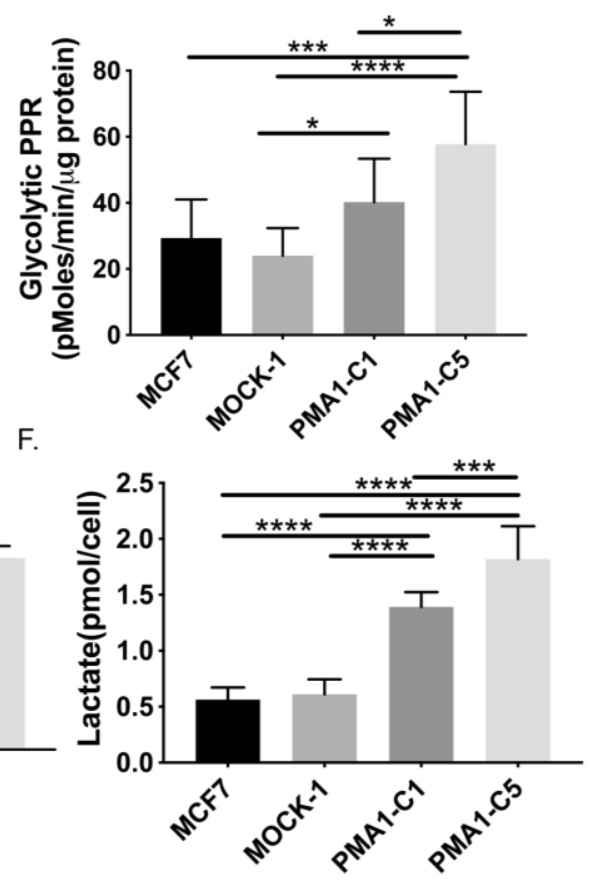

Figure 5: Over-expression of yeast ATPase proton pump, PMA1, in MCF-7 breast cancer cells increases glycolytic metabolism, migration, and invasion in vitro A: Immunoblotting of protein lysates from MCF-7 cells transfected with empty vector (MOCK-1) or PMA1 vector (C1 and C5). Proteins from total cell extracts were immunoblotted for PMA1 and GAPDH (loading control). B: Representative immunocytochemistry image of PMA1 expression(yellow), overlayed with DAPI nuclear stain(blue), in PMA1C5 non-permeabilized MCF-7 cells. PMA1 clones exhibit PMA1 staining, whereas MOCK-1 cells do not. C: Seahorse extracellular flux analysis of glycolysis associated proton production rate, measured after glucose is added, in MCF-7 parental, MOCK-1, PMA-C1, and PMA1-C5 MCF-7 cells. Data shown as mean \pm SD n=9 biological replicates. Statistical analysis using ordinary one-way ANOVA. D: Seahorse extracellular flux analysis of basal oxygen consumption in the presence of glucose for MCF-7 parental, MOCK-1, PMA-C1, and PMA1-C5 MCF-7 cells. Data shown as mean \pm SD n=20 biological replicates. Statistical analysis using ordinary one-way ANOVA. E: Glucose concentration in tumor-conditioned media collected after culturing to confluence from MCF-7 parental, MOCK-1, PMA-C1 and PMA1-C5 MCF-7 cells for 24hrs, measured using hexokinase activity assay. Data shown as mean $\pm \mathrm{SD} n=9$ biological replicates. Statistical analysis using ordinary one-way ANOVA. F: Lactate concentration in tumor-conditioned media collected after culturing to confluence from MCF-7 parental, MOCK-1, PMA-C1 and PMA1-C5 MCF-7 cells for 24hrs, measured using fluorescent lactate assay. Data shown as mean $\pm \mathrm{SD} n=9$ biological replicates. Statistical analysis using ordinary one-way ANOVA. G: Gel escape assay to measure migration and invasion in MOCK-1, PMA-C1 and PMA1-C5 MCF-7 cells. Cells are embedded in a Matrigel droplet without serum, and they are surrounded by media containing serum. Droplets 
are monitored over one week for cell invasion out of the droplet and the area measured is normalized to cellular proliferation rates. $\mathrm{N}=4$ biological replicates. Statistical analysis using ordinary one-way ANOVA. H. Circular wound healing assay of MOCK-1, PMA-C1 and PMA1-C5 MCF-7 cells. A circular wound is created with a rubber stopper and then cells are monitored migrating into the area to close the wound. The area healed is quantified in \% relative to starting area and normalized to the cellular proliferation rate. $\quad \mathrm{N}=4$ biological replicates. Statistical analysis using ordinary one-way ANOVA. ${ }^{*} \mathrm{p}<0.05, * * \mathrm{p}<0.01, * * * \mathrm{p}<0.001, * * * * \mathrm{p}<0.0001$

To characterize the metabolic activity of PMA1 transfectants, we again utilized the glycolysis and mitochondrial stress tests (GST and MST, respectively) of the Seahorse (XFe) Analyzer. The glucose-induced PPR (Fig.5C), and the glycolytic reserve (Supplementary Fig. 17) were significantly higher in the PMA1 clones compared to empty vector MOCK-1 or parental clones, suggesting functional activities of the transfected pump. In contrast to the CA-IX transfectants, there were no significant differences in oxygen consumption rates (OCR) between PMA1 clones and controls (Fig. 5D). This could be due to increased energy demand from the ATPase proton pump. We further confirmed these metabolic alterations by measuring glycolytic flux. PMA1 clones had significantly higher glucose consumption rates (Fig. 5E) and lactate production rates (Fig. 5F) compared to MOCK-1 or parental MCF-7 clones. These data, together with the CA-IX results, indicate that acid export can drive cells to exhibit a Warburg phenotype.

As with the CA-IX transfectants, we also measured invasion and migration using gel escape and circular wound healing assays, respectively. Compared to the MOCK-1 cells, both PMA1 clones expanded significantly more out of the gel drop (Fig. 5G \& Supplementary Fig. 18). In the circular "wound-healing" assay, we monitored the migration of cells into a cell-free area. Again, compared to MOCK-1, both PMA1 clones had increased migration rates (Fig. 5H \& Supplementary Fig. 19). Together, these results indicate that cellular invasion and migration were significantly enhanced by PMA1 expression and acid production.

PMAl induces a metastatic phenotype in vivo and alters the expression of proteins involved in $\underline{\text { metabolism and } \mathrm{pH} \text { regulation }}$

To investigate if proton export enhanced aggressiveness, as seen in the CA-IX model, we measured the PMA1 cells' metastatic ability in vivo in both spontaneous and experimental metastasis models. In our in vitro studies, the proliferation rates of PMA1-C1 and the empty vector MOCK-1 clones were similar, whereas the growth rate of PMA-C5 was significantly 
313 slower (Supplementary Fig. 20). Hence, we omitted PMA-C5 in our in vivo studies to reduce

314 the possibility of proliferation being a confounding variable. In both the spontaneous and tail

315 vein metastases models, only 1 of 10 mice in each MOCK-1 group developed lung metastases. In

316 contrast, 7 of 12 PMA-C1 mice developed lung metastases following tail vein injection and 4 of

3179 formed spontaneous metastases (Supplementary Table 2.).

Lung metastases of PMA1 cells, visualized by H\&E staining (Fig. 6A), were further

320 validated by immunohistochemistry (IHC) of PMA1 (Fig. 6A) and RNA analysis of FFPE lung

321 tissue for PMA1 gene expression (Supplementary Fig. 21). Notably, primary tumors revealed

322 no significant growth differences between PMA1 and MOCK-1 tumors (Fig. 6B) or final tumor

323 volume (Fig. 6C). However, blind grading (1 to 4+) of H\&E-stained tumor sections by a board-

324 certified pathologist (A.L.) indicated that PMA1 primary tumors were of significantly higher

325 grade compared to MOCK-1 controls ( $\mathrm{p}=0.016)$. The average grade was $2.7 \pm 0.52$ for MOCK-1

326 compared with $3.4 \pm 0.67$ for the PMA1 primary tumors (Fig. 6D and 6E). Maintenance of

327 PMA1 expression in vivo was confirmed with quantitative IHC of the resected primary tumors,

328 demonstrating a significant difference in PMA1 protein expression between the MOCK-1 (19\% \pm

$3293.0, \mathrm{n}=10)$ and PMA-C1 $(90 \% \pm 2.5, \mathrm{n}=9)$ tumors (Fig. 6F \& 6I). 
A.

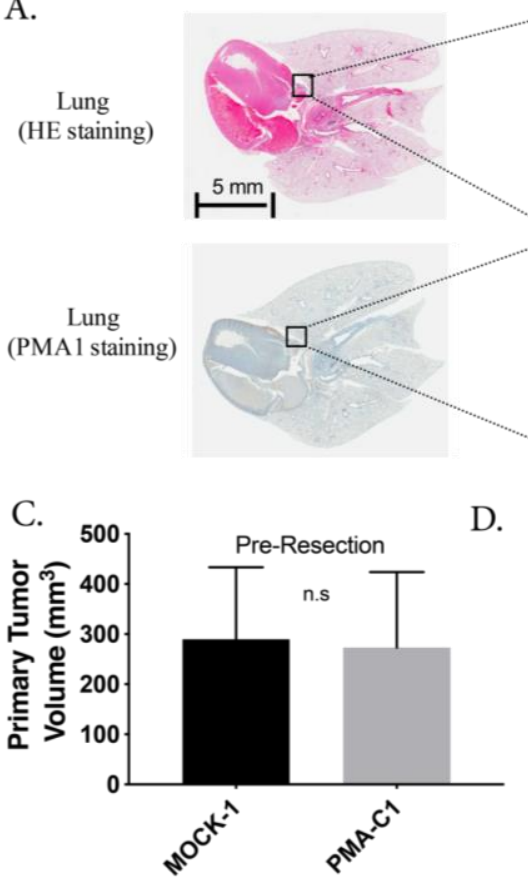

F.

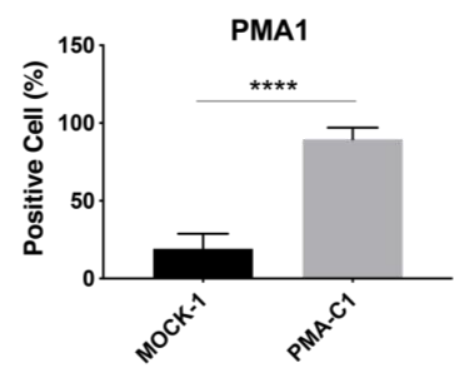

I.

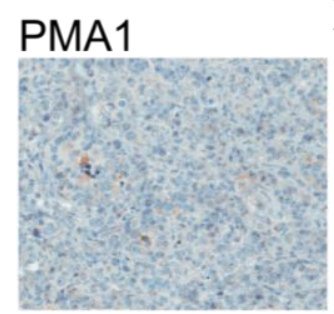

J. MCT1

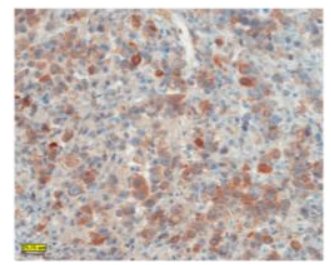

G.

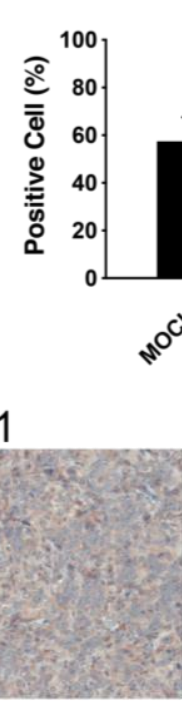

D.
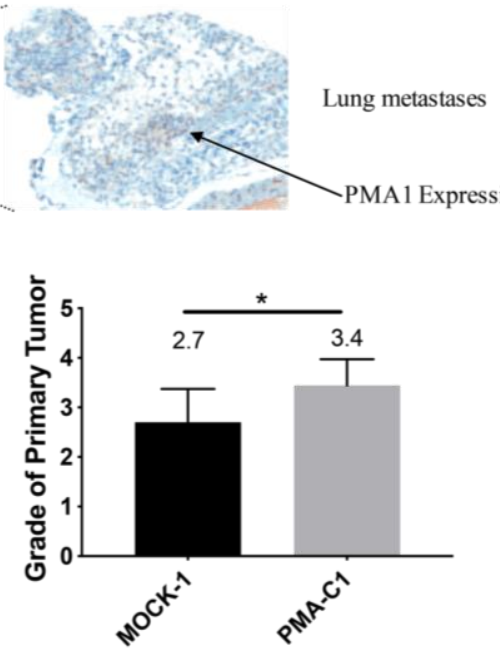

$g(0)$ PMA1 Expression
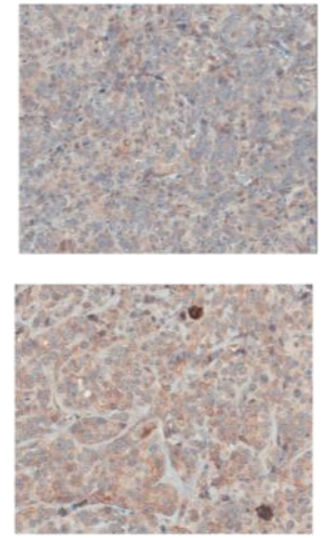

Lung metastases

B.

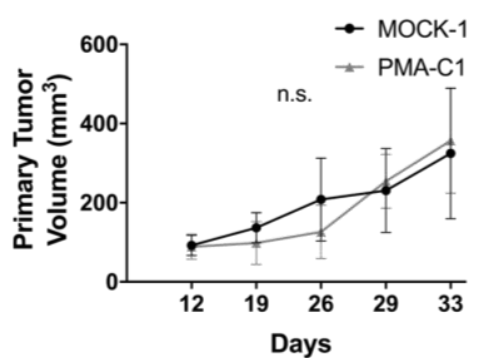

E.

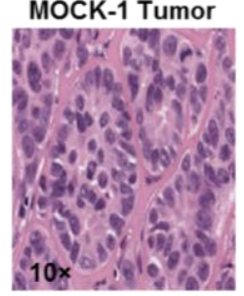

H.
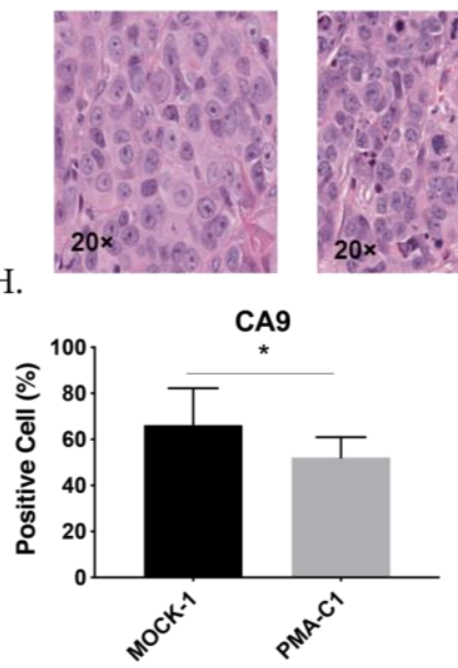

Figure 6: In vivo studies of PMA1 expressing cells and the effect on tumor growth, metastasis, and expression of metabolic markers. A: Representative lung images (5mm and 100um) from the experimental metastasis study in SCID beige mice, whereby MOCK-1 or PMA-C1 cells were injected via the tail vein and 
allowed to grow for 3 months. At the endpoint lungs were resected and sections were stained with $\mathrm{H} \& \mathrm{E}$ to look for metastases and PMA1 to confirm expression in the PMA C1 metastases. B: Primary tumor growth rate in SCID beige mice of MOCK-1 or PMA1-C1 cell lines, injected subcutaneously. Data are shown as mean \pm SD over time, N=7(MOCK-1) N=6 (PMA1-C1). C: Quantification of primary tumor volume, MOCK-1 or PMA1$\mathrm{C} 1$, resected after 33 days of growth in SCID beige mice. Tumors were resected to allow for spontaneous metastasis studies to continue. Data are shown as mean $\pm \mathrm{SD}, \mathrm{N}=9$ (MOCK-1) and $\mathrm{N}=9$ (PMA1), statistical analysis using Unpaired t-test with Welch's correction. D: Histological grade of MOCK-1 and PMA1 tumors. Data are shown as mean $\pm \mathrm{SD}, \mathrm{N}=10$ (MOCK-1) and $\mathrm{N}=9$ (PMA1), statistical analysis using Unpaired t-test with Welch's correction. E: Representative images of H \& E staining in MOCK-1 and PMA1 primary tumors were used to score histological grade. F. Quantification of immunohistochemistry staining for PMA1 protein in FFPE sections of resected primary tumors, MOCK-1 and PMA1-C1. Data are shown as mean $\pm \mathrm{SD}, \mathrm{N}=10$ (MOCK-1) and $\mathrm{N}=9$ (PMA1), statistical analysis using Unpaired t-test. G: Quantification of immunohistochemistry staining for MCT1 protein in FFPE sections of resected primary tumors, MOCK-1 and PMA1-C1. Data are shown as mean $\pm \mathrm{SD}, \mathrm{N}=10$ (MOCK-1) and $\mathrm{N}=9$ (PMA1), statistical analysis using Unpaired t-test with Welch's correction. H: Quantification of immunohistochemistry staining for CA- IX protein in FFPE sections of resected primary tumors, MOCK-1 and PMA1-C1. Data are shown as mean $\pm \mathrm{SD}, \mathrm{N}=10$ (MOCK-1) and N=9 (PMA1), statistical analysis using Unpaired t-test. F: Immunohistochemistry representative images of PMA1 and MOCK-1 primary tumors stained for PMA1 protein expression. I: Representative immunohistochemistry images of FFPE sections of resected primary tumors, MOCK-1 and PMA1-C1 stained with antibody for MCT1. K: Representative immunohistochemistry images of FFPE sections of resected primary tumors, MOCK-1 and PMA1-C1, stained with antibody for CA-IX. *p<0.05, **p<0.01, ***p<0.001, $* * * * \mathrm{p}<0.0001$ expression than MOCK-1 (Fig. 6H \&6K). As CA-IX plays a vital role in regulating tumor pH (Doherty et al., 2014; Lee et al., 2018; Swietach et al., 2009), we postulate that its activity may have been made redundant by PMA1. PMA1 expressing tumors also had higher levels of the monocarboxylate (lactate) transporter, MCT1 (Fig. 6G \&6J), which has been associated with increased aggressiveness in breast cancer (Doherty et al., 2014). Notably, other proteins, such as glucose transporter 1, GLUT1 (Supplementary Fig. 22), the sodium hydrogen exchanger 1, NHE1 (Supplementary Fig. 23), and MCT4 (Supplementary Fig. 24) showed no differences between the PMA1 and MOCK-1 groups. These data suggest that the increased glycolytic flux, which requires glucose uptake by GLUT1, can be accommodated by native protein levels of GLUT1 (i.e., it is not rate-limiting). 


\section{DISCUSSION}

The primary goal of this study was to determine if acid export per se could drive aerobic glycolysis, the "Warburg Effect", in cancer. Aerobic glycolysis, a cancer hallmark, is often associated with more aggressive tumors. Numerous studies have attempted to determine why tumors favor fermentative glycolysis, even in the presence of sufficient oxygen (Gatenby and Gillies, 2004a; Vander Heiden et al., 2009). Aerobic glycolysis is bioenergetically inefficient, producing only 2 ATP per glucose, compared to 36 ATP upon complete oxidation. Thus, it is not obvious why this should be such a prevalent phenotype. It is axiomatic that common phenotypes must confer a selective advantage, yet the evolutionary drivers of aerobic glycolysis are not clear. Theories proposed include glucose addiction (Buzzai et al., 2005), dysfunctional mitochondria (Shiratori et al., 2019), which is not the case in most cancers, and to meet the rapid energetic requirements of membrane transporters (Epstein et al., 2014). Another theory is that glycolysis enhances tumor cell proliferation by generating the anabolic building blocks for macromolecules. However, most of the glucose-derived carbons are exported out of the cell as lactate (Lunt and Vander Heiden, 2011). Moreover, TCA cycle intermediates are considered more important for lipid, amino acid, and nucleotide synthesis, compared to glycolytic intermediates (Carracedo et al., 2013; Wellen and Thompson, 2012). However, none of these theories clearly demonstrate why so many cancers favor aerobic glycolysis. We hypothesize that acid export per se and extracellular acidification provides a distinct selective advantage, and that it is enabled by increased glucose fermentation. This theory was first proposed as the "acid mediated invasion hypothesis" (Gatenby et al., 2006a) and has been subsequently elaborated (Gillies et al., 2008).

To test the hypothesis that acid export increases glycolysis in cancer, we over-expressed a proton exporter, CA-IX, in an OXPHOS dominant cell line, MCF-7. In MCF-7 cells, CA-IX is not expressed under normoxic conditions, and over-expression resulted in cells that more rapidly exported acid and up-regulated glycolysis. Both glucose consumption and lactate production rates increased. Other studies have shown that CA-IX over-expression can increase lactate production, albeit under hypoxic conditions (Jamali et al., 2015). As glycolysis was specifically 
increased, we investigated the mechanisms whereby acid export could be causing this shift in metabolism. We broadly interrogated cellular metabolism using a targeted metabolomics panel and found that the most significantly altered metabolites in the CA-IX expressing clones were glycolytic intermediates. Specifically, all glycolytic intermediates upstream of pyruvate kinase were increased. Enzyme activity can be affected by $\mathrm{pH}$, including those in the glycolytic pathway, and are most active at the $\mathrm{pH}$ of their subcellular compartment from acidic lysosomes to alkaline mitochondria (Persi et al., 2018). For glycolytic enzymes, pH optima are slightly on the alkaline side of neutral (7.2-7.4), meaning that raising $\mathrm{pH}$ above neutrality will globally increase activities of glycolytic enzymes. Because the data suggested pleiotropic increases in enzyme activity, we measured intracellular $\mathrm{pH}$ using fluorescence ratio imaging in our CA-IX expressing clones. These clones, had a higher $\mathrm{pHi}$ in biologically relevant extracellular $\mathrm{pH}$ conditions, compared to the parental. Specifically, at pHe 6.8 and 7.2, at which CA-IX can function as a proton equivalent exporter, the CA-IX clones had increased pHi compared to parental. One caveat of this experiment was that the MOCK cells were unquantifiable as they did not accumulate SNARF-1, possibly due to increased activity of multidrug resistance transporters. In addition, the experiments in low-chloride directly implicate increased $\mathrm{pHi}$ in regulating aerobic glycolytic flux. These data indicate loading cells with $\mathrm{HCO}_{3}{ }^{-}$ions raises the intracellular pH sufficiently to enhance enzyme activity and result in increased glycolytic flux.

We tested our hypothesis using two more models and another acid exporting protein to minimize cell line and protein-specific effects. Similar to the MCF-7 results, over-expression of CA-IX in U2-OS and HEK293 cells increased glycolysis compared to controls. Although parental HEK293 cells are more glycolytic than the other cell lines chosen, over-expression of CA-IX still enhanced glycolysis. We tested another acid exporting protein, PMA-1, which has an unequivocal activity of exporting protons at the expense of ATP. PMA-1 over-expression in MCF-7 cells similarly resulted in increased glycolysis, as measured by increased glucose uptake and lactate production. These findings, together with our CA-IX results, suggest that expression of proton exporting activity can up-regulate aerobic glycolysis, likely through a global increase of intracellular $\mathrm{pH}$. Notably, while the CA-IX transfectants had reduced oxygen consumption, this was not observed in the PMA1 cells. The cause of this difference is not known and may reflect differences in the bioenergetic requirements for the two transporting systems. 
We hypothesize that acid export-driven glycolysis would make them more aggressive, as measured in vitro with motility and invasion assays, and in vivo with experimental and spontaneous metastases studies. Glycolysis and acidity have been correlated with poor prognosis and metastasis (Walenta et al., 2000; Webb et al., 2011a). Our focus on CA-IX as an acid exporter was due to its clinical relevance in many cancer types, such as breast, ovarian, and astrocytoma, where CA-IX over-expression correlates with poor prognosis, reduced survival, and reduced metastasis-free survival. This suggests CA-IX specifically and perhaps acid export generally enhances cancer aggressiveness and subsequently metastasis. In our models, in vitro acid export driven by CA-IX or PMA1 was linked to enhanced migration and invasion in vitro, which is consistent with prior studies (Csaderova et al., 2013; Shin et al., 2011; Svastova et al., 2012). In vivo, cells at the invasive edge tumor periphery are known to be more acidic and express CA-IX (Lloyd et al., 2016; Rohani et al., 2019). CA-IX has also been shown to enhance matrix metalloproteinase activity, in particular MMP-14 which is active at an acidic $\mathrm{pH}$, resulting in stromal degradation that aids cancer migration into the periphery (Swayampakula et al., 2017).

Our encouraging in vitro results led us to take these models, CA-IX and PMA-1, in vivo. We found that aggression and metastasis were higher in both PMA-1 and CA-IX transfectants. Primary tumor growth was enhanced in the CA-IX model compared to controls. In the PMA-1 model, a pathologist blindly scored the primary tumors a higher grade compared to control tumors. However, spontaneous metastasis after primary tumor resection was not significantly increased in PMA-1 or CA-IX transfectants compared to controls (Table 1 \& Supplementary

392 Table 2). It is notable, however, that in our spontaneous models 10/45 mice with PMA-1 or CA393 IX clones had metastases, compared to 2/20 control mice with parental or MOCK-transfections.

394 In contrast, our experimental metastasis model, which skips the intravasation step, showed 395 enhanced experimental metastasis in both models, with 17/25 mice in PMA-1 or CA-IX 396 transfectants developing metastasis, compared to 1/21 metastases in control mice (Table 1 \&

397 Supplementary Table 2). We did not quantify the number or size of metastatic lesions, because 398 the important metric is binary: i.e. whether or not these clones were able to metastasize at all. A 399 related study in 4T1 breast cancer showed that inhibiting CA-IX reduced tumor growth and 400 experimental metastasis (Lou et al., 2011). However, inhibition is different than induction, and 
4T1 are highly glycolytic and acidic to begin with. However, this study does indicate the importance of acid export and its role in enhancing tumor growth. Due to the robust enhanced metastasis formation in the experimental metastasis studies, it indicates that acid export can facilitate tumor cell extravasation out of the blood vessels and colonization of metastatic sites. In our CA-IX model buffer therapy significantly reduced tumor burden in the lungs compared to their untreated counterparts. Although this did not completely prevent metastasis, combinations of buffer therapy with specific acid exporter inhibitors may be necessary. CA-IX is minimally expressed in normal tissue and could be a viable therapeutic target (Silvia Pastorekova et al., 1997) and other proton pump inhibitors are currently in clinical trials (Fais, 2015). Many studies have hinted at the importance of acidity, and many have proposed reasons as to why

411 cancer cells favor aerobic glycolysis, but few have proposed that acidity is the driver. This study 412 represents the first to test whether acid export can increase aerobic glycolysis and enhance cancer 413 aggressiveness, rather than acid merely being a by-product.

416 Plasmids. Yeast plasma membrane ATPase 1 (PMA1) cDNA construct was designed based on 417 the sequence (Accession Number: NM_001180873; Saccharomyces cerevisiae S288c PMA1). 418 The codons were optimized for the suitable expression in mammalian cells and restriction enzyme sequences Hind III and Xho I were inserted at the 5' and 3' ends of the full-length sequence, respectively. The fully designed DNA sequence was commercially synthesized (Blue Heron Biotechnology, Bothell, WA, 98021). This was cloned into pcDNA3.1/Zeo (+) vector in which PMA1 gene expression was driven under the CMV promoter. The sequence of the pcDNA/PMA1 construct and the identity of the parental cell line were confirmed by the molecular genomics core facility (Moffitt Research Institute, Tampa, FL). Carbonic anhydrase 9 (CA9) construct was designed by Origene based on the sequence(Accession Number:NM_001216 ; Homo sapiens) and cloned into a pCMV6 vector (PS10001, Origene, MD) to form pCMV6/CA-IX vectors (CQ10630, RC204839 subclone, Origene, MD)in which CA9 gene expression was driven under the CMV promoter. 
Cell lines. The MCF-7 cells and HEK 293 cells as transfection host cell lines were acquired from American Type Culture Collection (ATCC HTB-22, Manassas, VA) and maintained in RPMI media 1640 (Life Technologies Gibco®, 11875-093) supplemented with 10\% FBS (Hyclone Laboratories, UT) under standard cell culture conditions. The U2-OS cell line was a gift from Jillaina Menth, Moffitt Cancer Centre Translational Research Core, and maintained in RPMI media 1640 (Life Technologies Gibco®, 11875-093) supplemented with 10\% FBS (Hyclone Laboratories, UT) under standard cell culture conditions. The MCF-7 cells were transfected with empty pcDNA, pcDNA/PMA1, pCMV6 (PS10001, Origene, MD) and pCMV6/CA-IX vectors (CQ10630, RC204839 subclone, Origene, MD) respectively, resulted in MCF-7/MOCK-1 cells, MCF-7/PMA1, MCF-7/MOCK-2, and MCF-7/CA-IX cell lines by standard clonogenic stable cell construction procedures using Fugene HD (Promega, E 2311). The U2-OS and HEK-293 cells transfected with empty pCMV6 (PS10001, Origene, MD) and pCMV6/CA-IX vectors (CQ10630, RC204839 subclone, Origene, MD) respectively, resulted in U2-OS/MOCK-2, HEK/MOCK-2, and U2-OS/CA-IX and HEK/CA-IX clones. Briefly, a number of individual single clones were selected in the media containing $300 \mu \mathrm{g} / \mathrm{ml}$ zeocin (Invitrogen, 450430, Carlsbad, CA), or $300 \mu \mathrm{g} / \mathrm{ml} \mathrm{G418}$ and stable expression in individual clones were verified using western blotting. Cell lines were tested for mycoplasma using MycoAlert assay (Lonza).

Spheroid formation

\section{$\underline{\text { Western blotting }}$}

Chemiluminescence. The cell membrane protein samples were collected using Mem-PER

Spheroids were formed as previously described (Russell et al., 2017). Briefly, cells were suspended in Perfecta 3D hanging drop plates (HDP1096, 3D Biomatrix, MI) at 25K cells/40ul droplet. Spheroids were allowed to form for 5 days and then centrifuged at 450rpm, with no brake, into media-containing Costar Ultra low attachment U-bottom 96-well plates (CLS3474, Corning, NY). Spheroids were imaged in the Celigo Imaging Cytometer (Nexcelom Bioscience, MA) using bright field imaging single colony verification analysis. eukaryotic membrane protein extraction reagent kit (Thermo Scientific, 89826, MA) according to the protocol instruction, and the protein samples were further purified and concentrated by Pierce SDS-PAGE sample prep kit (Thermo Scientific, 89888). Thirty micrograms of protein per sample was separated on polyacrylamide-SDS gels and electrophoretically transferred to nitrocellulose membranes. Membranes were incubated with primary antibody against PMA1 (1:1000, Abcam, ab4645), and GAPDH (1:1000, Santa Cruz Biotechnology, TX, se-25778). For visualization, horseradish peroxidase (HRP)-conjugated secondary antibodies: Goat anti-rabbit IgG HRP and goat anti-mouse IgG HRP, followed by ECL kit (Thermo Scientific, 32209) were used.

Fluorescence. Fifteen $\mu \mathrm{g}$ of protein per sample was separated on a BioRad Mini-protein 4-15\% precast 12 well $20 \mu$ gels (4561085, Bio-Rad, CA) and electrophoretically transferred to Odyssey Nitrocellulose membrane (P/N 926-31092, LI-COR, NE). Membranes were blocked 
with Odyssey TBS Blocking Buffer ( P/N 927-50000, LI-COR, NE) and incubated with primary antibody against CA-IX(1:1000, M75 mouse monoclonal CA-IX, Bioscience Slovakia), ER alpha ( 1:2000, Rabbit polyclonal ab 75635, Abcam), rabbit Anti-CA12 antibody [EPR14861] C-terminal (ab195233), rabbit Anti-Carbonic Anhydrase II antibody [EPR5195] (ab124687), $\beta$ Actin(1:2000, (8H10D10) Mouse mAb \#3700- Cell Signaling), GAPDH (1:4000, rabbit monoclonal ab 181602, Abcam). For visualization, IRDye Fluorescent secondary antibodies (LICOR) were used: IRDye 680RD Goat Anti-mouse IgG (H+L), IRDye 680RD Donkey anti-rabbit IgG $(\mathrm{H}+\mathrm{L})$, IRDye 800CW goat anti- mouse $\mathrm{IgG}(\mathrm{H}+\mathrm{L})$ and IRDye 800CW donkey anti-rabbit $\operatorname{IgG}(\mathrm{H}+\mathrm{L})$. Membranes were imaged on LI-COR Odyssey Blot Imager and quantified using Image Studio Version 2.1(LI-COR). Uncropped versions of western blots are available in Supplementary.

\section{Immunocytochemistry}

Cells were grown on glass coverslips and fixed in 4\% paraformaldehyde (Sigma-Aldrich)

\section{$\underline{\text { Proliferation rate assay }}$} for $10 \mathrm{~min}$ at room temperature. Cells were blocked in 5\% BSA for $1 \mathrm{hr}$ at room temperature. Cells were stained with the PMA1 antibody (1:100; SC-33735, Santa Cruz Biotechnology) or CA-IX antibody for 2 hours (1:500, ab184630, Abcam) and washed in PBS. Cells were further incubated for $1 \mathrm{~h}$ with secondary anti-rabbit-Alexa Fluor 594 antibody (1:2000; A11072, Invitrogen) or anti-mouse-Alexa Fluor 594(1:2000; A11005, Invitrogen) and additionally incubated in WGA, cell membrane marker (W6748, Invitrogen) for $10 \mathrm{~min}$ on ice. The cells were mounted for fluorescence with DAPI (H-1200, Vector). The slides were viewed by Leica inverted SP5 AOBS confocal microscope, and micrographs were taken, and images were subsequently acquired in the Moffitt Analytic Microscopy Core Facility by using dual photomultiplier tube detectors and LAS AF software (Leica Microsystems). For detection of intracellular PMA1, cells were fixed and permeabilized with 1:1 mixture of methanol and acetone, and immunostained with PMA1 antibody for $1 \mathrm{~h}$, followed by 1 hour of incubation with the secondary anti-rabbit Alexa488 antibody (Molecular Probes, Invitrogen). The cells were mounted and viewed by fluorescence microscopy.

Cells were cultured in a 24-well plate under standard cell culture conditions for 24, 48, 72,96 hours, and the cell number and viability were determined with a trypan blue dye by using the Countess automated cell counter (Invitrogen).

Real-time oxygen consumption (OCR) and proton production rate (PPR) were measured by using the Seahorse Extracellular Flux (XFe-96) Analyzer (Seahorse Bioscience, Chicopee, MA). The cells were seeded in an XFe-96 microplate (Seahorse, V3-PET, 101104-004) in normal growth media overnight. The growth media were replaced with DMEM powder base media ( Sigma D5030) supplemented with $1.85 \mathrm{~g} / \mathrm{L}$ sodium chloride and $1 \mathrm{mM}$ glutamine, and the 
cells were incubated in the media in the absence of glucose, when testing glycolysis, in a non$\mathrm{CO}_{2}$ incubator for one hour prior to the measurement. PPR and OCR were measured in the absence of glucose associated with the non-glycolytic activity, followed by two sequential injections of D-glucose $(6 \mathrm{mM})$ and oligomycin $(1 \mu \mathrm{M})$ in real-time, which are associated with glycolytic activity and glycolytic capacity (reserve). The mitochondrial stress test was also used where cells were incubated in glucose $(5.5 \mathrm{mM})$, and glutamine $(1 \mathrm{mM})$ containing media and basal OCR and PPR measured, prior to sequential injection of Oligomycin $(1 \mu \mathrm{M})$, associated with ATP linked OCR, $\mathrm{FCCP}(1 \mu \mathrm{M})$ associated with mitochondrial reserve capacity and Rotenone/Antimycin $\mathrm{A}(1 \mu \mathrm{M})$. Following the measurements, protein concentrations were determined in situ for each well using a standard BCA protein assay (Thermo Scientific Pierce). The OCR and PPR values were normalized to $\mu \mathrm{g}$ protein. Results were also normalized using Celigo High Throughput Micro-Well Imaging Cytometer (Nexcelom Bioscience) by bright-field direct cell counting and normalized per $10 \mathrm{~K}$ cells prior to assay.

\section{Glucose consumption and lactate production assays}

Figure 1: Cells were seeded in a 96-well plate in the growth media containing 10\% FBS. Once cells reached $90 \%$ confluence, the growth media were removed, and the cells were washed twice in PBS and media was replaced for $24 \mathrm{~h}$. The media were collected from $24 \mathrm{~h}$ incubation for both glucose consumption and lactate production assays. The cells were then trypsinized and the cell densities were determined. Glucose quantification was conducted using glucose bioluminescent assay kit (Glucose Glo Assay, Promega) as described per manufacturer instruction. The lactate assay kit (Lactate Assay kit, Sigma Aldrich) was used to measure L (+)-Lactate in the culture media according to the manufacturer's instructions. Data were normalized by cell density per well and were reported as lactate production and glucose consumption per ug protein.

Figure 5: Cells were seeded in a 6-well plate in growth media containing 10\% FBS. Once cells reached $90 \%$ confluence, the growth media were removed, and the cells were washed twice in PBS and incubated in serum-free and phenol-red free media for $24 \mathrm{~h}$. The media were collected from $24 \mathrm{~h}$ incubation for both glucose consumption and lactate production assays. The cells were trypsinized and the cell densities were determined. Glucose quantification was conducted using glucose colorimetric/fluorometric assay kit (BioVision, K606-100) as described per manufacturer instruction. The lactate assay kit II (BioVision, K627-100) was used to measure L (+)-Lactate in the culture media according to the manufacturer's instructions. Data were normalized by cell density per well and were reported as lactate production and glucose consumption as pmol per cell.

\section{Glucose uptake radioactive assay}

Cells were seeded in 24 well plates to $80 \%$ confluence. Cells were incubated for $1 \mathrm{hr}$ with $1 \mu \mathrm{Ci}$ of Deoxy-D-glucose, 2-[1,2- $\left.{ }^{3} \mathrm{H}(\mathrm{N})\right]$ (NET549250UC, Perkin Elmer, MA) at 37. Cells were washed 2 x DPBS and lysed with $300 \mathrm{ul}$ of $\mathrm{NaOH}$, cell extract was added to a vial with $6 \mathrm{ml}$ of Eoscint XR scintillation liquid (LS-272, National Diagnostics, GA). Uptake was quantified by 
measuring ${ }^{3} \mathrm{H}$ in a Perkin Elmer TriCarb scintillation counter and normalizing to protein concentration.

\section{$\underline{\text { YSI } 2950 D \text { biochemical analysis of lactate }}$}

Cells were seeded in a 96-well plate in the growth media containing $10 \%$ FBS. Once cells reached $90 \%$ confluence, the growth media were removed, and the cells were washed twice in PBS and media was replaced for $24 \mathrm{~h}$ or $48 \mathrm{hr}$. The media were collected from $24 \mathrm{~h} \mathrm{\&} 48 \mathrm{hr}$ incubation for lactate production measurement. The cell densities per well were determined by Celligo imaging cytometer brightfield cell count application. Lactate quantification was measured by the YSI. Data were normalized by relative cell number and were reported as lactate production in $\mathrm{g} / \mathrm{L} /$ per cell.

\section{Untargeted metabolomics}

Samples were prepared according to Beth Israel Deaconess Medical Centre Mass Spectrometry Core and run on a Thermo QExactive Plus/HF Orbitrap LC-MS/MS. Briefly, cells were grown to $80 \%$ confluence in $10 \mathrm{~cm}^{2}$ dishes. Cells were changed into fresh media two hours prior to collection, media was aspirated, cells were washed in ice cold PBS, and $1 \mathrm{ml}$ of $80 \%$ methanol $\left(-80^{\circ} \mathrm{C}\right)$ added to plate on dry ice, then transferred to $-80^{\circ} \mathrm{C}$ freezer for 15 minutes. The cell plate was scraped on dry ice and contents collected. Sample was spun in cold centrifuge at max speed for 20min and supernatant removed. Supernatant was dried in speed vac for $5 \mathrm{hrs}$ then stored at $-80^{\circ} \mathrm{C}$. Before Mass Spec analysis, samples were resuspended in HPLC grade water relative to protein concentration. Data were analyzed using Metaboanalyst online software, there was no data filtering, and data were normalized by sum of all metabolites per sample.

\section{Intracellular $\mathrm{pH}(\mathrm{pHi})$}

Solutions and media. (i) Solutions for Seahorse experiments: 2mM HEPES, 2mM MES, $5.3 \mathrm{mM}$ $\mathrm{KCl}, 5.6 \mathrm{mM}$ NaPhosphate, $11 \mathrm{mM}$ glucose, $133 \mathrm{mM} \mathrm{NaCl}, 0.4 \mathrm{mM} \mathrm{MgCl} 2,0.42 \mathrm{mM} \mathrm{CaCl}$, titrated to given $\mathrm{pH}$ with $\mathrm{NaOH}$. For reduced $\mathrm{Cl}^{-}$experiments, $133 \mathrm{mM} \mathrm{NaCl}$ was replaced with $133 \mathrm{mM} \mathrm{NaGluconate}$ and $\mathrm{MgCl}_{2}$ and $\mathrm{CaCl}_{2}$ were raised to $0.74 \mathrm{mM}$ and $1.46 \mathrm{mM}$, respectively, to account for gluconate-divalent binding. Calibration solutions for nigericin: $145 \mathrm{mM} \mathrm{KCl}, 1$ $\mathrm{mM} \mathrm{MgCl2}$, $0.5 \mathrm{mM}$ EGTA, $10 \mathrm{mM}$ HEPES, $10 \mathrm{mM}$ MES and adjusted with $\mathrm{NaOH}$ to required pH. pHe media to measure pHi: Solution A: $125 \mathrm{mM} \mathrm{NaCl}, 4.5 \mathrm{mM} \mathrm{KCl}, 1 \mathrm{mM} \mathrm{CaCl} 2,1 \mathrm{mM}$ $\mathrm{MgCl}_{2}, 11 \mathrm{mM}$ glucose base media. Split solution A into two parts- Solution B: $22 \mathrm{mM} \mathrm{HCO}_{3}^{-}$ and Solution C: $22 \mathrm{mM} \mathrm{NaCl}$. Mix B\&C as follows- 40ml B \& $0 \mathrm{ml} \mathrm{C}=22 \mathrm{mM} \mathrm{HCO}_{3}^{-}(\mathrm{pH} 7.41)$, $20 \mathrm{ml} \mathrm{B} \& 20 \mathrm{ml} \mathrm{C}=11 \mathrm{mM} \mathrm{HCO}_{3}^{-}\left(\mathrm{pH}_{7.11}\right), 10 \mathrm{ml} \mathrm{B} \& 30 \mathrm{ml} \mathrm{C}^{-}=5.5 \mathrm{mM} \mathrm{HCO}_{3}^{-}$(pH6.81), and $4 \mathrm{ml} \mathrm{B} \& 36 \mathrm{ml} \mathrm{C}=2.2 \mathrm{mM}(\mathrm{pH} 6.41)$. Fluorescent Labeling and Image Analysis. Cells were loaded with 10uM cSNARF1 and 2.7uM Hoechst 33342 for $10 \mathrm{mins}$ at $37^{\circ}$. Cells were washed in neutral $\mathrm{pH}$ media and imaged in various pHe media (6.4-7.4) on Leica SP5 Confocal Microscopy x40 objective. Cytoplasmic pH was 
measured by gating pixels according to a threshold level of Hoechst signal within cSNARF1positive pixels. Fluorescence at 580 and $640 \mathrm{~nm}$ was averaged, background offset and ratioed for each particle representing a cell.

In vitro cell motility and invasiveness were measured by methods as previously reported with some modifications 30 . The motility change was measured by the circular wound healing assay using OrisTM Cell Migration Assay Kit (Platypus, CMAU101). Cells were plated on a 96well plate at $1 \times 10^{6}$ cells/ml while a cell seeding stopper masker the circular area at the center of each well. The cell seeding stoppers were removed 24 hours after the plating and cells were cultured a further 30 hours to monitor the closing of the cell-free area (wound area). The area covered by live cells was measured by labeling cells with Calcein-AM (Life Technology, C3099) and analyzing microscopic images $(2.5 x)$ by Image $\mathrm{J}(\mathrm{NIH})$. The smaller wound size represents the higher motility.

Wound healing scratch assay was used to measure motility into CA-IX clones. 96-well plates were seeded with 1 x 106 cells/ml per well in 10\% FBS, 1\% PenStrep RPMI-1640 and incubated overnight. The plate was uniformly scratched with Essen Bioscience 96 Woundmaker, media was removed, and the plate washed with DPBS and then 200ul of media was added to each well. The wound was imaged on Celigo Imaging Cytometer and the number of cells that migrated into the wound was quantified by direct bright field cell counting at $0,24,48 \mathrm{hr}$.

Cell invasiveness was measured by monitoring cells escaping from Matrigel (Becton Dickenson, 356231). Cells were suspended in 50\% Matrigel in serum-free RPMI-1640 at 1 x 107 cells $/ \mathrm{ml}$. A Matrigel droplet (volume $=5 \mu \mathrm{l}$ ) was placed on each well of a 24 -well plate. The Matrigel was solidified by incubating at $37^{\circ} \mathrm{C}$ overnight and then FBS-containing normal growth media was added. The cells escaped from the Matrigel droplet were monitored in real-time by using the IncuCyte ZOOM system (Essen BioScience) or Celigo Imaging Cytometer (Nexcelom Bioscience, MA). After 7 days of culture, the cell expansion from the droplets was quantified by Celigo single colony verification algorithm or Image $\mathrm{J}$ after fixing cells in $3.7 \%$ formaldehyde and staining in crystal violet solution. The larger area occupied by cells represents the higher invasion potential.

Normalization of invasion and migration assays. The results of invasion and migration assays were normalized by the proliferation rates of the cells. Proliferation rates were calculated by a linear fit of cell growth, 48 hours after seeding the cells (See Figure S16) and weighted by the standards error. The normalization was carried out in order to eliminate inherent differences between clones making it possible to compare them. In the case of the invasion assay, final growth was divided by the proliferation rate of each of the cells. For the migration assay (i.e. wound healing assay), the relative healed area was divided by its corresponding growth rate and then multiplied by the growth rate of the MOCK-1 cells. This allowed comparison between the normalized healed areas of each clone, to one of the MOCK-1 cells. We used the Matlab R2012a curve fitting toolbox (The MathWorks, MA). Matlab code is available in the Supplementary materials. 

ice were given a week to acclimate to the animal facility before they were studied. To minimize the risk of any exogenous infection, the SCID mice were maintained and cared for in a sterile, static micro-isolation cage. Mice received irradiated food (Harlan Laboratories) and sterile water ad libitum. All animal experiments were performed under a protocol approved by the University of South Florida Institutional Animal Care and Use Committee. \\ Metastasis assays in vivo}

\section{$\underline{\text { Treatment model }}$}

Female SCID Beige mice received 200mmol/L of sodium bicarbonate water 2 days prior

Since MCF-7 cells are estrogen-dependent for tumor formation, estrogen pellets, $17 \beta$ estradiol, $0.72 \mathrm{mg} /$ pellet, 60-day release (Innovative Research of America, SE-121) were subcutaneously implanted in the shoulder region of the mice two days prior to tumor inoculation. For the primary tumor growth study with MCF-7/MOCK-2 or MCF-7/ CA-IX M6 cells, mice were given $200 \mathrm{nM} 17 \beta$ estradiol in drinking water to try and prevent adverse side effects of pellet use, including balder stones and urinary tract infections.

For the experimental metastasis, SCID mice were injected through tail veins with $1 \times$ $10^{6}$ cells in $200 \mu \mathrm{l}$ of PBS solution (either MCF-7/MOCK-1, MCF-7/PMA1-C1, MCF-7/MOCK2, MCF-7/CA-IX M1 or MCF-7/CA-IX M6 cells). Three months after injection of the cancer cells, the mice were euthanized, and the lung tissues were surgically excised, fixed, and stained with hematoxylin and eosin (HE). Lung sections (at least three histologic sections for each lung specimen) were examined for metastatic nodules under a light microscope by a breast cancer pathologist (A.L or M.M.B) who was blinded to identifiers.

For the spontaneous metastasis studies, approximately $10 \times 10^{6}$ cells (either MCF7/MOCK-1 and MCF-7/PMA1-C1) in $100 \mu 1$ of PBS $+100 \mu 1$ of Matrigel were injected into the mammary fat pads of mice. Once tumors reached approximately $400 \mathrm{~mm}^{3}$, or 6 weeks post-cell injection, the tumors were resected, fixed, and stained with H\&E, or PMA1 antibody. Three months after resection, the mice were sacrificed, and lung sections were examined for lung metastases. The tumors were measured twice every week throughout the study with a digital caliper and volume values were calculated with the formula $V=\left(\right.$ Length $\left.\times \mathrm{Width}^{2}\right) / 2$. The body weights were monitored twice a week throughout the study. to tail vein injection for experimental metastasis study. Mice continued receiving bicarbonate water until the end of the experiment. Control mice received regular tap water. Since MCF-7 cells are estrogen-dependent for tumor formation, estrogen pellets, $17 \beta$-estradiol, 0.36 $\mathrm{mg} /$ pellet, 90-day release (Innovative Research of America, SE-121) were subcutaneously implanted in the shoulder region of the mice two days prior to tumor inoculation. For the experimental metastasis, SCID mice were injected through tail veins with $1 \times 10^{6}$ cells in 200 
658 control group had observable lung metastasis by T2 MRI ( 74 days), mice were humanely

659 euthanized, and lungs and kidney collected.

$\underline{\text { Histology }}$

The tissues were harvested, fixed in $10 \%$ neutral buffered formalin (Thermo Scientific), processed, and embedded in paraffin. Tissue sections $(4 \mu \mathrm{m})$ were prepared and stained with $\mathrm{H} \& \mathrm{E}$ in the Moffitt Cancer Center Tissue Core. The histological slides of resected primary breast tumor xenografts from MCF-7/MOCK-1 or MCF-7/PMA1-C1 groups, and MCF-7/MOCK-2, MCF-7/CA-IX M1 and MCF-7/CA-IX M6 groups. were blindly examined under a light microscope by a pathologist (A.L or M.M.B) for tumor grades using the most common grading system: G1: well differentiated (low grade); G2: moderately differentiated (intermediate grade) G3: poorly differentiated (high grade); G4: undifferentiated (very high grade), as assessed according to histological features of stromal hypercellularity, atypia, stromal mitotic activity, presence of stromal over-growth and mitosis, necrosis, spindle cells differential and chromatin activity. Tumor burden in the lung was measured by Aperio ImageScope (Leica Biosystems, IL) and calculated as $\%$ of total lung tissue and compared between groups. Tumors were drawn around by hand using the Aperio software and confirmed by a pathologist (M.M.B), \% area of tumor in lungs was then calculated by comparing the area of total lung tissue to the area of the tumor within lungs. For all lung metastases IHC, three different sections were taken from each lung and analyzed, with 5-6 sections taken between each analyzed slice to ensure entirety of lungs, and metastatic burden was analyzed.

\section{Immunohistochemical (IHC) staining}

The cross-sections were stained with various antibodies as per normal laboratory protocol in the Moffitt Tissue Core Histology Facility. Positive and negative controls were used for each antibody staining and staining condition was optimized for each antibody. The antibodies were utilized in this study as follows: rabbit anti-Saccharomyces cerevisiae PMA1 (sc-33735, Santa Cruz Biotechnology); rabbit anti-human CA-IX (ab15086, Abcam, Cambridge, MA); rabbit antihuman MCT1 (sc-50324, Santa Cruz, CA); rabbit anti-human GLUT1 (ab15309, Abcam, Cambridge, MA); rabbit anti-human NHE1 (sc-28758, Santa Cruz, CA); rabbit anti-human ER( \#RM9101,ThermoFisher Scientific, MA). Histological stained slides were scanned using the Aperio ScanScope XT digital slide scanner and positivity analysis for each target gene staining was carried out using Aperio ImageScope V 10.2.1.2314 software. Positive cell percentage was calculated for PMA1, CA9, MCT1, GLUT1, and NHE1 expression on the entire tissue crosssection using algorithm membrane 9 in which positive cells include the cells with $\left(3_{+}\right)$strong; (2+) medium; $\left(1_{+}\right)$weak membrane intensity staining. 


\section{RNA analyses in formalin-fixed, paraffin-embedded (FFPE) tissue}

FFPE tissue samples were cut in $10 \mu \mathrm{m}$ - thick sections on a microtome, and deparaffinized by deparaffinization solution (Qiagen, 19093). Total RNA was extracted from deparaffinized FFPE sections with the miRNeasy FFPE kit (Qiagen, 217504) following the manufacturer's protocol. Real-time qRT-PCR analyses for PMA1 mRNA were described above in the qRT-PCR section. Experimental $\mathrm{C}_{t}$ values from PMA1 amplification were normalized with

$\underline{\text { Statistical analyses }}$ GAPDH $C_{t}$ values and were expressed relative to MCF-7/MOCK-1 control $C_{t}$ values.

$\underline{\text { Data and code availability }}$

The authors declare that the data supporting the findings of this study are available within the paper and its Supplementary information files. The code is available in the Supplementary

710 Supplementary figures S19.

\section{REFERENCES}

711 Beketic-Oreskovic, L., Ozretic, P., Rabbani, Z.N., Jackson, I.L., Sarcevic, B., Levanat, S., and 712 Vujaskovic, Z. (2010). Prognostic significance of carbonic anhydrase IX (CAIX), endoglin 713 (CD105), and 8-hydroxy-2deoxyguanosine (8-OHdG) in breast cancer patients. Journal of Clinical 714 Oncology 28, e21048-e21048.

715 Birchmeier, C., Birchmeier, W., Gherardi, E., and Vande Woude, G.F. (2003). Met, metastasis, 716 motility and more. Nat Rev Mol Cell Biol 4, 915-925.

717 Boedtkjer, E. (2019). Na(+),HCO3(-) cotransporter NBCn1 accelerates breast carcinogenesis. 718 Cancer Metastasis Rev 38, 165-178.

719 Brand, A., Singer, K., Koehl, G.E., Kolitzus, M., Schoenhammer, G., Thiel, A., Matos, C., Bruss, 720 C., Klobuch, S., Peter, K., et al. (2016). LDHA-Associated Lactic Acid Production Blunts Tumor 721 Immunosurveillance by $\mathrm{T}$ and NK Cells. Cell Metab 24, 657-671. 
Buzzai, M., Bauer, D.E., Jones, R.G., Deberardinis, R.J., Hatzivassiliou, G., Elstrom, R.L., and Thompson, C.B. (2005). The glucose dependence of Akt-transformed cells can be reversed by pharmacologic activation of fatty acid beta-oxidation. Oncogene 24, 4165-4173.

Cardone, R.A., Greco, M.R., Zeeberg, K., Zaccagnino, A., Saccomano, M., Bellizzi, A., Bruns, P., Menga, M., Pilarsky, C., Schwab, A., et al. (2015). A novel NHE1-centered signaling cassette drives epidermal growth factor receptor-dependent pancreatic tumor metastasis and is a target for combination therapy. Neoplasia 17, 155-166.

729 Carracedo, A., Cantley, L.C., and Pandolfi, P.P. (2013). Cancer metabolism: fatty acid oxidation in the limelight. Nature reviews Cancer 13, 227-232.

731 Cheng, P.C., Lin, H.Y., Chen, Y.S., Cheng, R.C., Su, H.C., and Huang, R.C. (2019). The $\mathrm{Na}(+/) \mathrm{H}(+)$-Exchanger NHE1 Regulates Extra- and Intracellular $\mathrm{pH}$ and Nimodipine-sensitive $733[\mathrm{Ca}(2+)] \mathrm{i}$ in the Suprachiasmatic Nucleus. Sci Rep 9, 6430.

734 Choschzick, M., Oosterwijk, E., Muller, V., Woelber, L., Simon, R., Moch, H., and Tennstedt, P. (2011). Overexpression of carbonic anhydrase IX (CA-IX) is an independent unfavorable prognostic marker in endometrioid ovarian cancer. Virchows Archiv : an international journal of 737 pathology 459, 193-200.

Cori, C.F., and Cori, G.T. (1925). The Carbohydrate Metabolism of Tumors I: THE FREE SUGAR, LACTIC ACID, AND GLYCOGEN CONTENT OF MALIGNANT TUMORS. J Biol 740 Chem 64, 11.

741 Csaderova, L., Debreova, M., Radvak, P., Stano, M., Vrestiakova, M., Kopacek, J., Pastorekova, 742 S., and Svastova, E. (2013). The effect of carbonic anhydrase IX on focal contacts during cell 743 spreading and migration. Front Physiol 4, 271.

744 Damaghi, M., Tafreshi, N.K., Lloyd, M.C., Sprung, R., Estrella, V., Wojtkowiak, J.W., Morse, 745 D.L., Koomen, J.M., Bui, M.M., Gatenby, R.A., et al. (2015). Chronic acidosis in the tumour 746 microenvironment selects for overexpression of LAMP2 in the plasma membrane. Nat Commun 7476,8752 .

748 Damaghi, M., West, J., Robertson-Tessi, M., Xu, L., Ferrall-Fairbanks, M.C., Stewart, P.A., Persi, 749 E., Fridley, B.L., Altrock, P.M., Gatenby, R.A., et al. (2021). The harsh microenvironment in early 750 breast cancer selects for a Warburg phenotype. Proc Nat Acad Sci USA (in press).

751 DeBerardninis, R.J., and Chandel, N.S. (2020). We need to talk about the Warburg effect. Nature 752 Metabolism 2, 127-129.

753 Doherty, J.R., Yang, C., Scott, K.E., Cameron, M.D., Fallahi, M., Li, W., Hall, M.A., Amelio, 754 A.L., Mishra, J.K., Li, F., et al. (2014). Blocking lactate export by inhibiting the Myc target MCT1 755 Disables glycolysis and glutathione synthesis. Cancer Res 74, 908-920. 
Epstein, T., Xu, L., Gillies, R.J., and Gatenby, R.A. (2014). Separation of metabolic supply and demand: aerobic glycolysis as a normal physiological response to fluctuating energetic demands in the membrane. Cancer \& metabolism 2, 7.

Estrella, V., Chen, T., Lloyd, M., Wojtkowiak, J., Cornnell, H.H., Ibrahim-Hashim, A., Bailey, K., Balagurunathan, Y., Rothberg, J.M., Sloane, B.F., et al. (2013). Acidity generated by the tumor microenvironment drives local invasion. Cancer Res 73, 1524-1535.

762 Fais, S. (2015). Evidence-based support for the use of proton pump inhibitors in cancer therapy. J

763 Transl Med 13, 368.

764 Ferreira, T., Mason, A.B., and Slayman, C.W. (2001). The yeast Pma1 proton pump: a model for

765 understanding the biogenesis of plasma membrane proteins. The Journal of biological chemistry

$766276,29613-29616$.

767 Gatenby, R.A., Gawlinski, E.T., Gmitro, A.F., Kaylor, B., and Gillies, R.J. (2006a). Acid-mediated 768 tumor invasion: a multidisciplinary study. Cancer Res 66, 5216-5223.

769 Gatenby, R.A., Gawlinski, E.T., Gmitro, A.F., Kaylor, B., and Gillies, R.J. (2006b). Acid-mediated 770 tumor invasion: a multidisciplinary study. Cancer Res 66, 5216-5223.

771 Gatenby, R.A., and Gillies, R.J. (2004a). Why do cancers have high aerobic glycolysis? Nat Rev 772 Cancer 4, 891-899.

773 Gatenby, R.A., and Gillies, R.J. (2004b). Why do cancers have high aerobic glycolysis? Nature 774 reviews Cancer 4, 891-899.

775 Gillies, R.J., Robey, I., and Gatenby, R.A. (2008). Causes and consequences of increased glucose 776 metabolism of cancers. Journal of nuclear medicine : official publication, Society of Nuclear 777 Medicine 49 Suppl 2, 24S-42S.

778 Gillies, R.J.M.-Z., R.; Martinez, G.M.; Serrano, R.; Perona, R. (1990). Tumorigenic 3T3 cells 779 maintain an alkaline intracellular $\mathrm{pH}$ under physiological conditions.

780 Hanahan, D., and Weinberg, R.A. (2011). Hallmarks of cancer: the next generation. Cell 144, 646781674.

782 Hiraga, T., Ito, S., and Nakamura, H. (2013). Cancer stem-like cell marker CD44 promotes bone 783 metastases by enhancing tumorigenicity, cell motility, and hyaluronan production. Cancer Res 73, $784 \quad 4112-4122$.

785 Ibrahim-Hashim, A., Abrahams, D., Enriquez-Navas, P.M., Luddy, K., Gatenby, R.A., and Gillies, 786 R.J. (2017). Tris-base buffer: a promising new inhibitor for cancer progression and metastasis. 787 Cancer Medicine 6, 1720-1729. 
Ibrahim-Hashim, A., Cornnell, H.H., Abrahams, D., Lloyd, M., Bui, M., Gillies, R.J., and Gatenby, R.A. (2012). Systemic buffers inhibit carcinogenesis in TRAMP mice. The Journal of urology 188, 624-631.

Jamali, S., Klier, M., Ames, S., Barros, L.F., McKenna, R., Deitmer, J.W., and Becker, H.M. (2015). Hypoxia-induced carbonic anhydrase IX facilitates lactate flux in human breast cancer cells by non-catalytic function. Sci Rep 5, 13605.

Jin, L., Chun, J., Pan, C., Kumar, A., Zhang, G., Ha, Y., Li, D., Alesi, G.N., Kang, Y., Zhou, L., et al. (2018). The PLAG1-GDH1 Axis Promotes Anoikis Resistance and Tumor Metastasis through CamKK2-AMPK Signaling in LKB1-Deficient Lung Cancer. Mol Cell 69, 87-99 e87.

Kato, H., Semba, S., Miskad, U.A., Seo, Y., Kasuga, M., and Yokozaki, H. (2004). High Expression of PRL-3 Promotes Cancer Cell Motility and Liver Metastasis in Human Colorectal Cancer: A Predictive Molecular Marker of Metachronous Liver and Lung Metastases. Clin Cancer 800 Res.

Kato, Y., Lambert, C.A., Colige, A.C., Mineur, P., Noel, A., Frankenne, F., Foidart, J.M., Baba, M., Hata, R., Miyazaki, K., et al. (2005). Acidic extracellular pH induces matrix metalloproteinase-9 expression in mouse metastatic melanoma cells through the phospholipase Dmitogen-activated protein kinase signaling. The Journal of biological chemistry 280, 1093810944.

Kim, J.W., Gao, P., Liu, Y.C., Semenza, G.L., and Dang, C.V. (2007). Hypoxia-inducible factor 1 and dysregulated c-Myc cooperatively induce vascular endothelial growth factor and metabolic switches hexokinase 2 and pyruvate dehydrogenase kinase 1. Mol Cell Biol 27, 7381-7393. of the tumor-associated carbonic anhydrase IX. Biochim Biophys Acta 1729, 41-49.

Kunkel, M., Reichert, T.E., Benz, P., Lehr, H.A., Jeong, J.H., Wieand, S., Bartenstein, P., Wagner, W., and Whiteside, T.L. (2003). Overexpression of Glut-1 and increased glucose metabolism in tumors are associated with a poor prognosis in patients with oral squamous cell carcinoma. Cancer 97, 1015-1024.

816 Lee, S.H., McIntyre, D., Honess, D., Hulikova, A., Pacheco-Torres, J., Cerdan, S., Swietach, P., 817 Harris, A.L., and Griffiths, J.R. (2018). Carbonic anhydrase IX is a pH-stat that sets an acidic 818 tumour extracellular pH in vivo. Br J Cancer 119, 622-630. membrane-associated carbonic anhydrase IX in MDA-MB-231 breast cancer cells. The Journal of 821 biological chemistry $286,15789-15796$.

822 Lloyd, M.C., Cunningham, J.J., Bui, M.M., Gillies, R.J., Brown, J.S., and Gatenby, R.A. (2016). 823 Darwinian Dynamics of Intratumoral Heterogeneity: Not Solely Random Mutations but Also 824 Variable Environmental Selection Forces. Cancer research 76, 3136-3144. 
Lou, Y., McDonald, P.C., Oloumi, A., Chia, S., Ostlund, C., Ahmadi, A., Kyle, A., Auf dem Keller, U., Leung, S., Huntsman, D., et al. (2011). Targeting tumor hypoxia: suppression of breast tumor growth and metastasis by novel carbonic anhydrase IX inhibitors. Cancer Res 71, 33643376.

829 Lunt, S.Y., and Vander Heiden, M.G. (2011). Aerobic glycolysis: meeting the metabolic requirements of cell proliferation. Annu Rev Cell Dev Biol 27, 441-464.

831 Mahon, B.P., Bhatt, A., Socorro, L., Driscoll, J.M., Okoh, C., Lomelino, C.L., Mboge, M.Y., 832 Kurian, J.J., Tu, C., Agbandje-McKenna, M., et al. (2016). Structure of carbonic anhydrase IX is 833 adapted for low $\mathrm{pH}$ catalysis. Biochemistry.

834 Martinez, G.V., Martinez-Zaguilan, R., and Gillies, R.J. (1994). Effect of Glucose on intracellular $\mathrm{pH}$ and Ca2+ in NIH-3T3 Cells Transfected With the Yeast P-Type H+ATPase. J Cell Physiol.

836 McIntyre, A., Patiar, S., Wigfield, S., Li, J.L., Ledaki, I., Turley, H., Leek, R., Snell, C., Gatter, 837 K., Sly, W.S., et al. (2012). Carbonic anhydrase IX promotes tumor growth and necrosis in vivo 838 and inhibition enhances anti-VEGF therapy. Clinical cancer research : an official journal of the American Association for Cancer Research 18, 3100-3111.

840 Moellering, R.E., Black, K.C., Krishnamurty, C., Baggett, B.K., Stafford, P., Rain, M., Gatenby, 841 R.A., and Gillies, R.J. (2008). Acid treatment of melanoma cells selects for invasive phenotypes. 842 Clinical \& experimental metastasis 25, 411-425.

843 Morgan, P.E., Pastorekova, S., Stuart-Tilley, A.K., Alper, S.L., and Casey, J.R. (2007). 844 Interactions of transmembrane carbonic anhydrase, CAIX, with bicarbonate transporters. 845 American journal of physiology Cell physiology 293, C738-748.

846 Nieto, M.A., Huang, R.Y., Jackson, R.A., and Thiery, J.P. (2016). Emt: 2016. Cell 166, 21-45.

847 Nordfors, K., Haapasalo, J., Haapasalo, H., and Parkkil, S. (2013). Carbonic Anhydrase IX in 848 Adult and Pediatric Brain Tumors. In Evolution of the Molecular Biology of Brain Tumors and 849 the Therapeutic Implications.

850 Paoli, P., Giannoni, E., and Chiarugi, P. (2013). Anoikis molecular pathways and its role in cancer 851 progression. Biochim Biophys Acta 1833, 3481-3498.

852 Pastushenko, I., Brisebarre, A., Sifrim, A., Fioramonti, M., Revenco, T., Boumahdi, S., Van 853 Keymeulen, A., Brown, D., Moers, V., Lemaire, S., et al. (2018). Identification of the tumour 854 transition states occurring during EMT. Nature 556, 463-468.

855 Peppicelli, S., Ruzzolini, J., Bianchini, F., Andreucci, E., Nediani, C., Laurenzana, A., Margheri, 856 F., Fibbi, G., and Calorini, L. (2019). Anoikis Resistance as a Further Trait of Acidic-Adapted 857 Melanoma Cells. J Oncol 2019, 8340926.

858 Perona, R., and Serrano, R. (1988). Increase $\mathrm{pH}$ and tumorigenicity of fibroblasts expressing a 859 yeast proton pump. Nature. 
860 Persi, E., Duran-Frigola, M., Damaghi, M., Roush, W.R., Aloy, P., Cleveland, J.L., Gillies, R.J., 861 and Ruppin, E. (2018). Systems analysis of intracellular pH vulnerabilities for cancer therapy. Nat 862 Commun 9, 2997.

863 Puisieux, A., Brabletz, T., and Caramel, J. (2014). Oncogenic roles of EMT-inducing transcription 864 factors. Nat Cell Biol 16, 488-494.

865 Riemann, A., Rauschner, M., Giesselmann, M., Reime, S., Haupt, V., and Thews, O. (2019). 866 Extracellular Acidosis Modulates the Expression of Epithelial-Mesenchymal Transition (EMT) 867 Markers and Adhesion of Epithelial and Tumor Cells. Neoplasia 21, 450-458.

868 Rizwan, A., Serganova, I., Khanin, R., Karabeber, H., Ni, X., Thakur, S., Zakian, K.L., Blasberg, 869 R., and Koutcher, J.A. (2013). Relationships between LDH-A, lactate, and metastases in 4T1 870 breast tumors. Clin Cancer Res 19, 5158-5169.

871 Robey, I.F., Baggett, B.K., Kirkpatrick, N.D., Roe, D.J., Dosescu, J., Sloane, B.F., Hashim, A.I., 872 Morse, D.L., Raghunand, N., Gatenby, R.A., et al. (2009). Bicarbonate increases tumor pH and 873 inhibits spontaneous metastases. Cancer Res 69, 2260-2268.

874 Rohani, N., Hao, L., Alexis, M.S., Joughin, B.A., Krismer, K., Moufarrej, M.N., Soltis, A.R., 875 Lauffenburger, D.A., Yaffe, M.B., Burge, C.B., et al. (2019). Acidification of Tumor at Stromal 876 Boundaries Drives Transcriptome Alterations Associated with Aggressive Phenotypes. Cancer 877 research 79, 1952-1966.

878 Russell, S., Wojtkowiak, J., Neilson, A., and Gillies, R.J. (2017). Metabolic Profiling of healthy 879 and cancerous tissues in 2D and 3D. Sci Rep 7, 15285.

880 Sasaki, S., and Yoshiyama, N. (1988). Interaction of Chloride and Bicarbonate Transport across 881 the Basolateral Membrane of Rabbit Proximal Straight Tubule: Evidence for Sodium Coupled 882 Chloride/Bicarbonate Exchange. J Clin Invest.

883 Shin, H.J., Rho, S.B., Jung, D.C., Han, I.O., Oh, E.S., and Kim, J.Y. (2011). Carbonic anhydrase 884 IX (CA9) modulates tumor-associated cell migration and invasion. J Cell Sci 124, 1077-1087.

885 Shiratori, R., Furuichi, K., Yamaguchi, M., Miyazaki, N., Aoki, H., Chibana, H., Ito, K., and Aoki, 886 S. (2019). Glycolytic suppression dramatically changes the intracellular metabolic profile of 887 multiple cancer cell lines in a mitochondrial metabolism-dependent manner. Sci Rep 9, 18699.

888 Silvia Pastorekova, Seppo Parkkila, Anna-Kaisa Parkkila, Rene Opavsky, Vladimir Zelnik, Juha 889 Saarnio, and Pastorek., J. (1997). Carbonic Anhydrase IX, MN/CA IX: Analysis of Stomach 890 Complementary DNA Sequence and Expression in Human and Rat Alimentary Tracts. 891 Gastroenterology.

892 Stock, C., and Schwab, A. (2009). Protons make tumor cells move like clockwork. Pflugers Arch $893458,981-992$. 
Svastova, E., Witarski, W., Csaderova, L., Kosik, I., Skvarkova, L., Hulikova, A., Zatovicova, M., Barathova, M., Kopacek, J., Pastorek, J., et al. (2012). Carbonic anhydrase IX interacts with bicarbonate transporters in lamellipodia and increases cell migration via its catalytic domain. The Journal of biological chemistry 287, 3392-3402.

Swayampakula, M., McDonald, P.C., Vallejo, M., Coyaud, E., Chafe, S.C., Westerback, A., Venkateswaran, G., Shankar, J., Gao, G., Laurent, E.M.N., et al. (2017). The interactome of metabolic enzyme carbonic anhydrase IX reveals novel roles in tumor cell migration and invadopodia/MMP14-mediated invasion. Oncogene.

Swietach, P., Patiar, S., Supuran, C.T., Harris, A.L., and Vaughan-Jones, R.D. (2009). The role of carbonic anhydrase 9 in regulating extracellular and intracellular ph in three-dimensional tumor cell growths. The Journal of biological chemistry 284, 20299-20310.

Takacova, M., Holotnakova, T., Barathova, M., Pastorekova, S., Kopacek, J., and Pastorek, J. (2010). Src induces expression of carbonic anhydrase IX via hypoxia-inducible factor 1 . Oncol Rep 23, 869-874.

van Kuijk, S.J., Yaromina, A., Houben, R., Niemans, R., Lambin, P., and Dubois, L.J. (2016). Prognostic Significance of Carbonic Anhydrase IX Expression in Cancer Patients: A Meta910 Analysis. Front Oncol 6, 69.

911 Vander Heiden, M.G., Cantley, L.C., and Thompson, C.B. (2009). Understanding the Warburg 912 effect: the metabolic requirements of cell proliferation. Science 324, 1029-1033.

913 Vaupel, P., and Multhoff, G. (2020). Revisiting the warburg effect: historical dogma versus current 914 understanding. J Physiol.

915 Walenta, S., Wetterling, M., Lehrke, M., Schwickert, G., Sundfor, K., Rofstad, E.K., and Mueller916 Klieser, W. (2000). High lactate levels predict likelihood of metastases, tumor recurrence, and 917 restricted patient survival in human cervical cancers. Cancer research 60, 916-921.

918 Warburg, O., Posener, K., and Negelein, E. (1924). Uber den stoffwechsel der carcinomzelle. 919 Bioichem Z 152, 309-344.

920 Ward, C., Meehan, J., Mullen, P., Supuran, C., Dixon, J.M., Thomas, J.S., Winum, J.-Y., Lambin, 921 P., Dubois, L., Pavathaneni, N.-K., et al. (2015). Evaluation of carbonic anhydrase IX as a 922 therapeutic target for inhibition of breast cancer invasion and metastasis using a series of in vitro 923 breast cancer models.

924 Webb, B.A., Chimenti, M., Jacobson, M.P., and Barber, D.L. (2011a). Dysregulated pH: a perfect 925 storm for cancer progression. Nat Rev Cancer 11, 671-677.

926 Webb, B.A., Chimenti, M., Jacobson, M.P., and Barber, D.L. (2011b). Dysregulated pH: a perfect 927 storm for cancer progression. Nature reviews Cancer 11, 671-677. 
928 Wellen, K.E., and Thompson, C.B. (2012). A two-way street: reciprocal regulation of metabolism 929 and signalling. Nat Rev Mol Cell Biol 13, 270-276.

930 Wonsey, D.R., Zeller, K.I., and Dang, C.V. (2002). The c-Myc target gene PRDX3 is required for 931 mitochondrial homeostasis and neoplastic transformation. Proc Natl Acad Sci U S A 99, 66499326654.

933 Wu, H., Estrella, V., Beatty, M., Abrahams, D., El-Kenawi, A., Russell, S., Ibrahim-Hashim, A., 934 Longo, D.L., Reshetnyak, Y.K., Moshnikova, A., et al. (2020). T-cells produce acidic niches in 935 lymph nodes to suppress their own effector functions. Nature communications 11, 4113.

936 Yu, G., Yu, W., Jin, G., Xu, D., Chen, Y., Xia, T., Yu, A., Fang, W., Zhang, X., Li, Z., et al. 937 (2015). PKM2 regulates neural invasion of and predicts poor prognosis for human hilar 938 cholangiocarcinoma. Mol Cancer 14, 193. 
Appendix: Current Author Addresses

Shonagh Russell(shonagh.russell@moffitt.org)1,2,

Liping Xu(liping.xu@moffitt.org)1,

Yoonseok Kam(yoonseok.kam@agilent.com)9,

Dominique Abrahams(Dominique.abrahams@moffitt.org)1,

Daniel Verduzco(dverduzco@mdanderson.org)3,

Joseph Johnson(joseph.johnson@moffitt.org)10,

Tamir Epstein(tamir.epstein@gmail.com)7,

Epifanio Ruiz(epifanio.ruiz@,moffitt.org)4,

Mark C. Lloyd(Mlloyd@inspirata.com)6,

Jonathan Wojtkowiak(wojtkow2@gmail.com)1,

Alex S. Lopez(alexis.lopez@moffitt.org)5,

Marilyn M. Bui(marilyn.bui@moffitt.org)5,10

Robert J. Gillies(Robert.gillies@moffitt.org)1*

Pawel Swietach (pawel.swietach@dpag.ox.ac.uk)

Bryce Ordway (Bryce.ordway@moffitt.org)

Shonagh Russell, liping.xu@moffitt.org, yoonseok.kam@agilent.com,

Dominique.abrahams@moffitt.org,dverduzco@mdanderson.org, joseph.johnson@moffitt.org, tamir.epstein@gmail.com, epifanio.ruiz@moffitt.org, Mlloyd@inspirata.com, wojtkow2@gmail.com, alexis.lopez@moffitt.org), Alex S.Lopez(alexis.lopez@moffitt.org)5, marilyn.bui@moffitt.org, Robert.gillies@moffitt.org,pawel.swietach@dpag.ox.ac.uk, Bryce.ordway@moffitt.org

1Cancer Physiology, Moffitt Cancer Center, 12902 Magnolia Dr, Tampa, 33612, FL, USA ${ }_{2}$ University of South Florida, 4202 E Fowler Ave, Tampa, 33620, FL, USA 3 MD Anderson 4Small Animal Imaging Department, Moffitt Cancer Center, 12902 USF Magnolia Dr, Tampa, 33612, FL, USA

5Anatomic Pathology, Moffitt Cancer Center, 12902 USF Magnolia Dr, Tampa, 33612, Fl, USA 6 Inspirata, Inc. One North Dale Mabry Hwy. Suite 600 Tampa, FL 33609

7Mariotteplein 42, 1098PA, Amsterdam, the Netherlands 
bioRxiv preprint doi: https://doi.org/10.1101/2021.09.20.461019; this version posted September 21, 2021. The copyright holder for this preprint (which was not certified by peer review) is the author/funder, who has granted bioRxiv a license to display the preprint in perpetuity. It is made available under aCC-BY 4.0 International license.

8Genentech, 1 DNA Way Mailstop 258A, South San Francisco, CA 94080, USA

9Agilent Technologies, 5301 Stevens Creek Blvd, Santa Clara, CA 9505, USA

10Analytic Microscopy Core, Moffitt Cancer Center, 12902 USF Magnolia Dr, Tampa, 33612, FL, USA 


\section{Supplementary Tables (S1,S2) And Figures (S1 - S24)}

Raw western blots

Matlab code 


\section{Supplementary Table 1}

\begin{tabular}{|l|l|l|l|l|l|l|}
\hline \multirow{2}{*}{ pHe } & \multicolumn{5}{|c|}{ pHi } \\
\cline { 2 - 8 } & MCF7 & & M1 & M6 & \\
\hline & Average & SD & Average & SD & Average & SD \\
\hline 6.4 & 6.78 & 0.1966 & 6.78 & 0.178 & 6.75 & 0.1859 \\
\hline 6.8 & 6.88 & 0.1459 & 6.93 & 0.1224 & 6.97 & 0.08992 \\
\hline 7.1 & 6.98 & 0.1262 & 7.04 & 0.08474 & 7.04 & 0.09440 \\
\hline 7.4 & 7.05 & 0.1517 & 7.04 & 0.09170 & 7.03 & 0.07948 \\
\hline
\end{tabular}

Supplementary Table 1: Average intracellular pHi in control and CA-IX expressing MCF-7 cells as a function of extracellular $\mathrm{pH} . \mathrm{n}=158-438$ cells, standard deviation shown. 


\section{Supplementary Table 2}

\begin{tabular}{|l|l|l|}
\hline \multicolumn{1}{|c|}{ Mouse Model } & $\begin{array}{l}\text { Experimental } \\
\text { Metastasis }\end{array}$ & $\begin{array}{l}\text { Spontaneous } \\
\text { Metastasis }\end{array}$ \\
\hline $\begin{array}{l}\text { \# of mice with lung } \\
\text { mets }\end{array}$ & $\begin{array}{l}\text { \# of mice with lung } \\
\text { mets }\end{array}$ \\
\hline Group ID & & $4 / 9(44 \%)$ \\
\hline MCF7/PMA-1 & $7 / 12(58 \%)$ & $1 / 10(10 \%)$ \\
\hline MCF7/MOCK-1 & $1 / 10(10 \%)$ & 0.14 (n.s.) \\
\hline P-Value & $0.03^{*}$ & \\
\hline
\end{tabular}

Supplementary Table 2: Effect of PMA1 expression on experimental and spontaneous metastasis in MCF-7 cells. (Two-tailed Fisher's exact t-test $\left.\mathrm{p}<0.05^{\star}\right)$ 


\section{Supplementary Fig. 1}

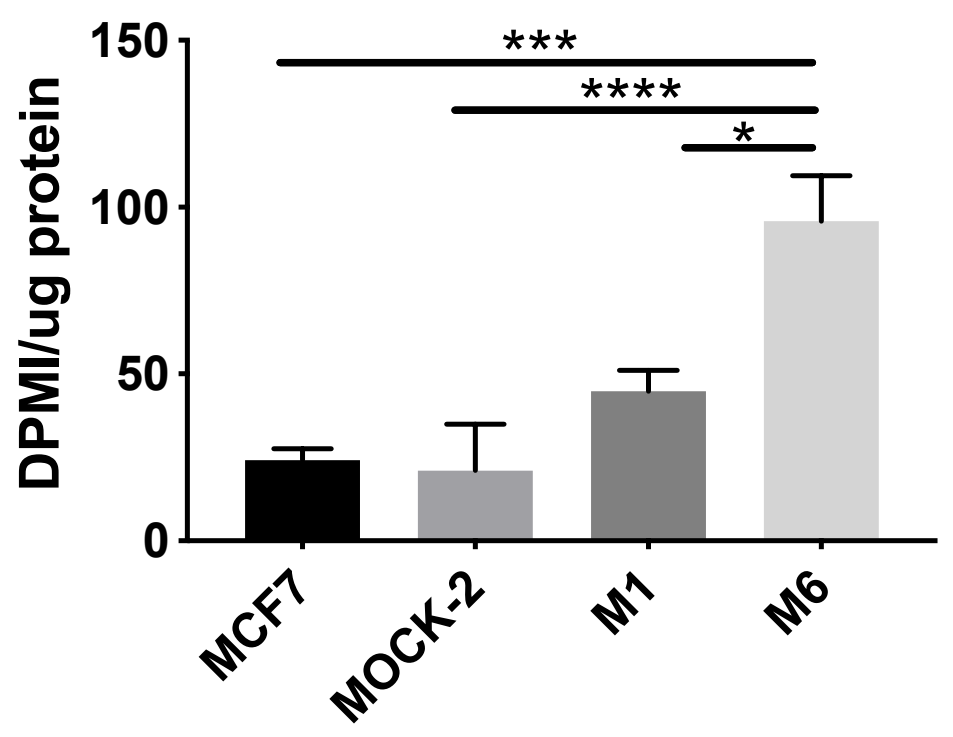

Supplementary Fig. 1. Uptake of ${ }^{3} \mathrm{H}$-2-deoxy glucose in control and CAIX MCF-7 clones ( $N=3$; Ordinary one-way ANOVA ${ }^{*},{ }^{* * *},{ }^{* * * *} \mathrm{p}<0.05,0.005$, $0.001)$ 


\section{Supplementary Fig. 2}
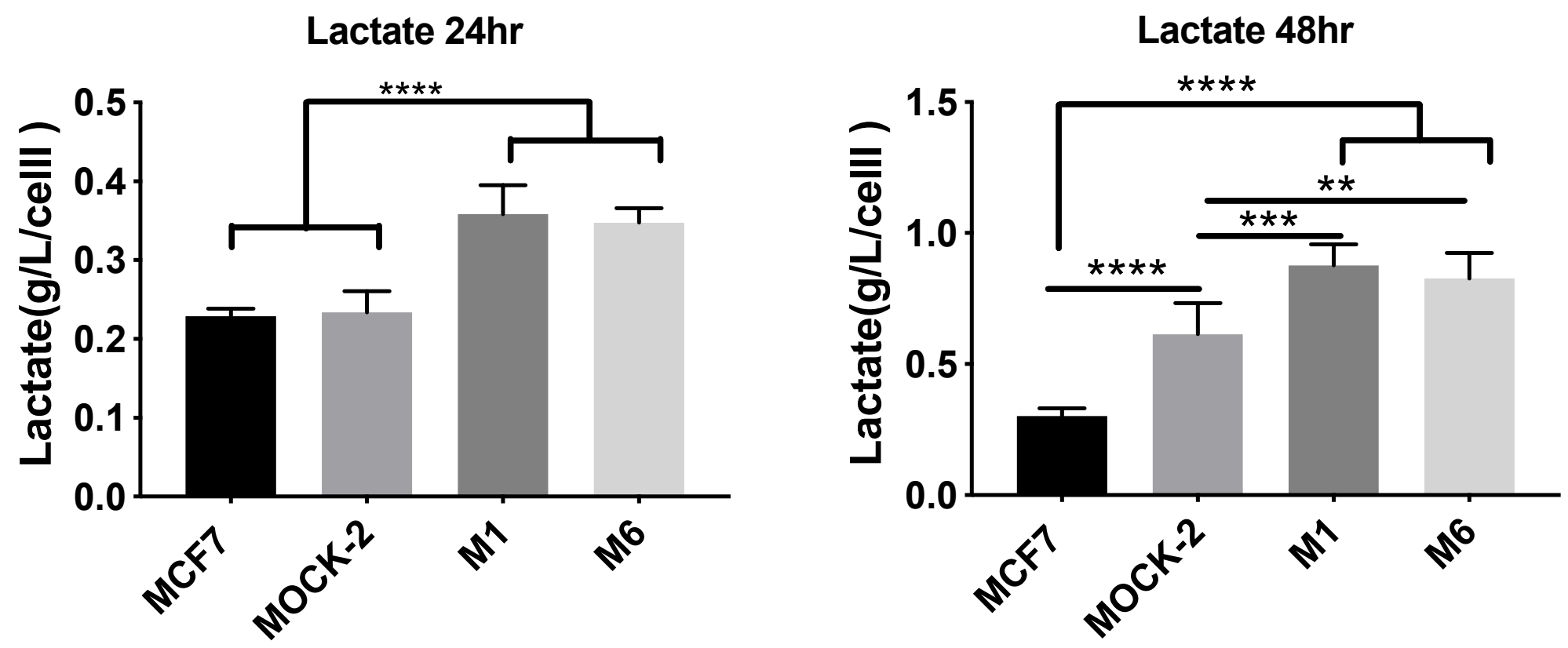

Supplementary Fig. 2. YSI analysis of lactate in media at 24 and 48 hours in CA-IX clones ( $\mathrm{N}=6$ replicates, Ordinary one-way ANOVA $\mathrm{p}<0.01^{* *}, 0.005^{\star * *}$, $0.001^{* * * *}$.) 


\section{Supplementary Fig. 3}

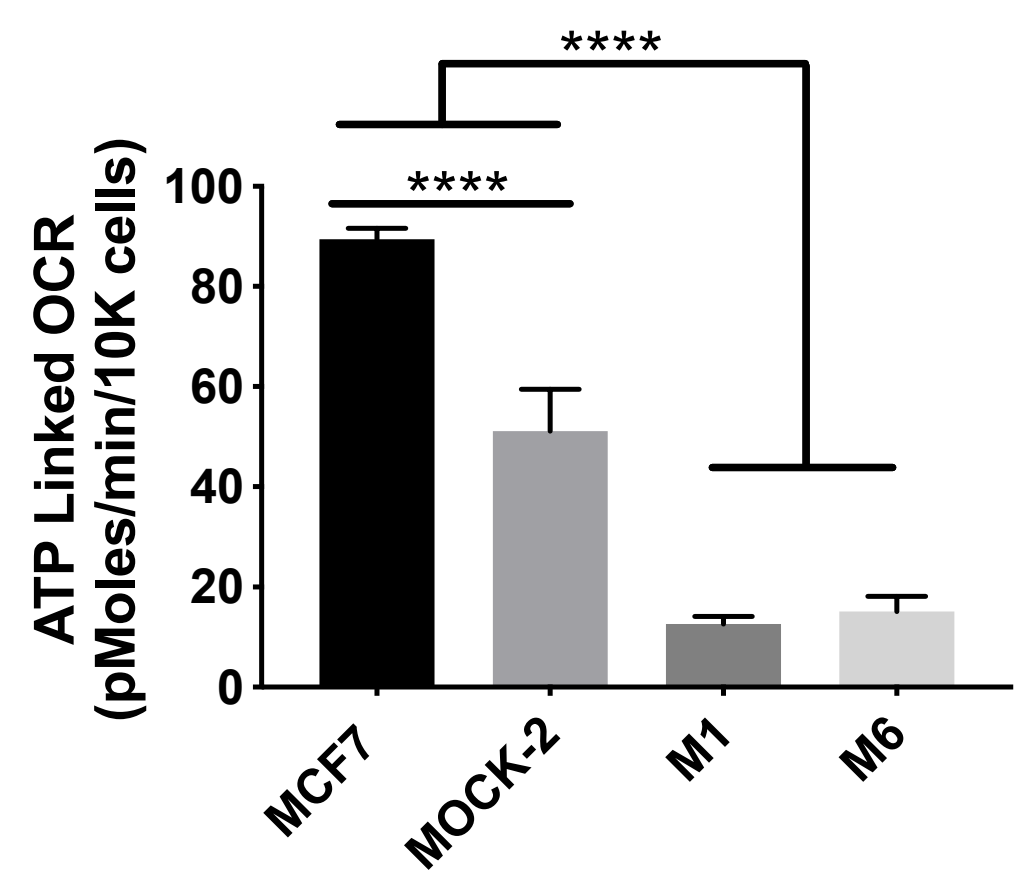

Supplementary Fig. 3. ATP linked OCR measured by mitochondrial stress test XFe96 Seahorse assay, by injecting oligomycin to shut off mitochondrial respiration. ( $\mathrm{N}=8$ replicates, ordinary one-way ANOVA $\mathrm{p}<0.001^{* * * *}$.) 


\section{Supplementary Fig. 4}

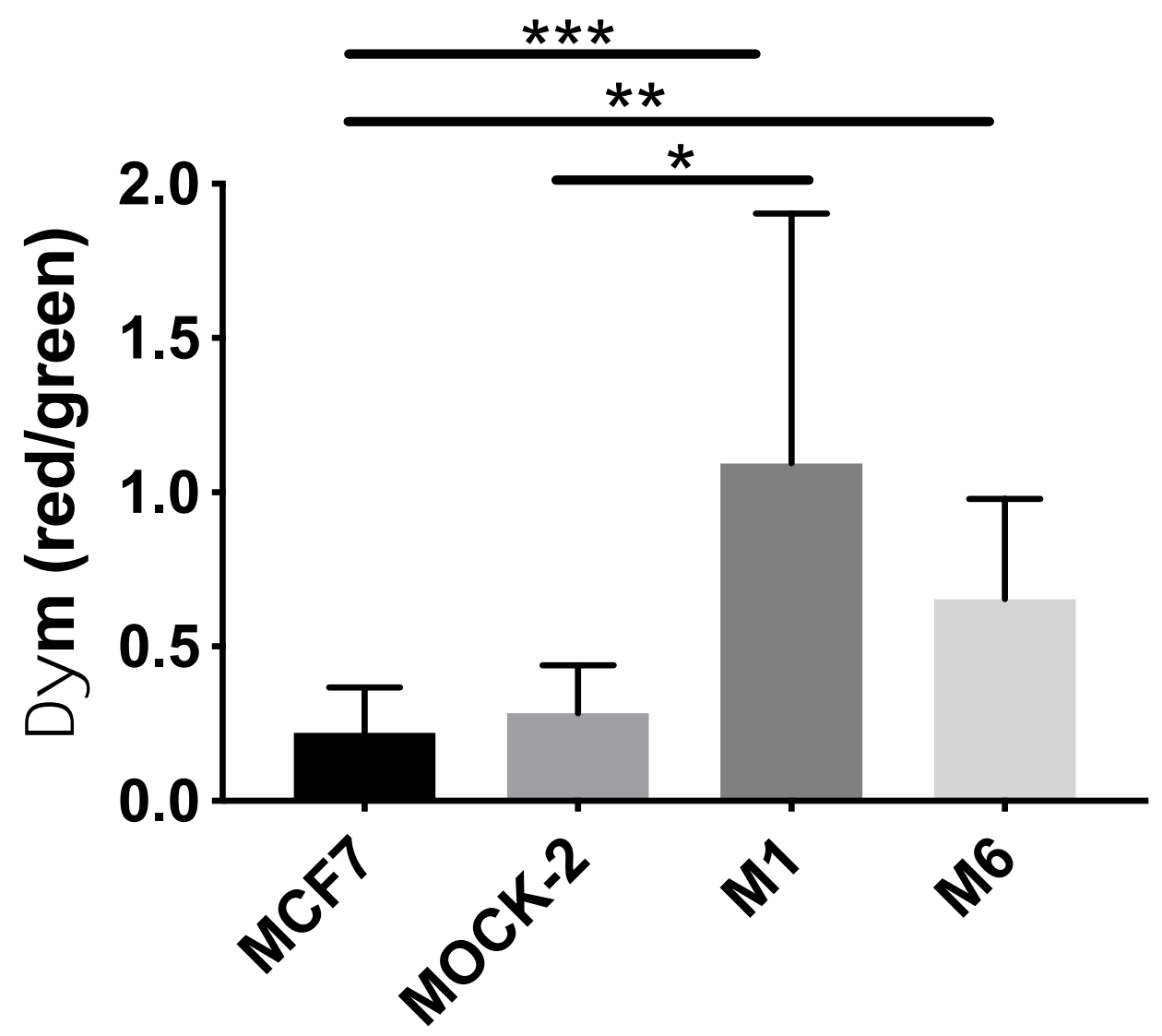

Supplementary Fig. 4. Mitochondrial polarization using JC-1 mitochondrial dye in CA-IX clones ( $\mathrm{N}=8-12$ per group, 2 bioreplicates; Kriskal Wallis Test $\left.\mathrm{p}<0.05^{\star}, \mathrm{p}<0.01^{\star \star}, \mathrm{p}<0.005^{\star \star *}\right)$ 


\section{Supplementary Fig. 5}
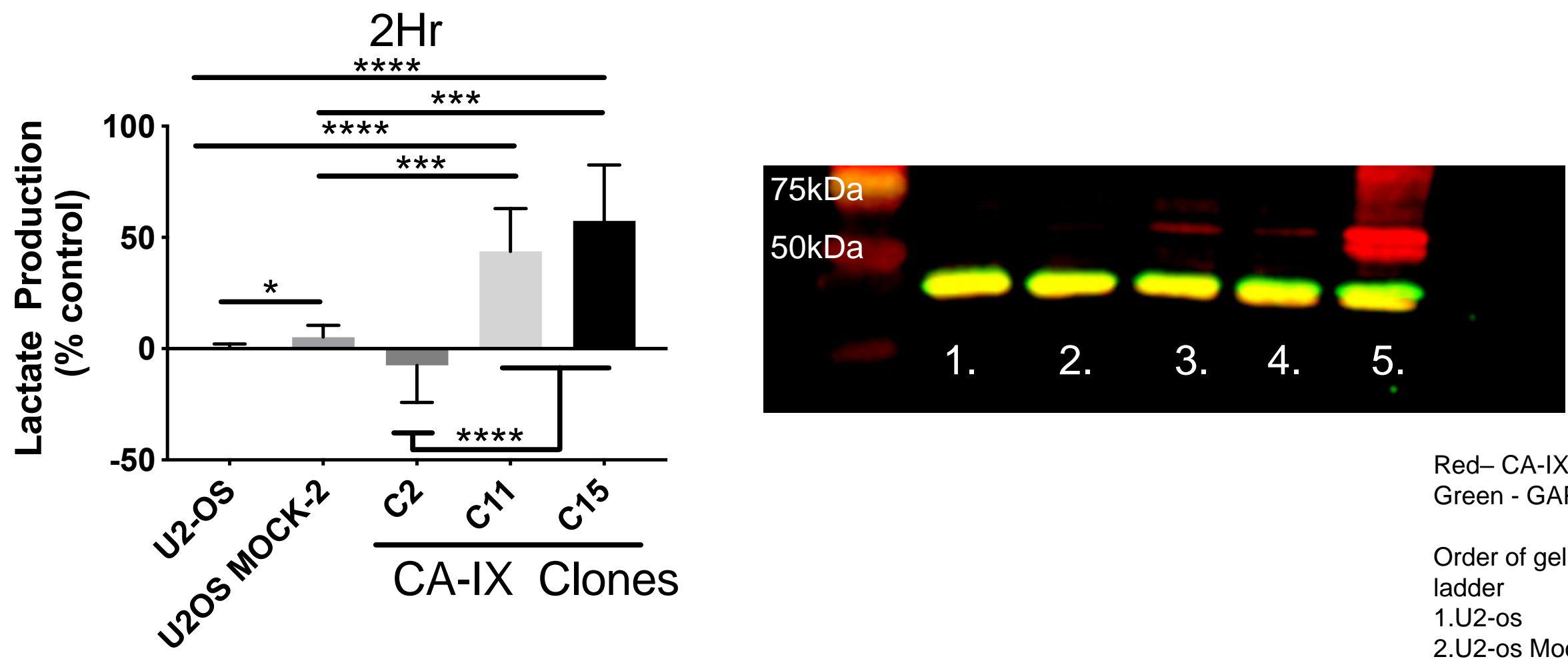

Red-CA-IX

Green - GAPDH

Order of gel

ladder

1.U2-os

2.U2-os Mock

3.U2-os C2 CA-IX

4.U2-os C11 CA-IX

5.U2-os C15 CA-IX

Supplementary Fig. 5. U2OS Lactate production rates and CA-IX western blot ( $N=12$; Brown Forsythe and Welch ANOVA, $p<0.05^{\star}, p<0.01^{* *}$, $\left.p<0.005^{\star \star *}, p<0.001^{* \star * *}.\right)$ 


\section{Supplementary Fig. 6}

\section{$1 \mathrm{Hr}$}

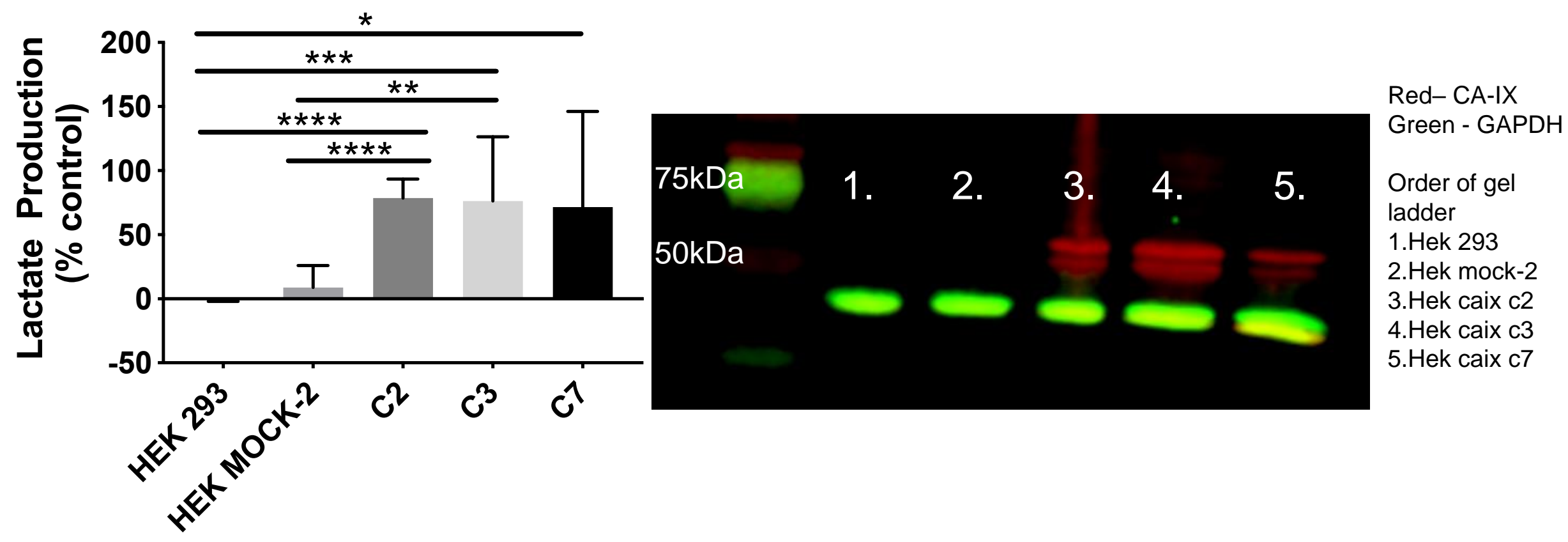

Supplementary Fig. 6. Lactate production and Western blot of CA-IX transfected HEK 293T cells. ( $N=15$; Brown Forsythe and Welch ANOVA, $p<0.05^{\star}, p<0.01^{* *}, p<0.005^{\star * *}, p<0.001^{* * * *}$.) 


\section{Supplementary Fig. 7}

MTT Growth Rate

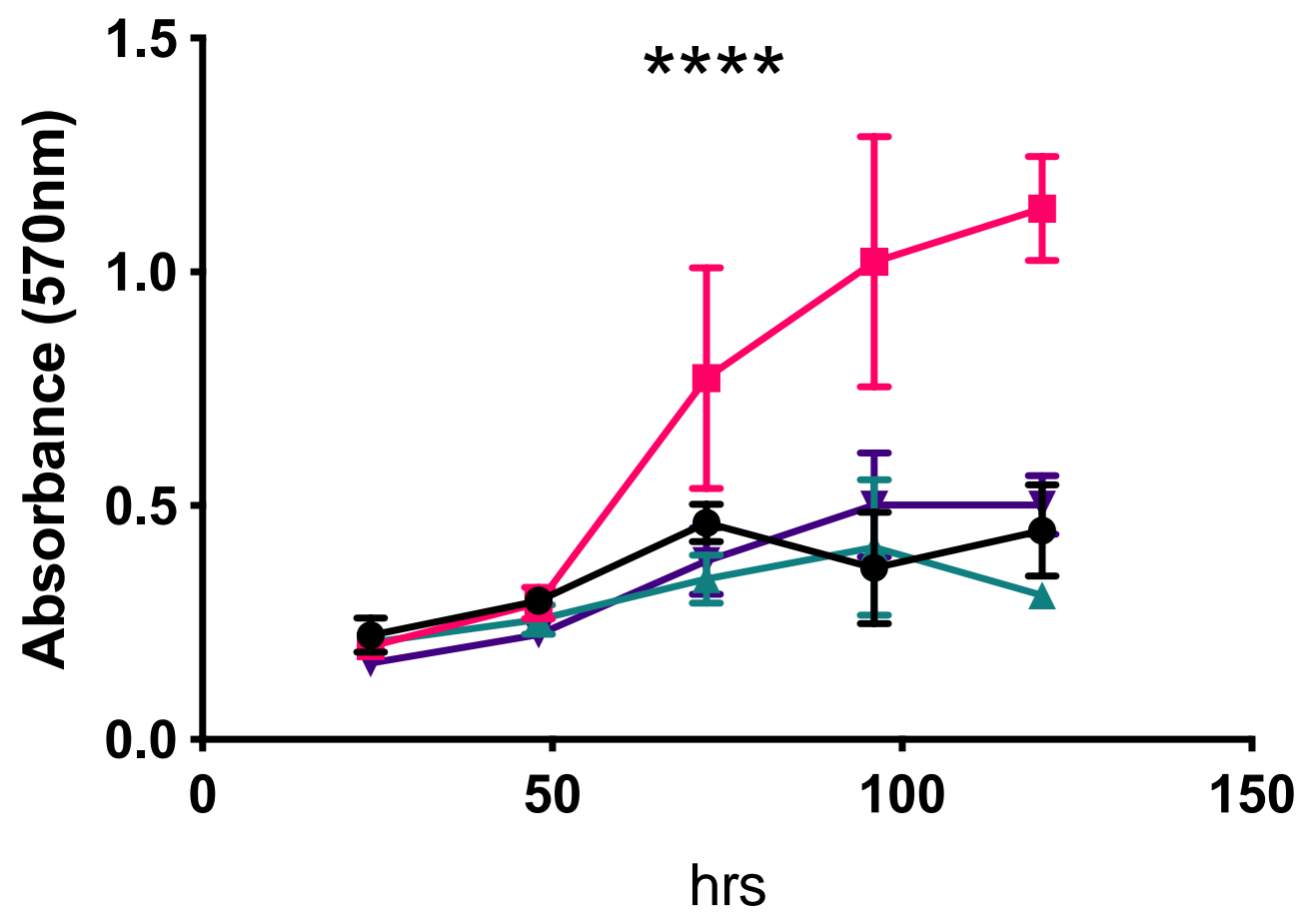

$\rightarrow$ MCF7

$\rightarrow-$ MOCK-2

$\rightarrow \mathrm{M} 1 \mathrm{CA}-\mathrm{IX}$

$\rightarrow$ M6 CA-IX

Supplementary Fig 7. In vitro growth rates of MCF-7, MOCK-2 and CA-IX clones M1 and M6. $n=3$, average \pm SD. $p<0.0001^{* \star * *}$. 


\section{Supplementary Fig. 8}
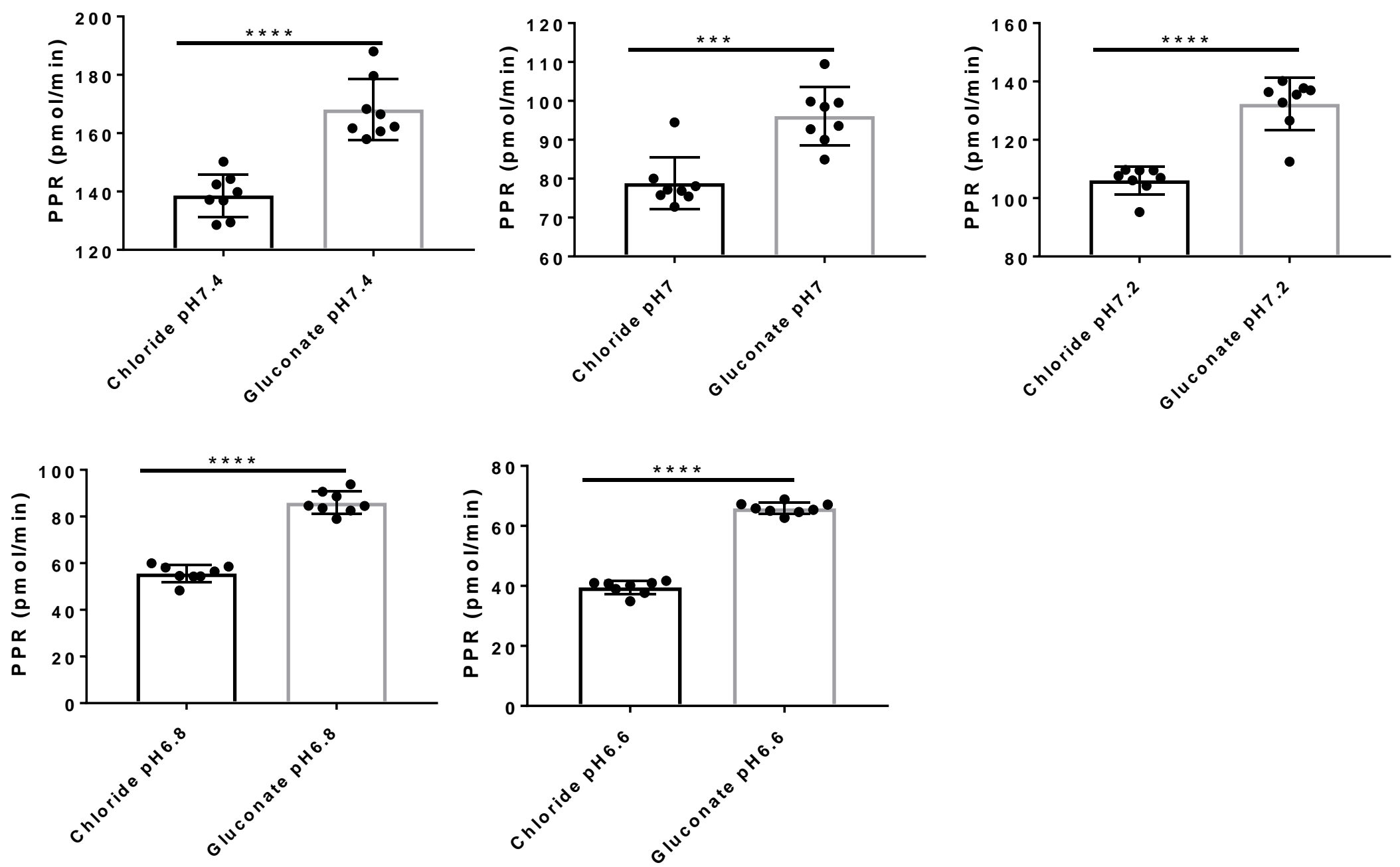

Supplementary Fig. 8. Effect of chloride vs gluconate on PPR. Average PPR \pm SD, $n=8$, unpaired t-test $p<0.005^{\star \star \star}, p<0.0001^{\star \star \star \star}$. 


\section{Supplementary Fig. 9}

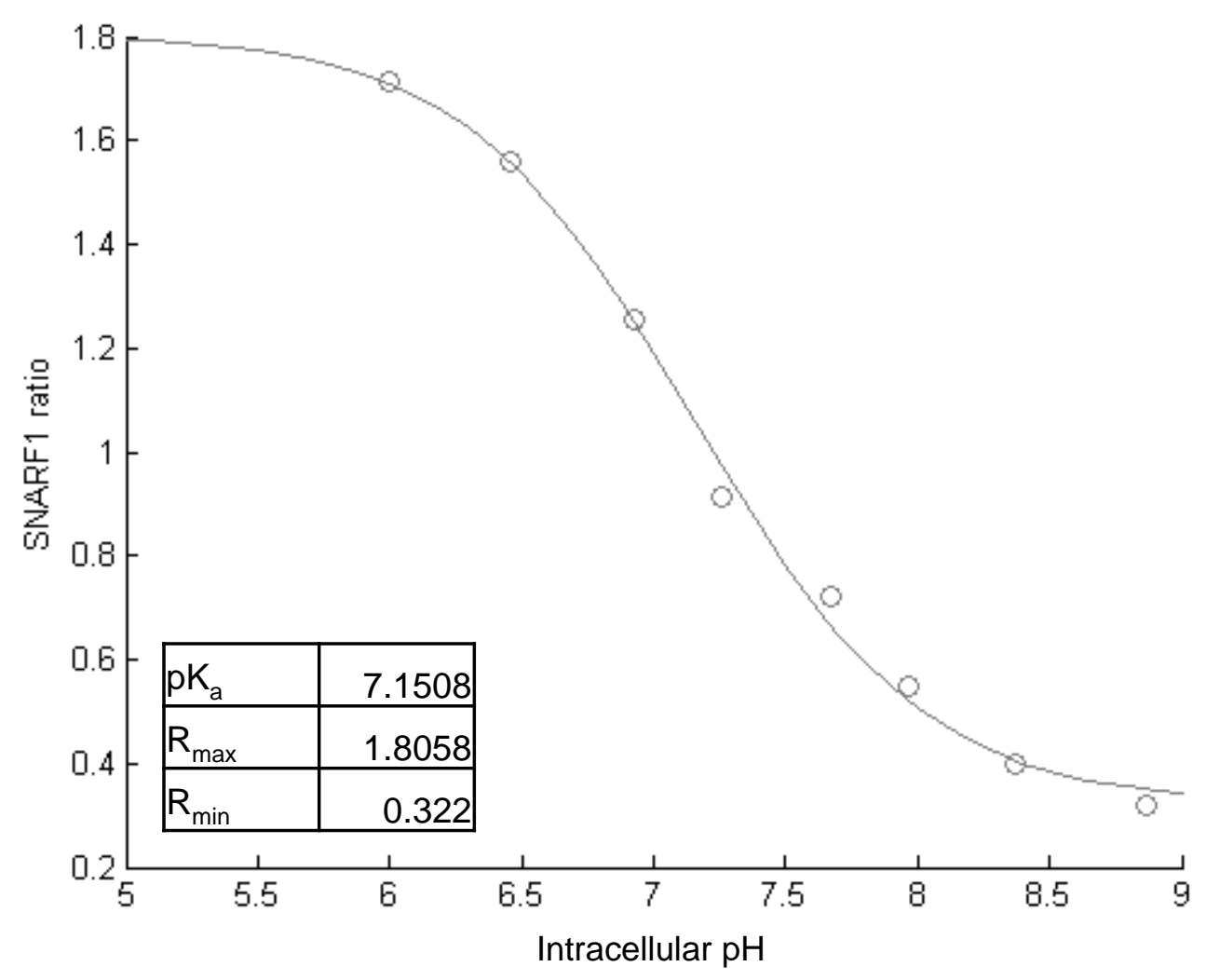

Supplementary Fig. 9. cSNARF1 calibration curve with nigericin/high $\mathrm{K}^{+}$ 


\section{Supplementary Fig.10}

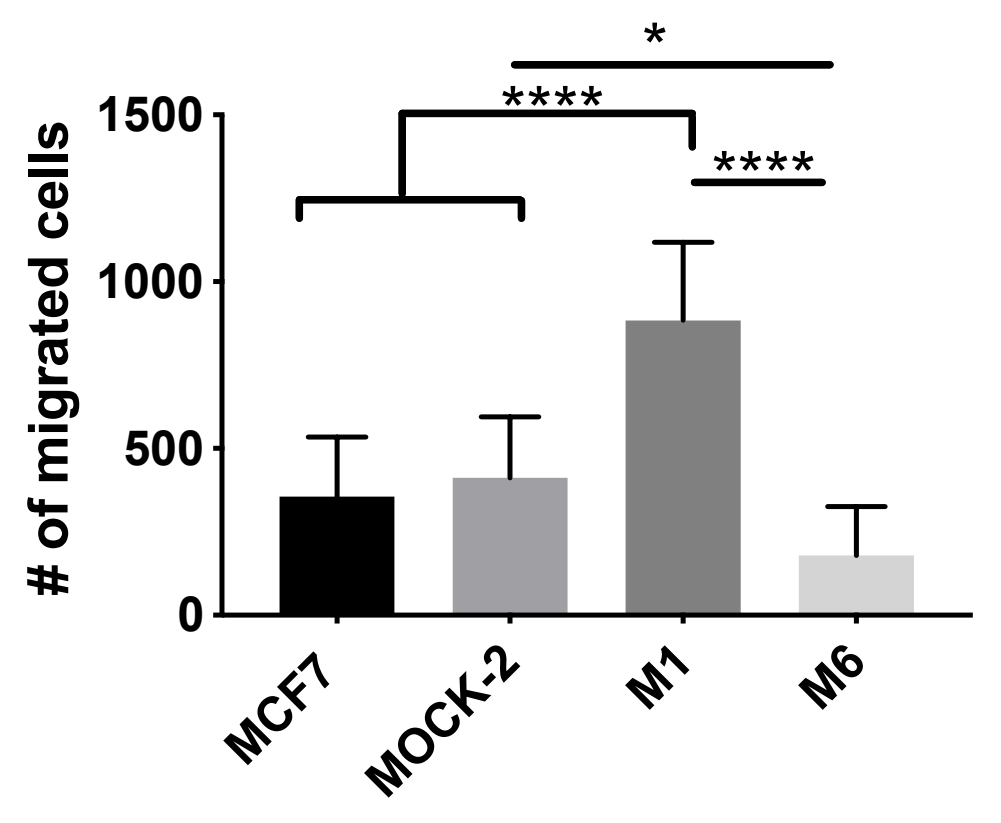

Supplementary Fig. 10. Migration assay to measure effects of CA-IX expression on migration of MCF7 cells. Imaged using Celigo, $\mathrm{n}=3$ bio-replicates in triplicate, average \pm SD. (Ordinary one-way ANOVA, $p<0.05^{\star}, p<0.005^{\star * *}, p<0.0001^{* \star * \star}$ ) 


\section{Supplementary Fig. 11}

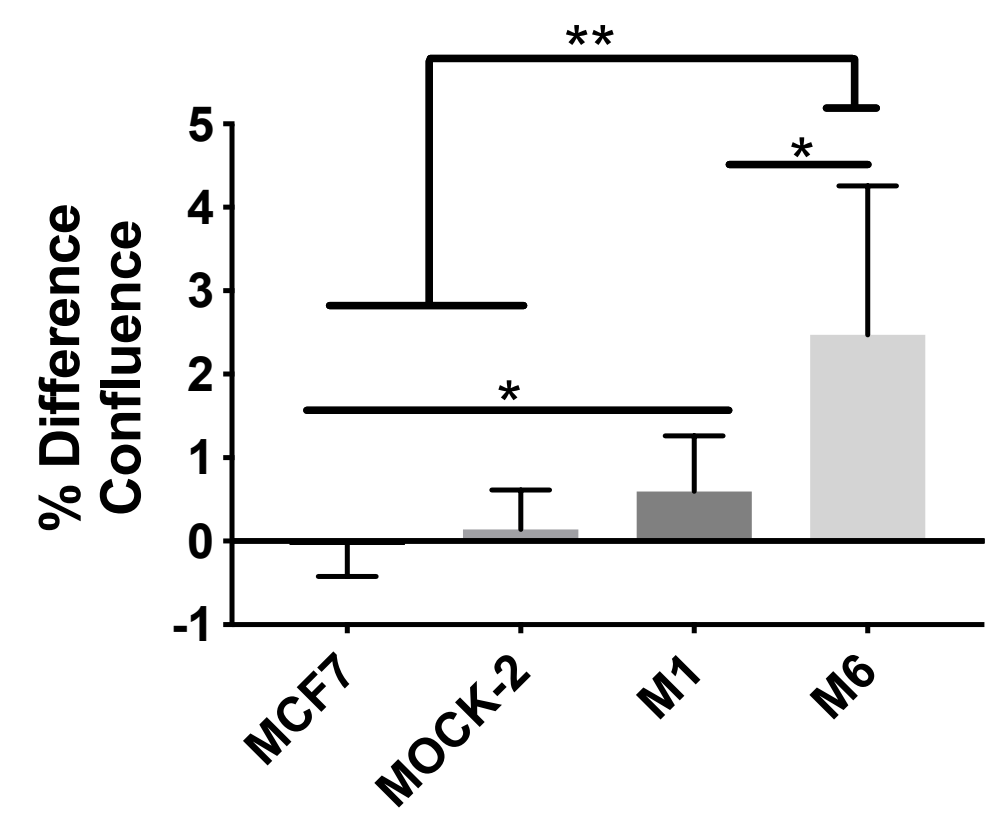

Supplementary Fig. 11. Gel escape assay to measure effects of CA-IX expression on invasion and migration in MCF7 cells. Imaged using Celigo, $n=3$ bio-replicates in triplicate, average \pm SD. (Brown-Forsythe and Welch ANOVA, $p<0.0001^{\star \star * *}$ ) 


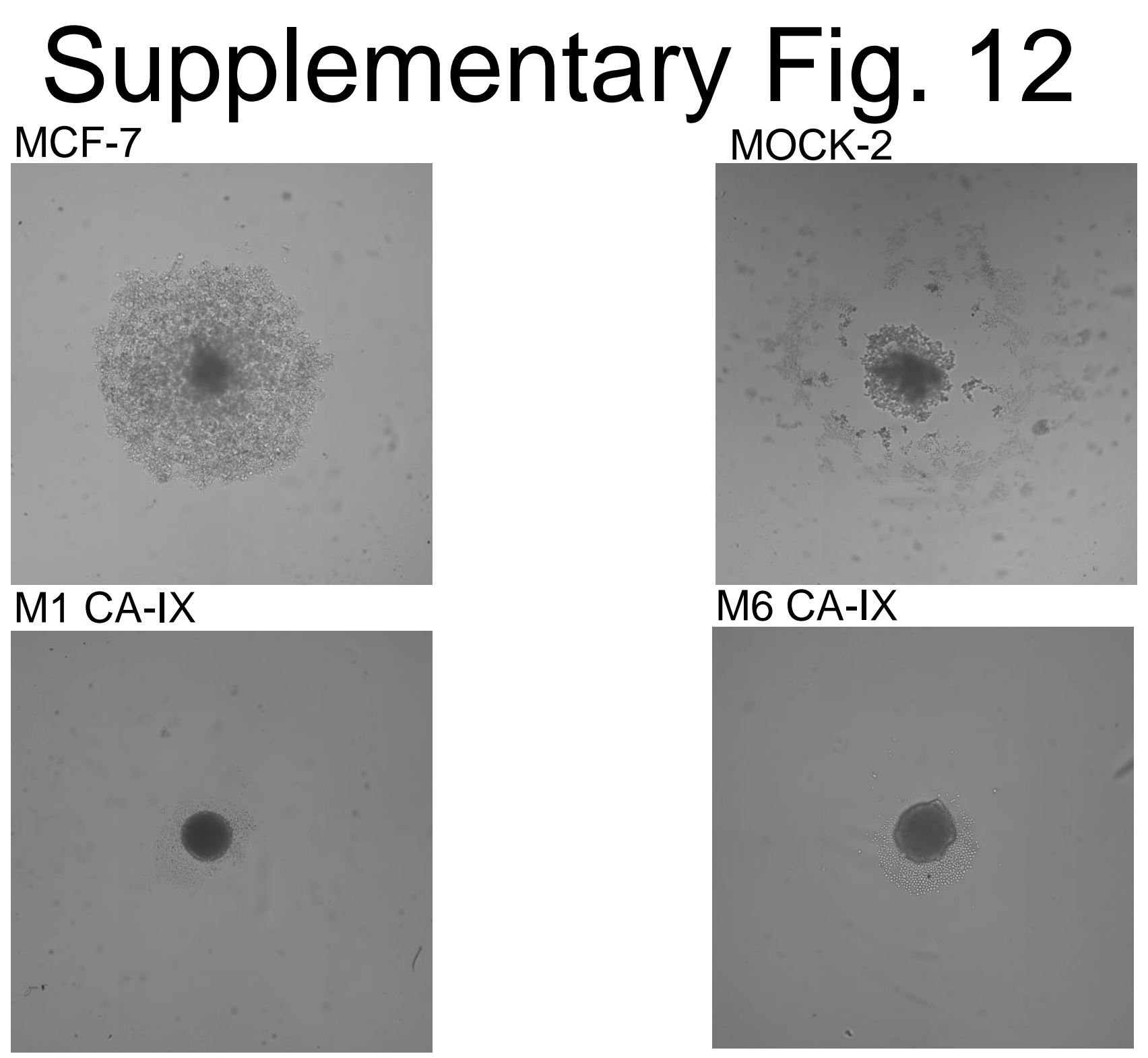

Supplementary Fig. 12. Spheroid formation assay to measure ability of cells to grow in 3D, an indicator of metastatic ability in vitro. Imaged using Celigo with single colony verification analysis after 5 days of growth in hanging drop plates. Representative images shown. 


\section{Supplementary Fig. 13}

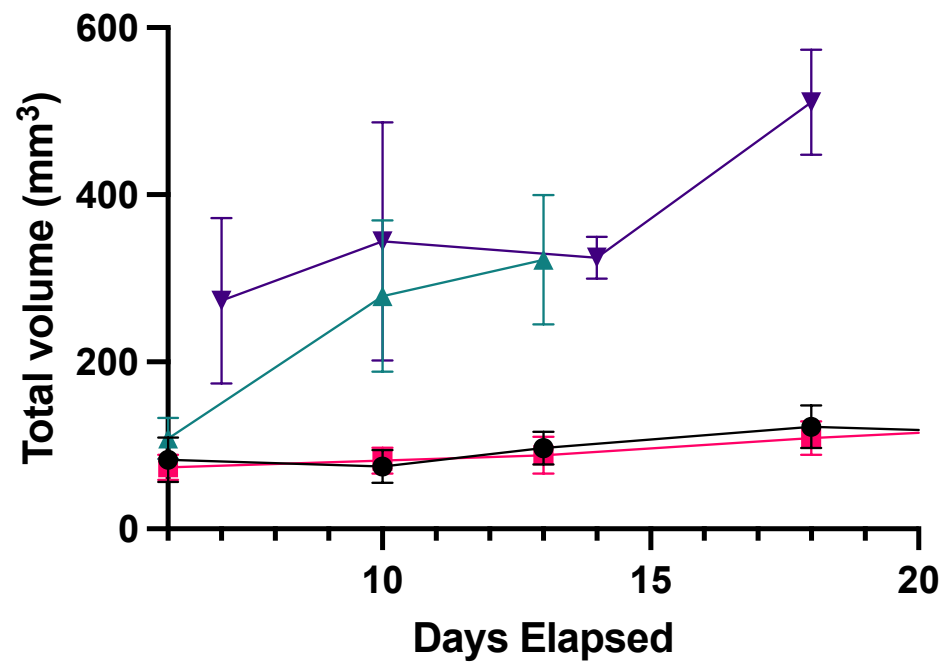

- MCF-7/ Parental

- MCF-7/MOCK-2

$\rightarrow$ MCF-7/CA-IX M1

$\rightarrow \mathrm{MCF}-7 / \mathrm{CA}-\mathrm{IX} \mathrm{M} 6$

Supplementary Figure 13: Effect of CA-IX expression on primary tumor growth of MCF-7 cells. $n=12-15$ mice per group 


\section{Supplementary Fig. 14}

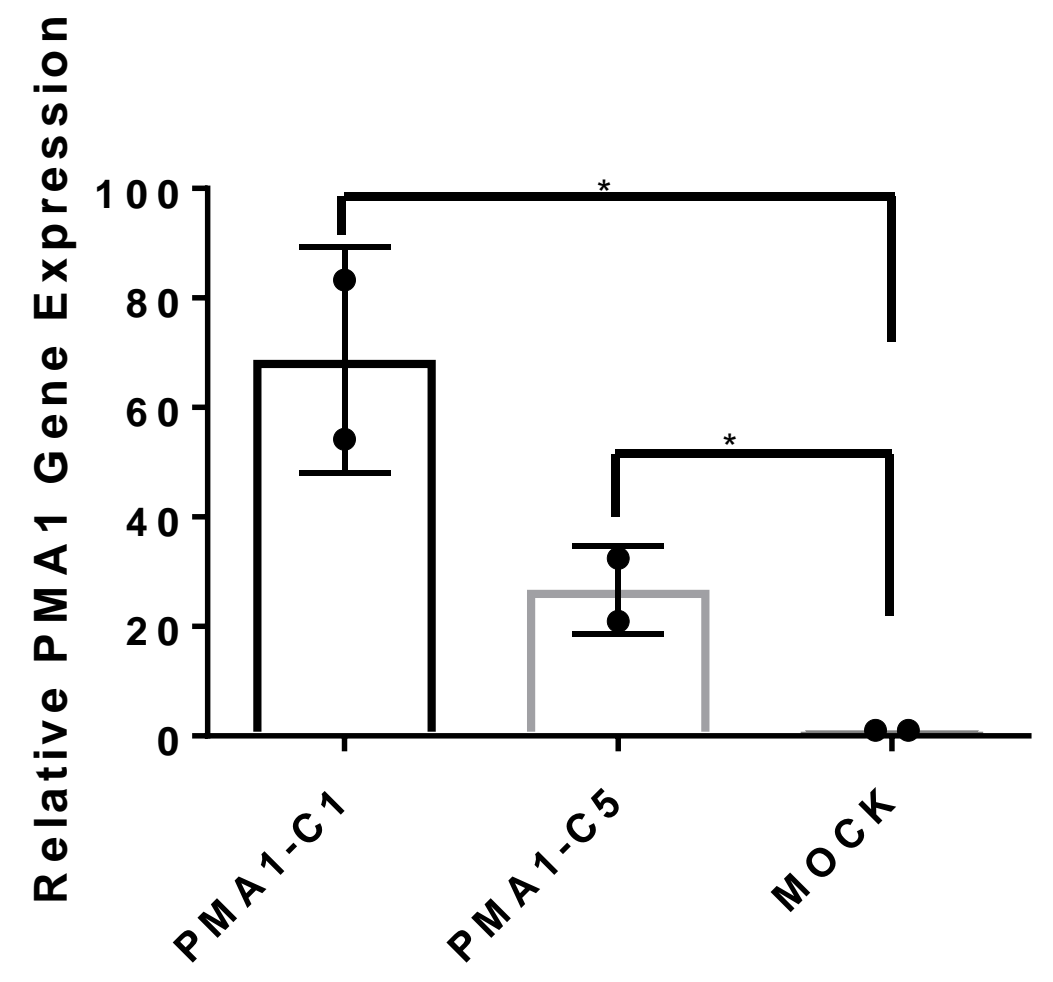

Supplementary Fig. 14. qRT PCR of relative PMA1 gene expression in PMA1 transfected clones compared to MOCK (empty vector clone). Average $\pm \mathrm{SD}$. (Ordinary one-way ANOVA. $p<0.05^{\star}$ ) 
WGA
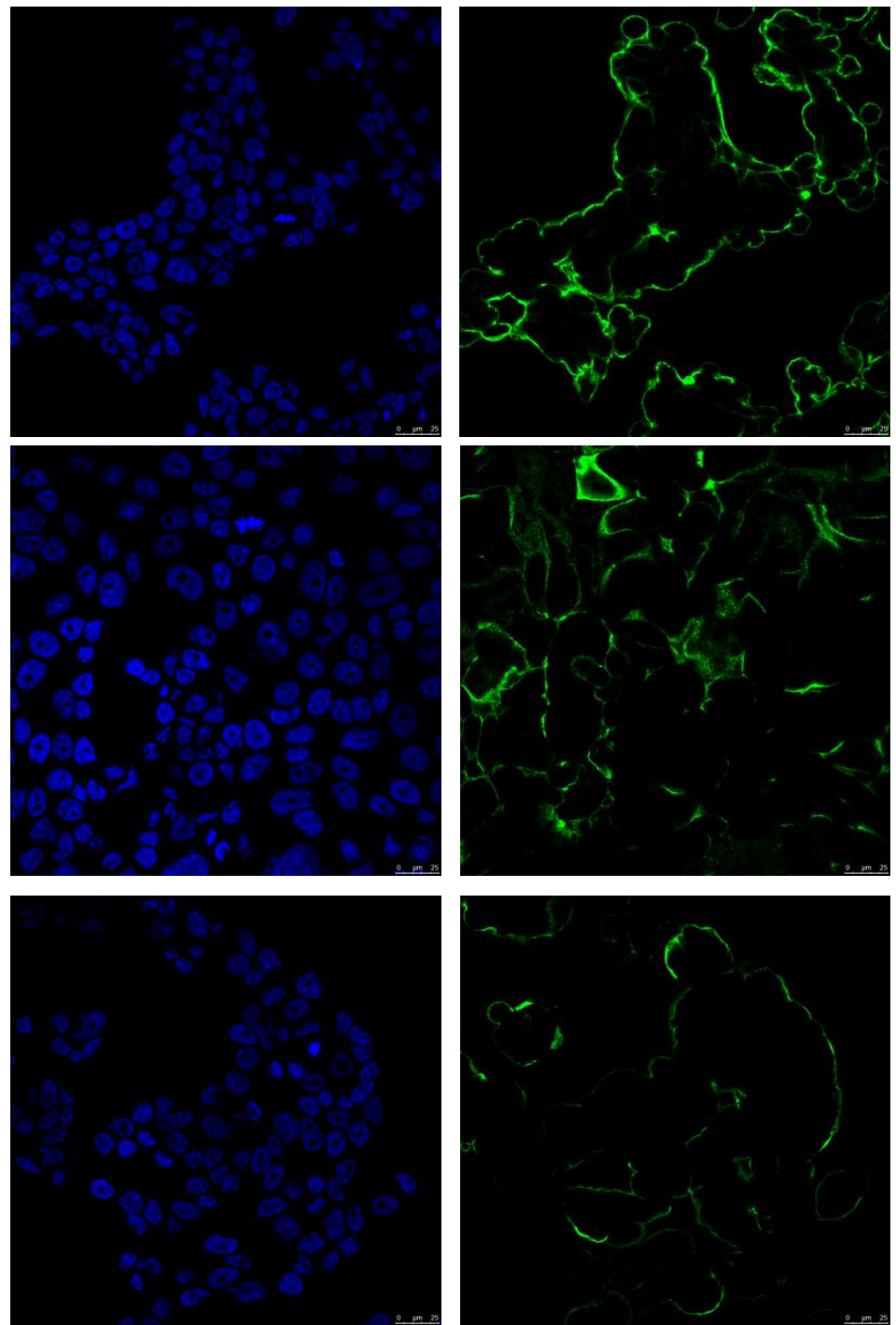

PMA1

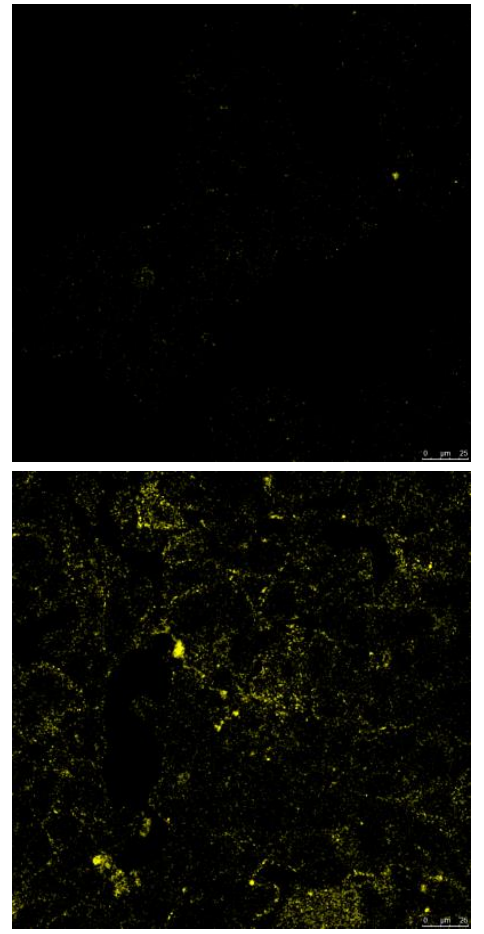

Brightfield Merged

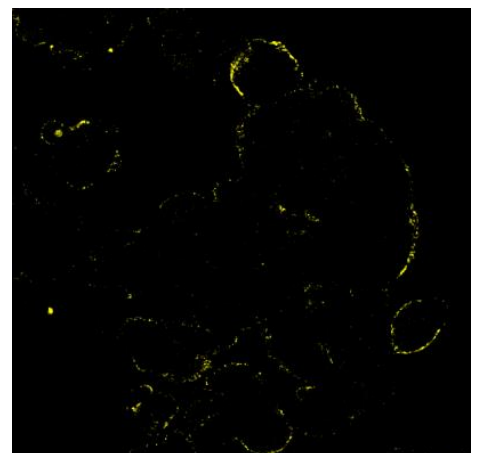

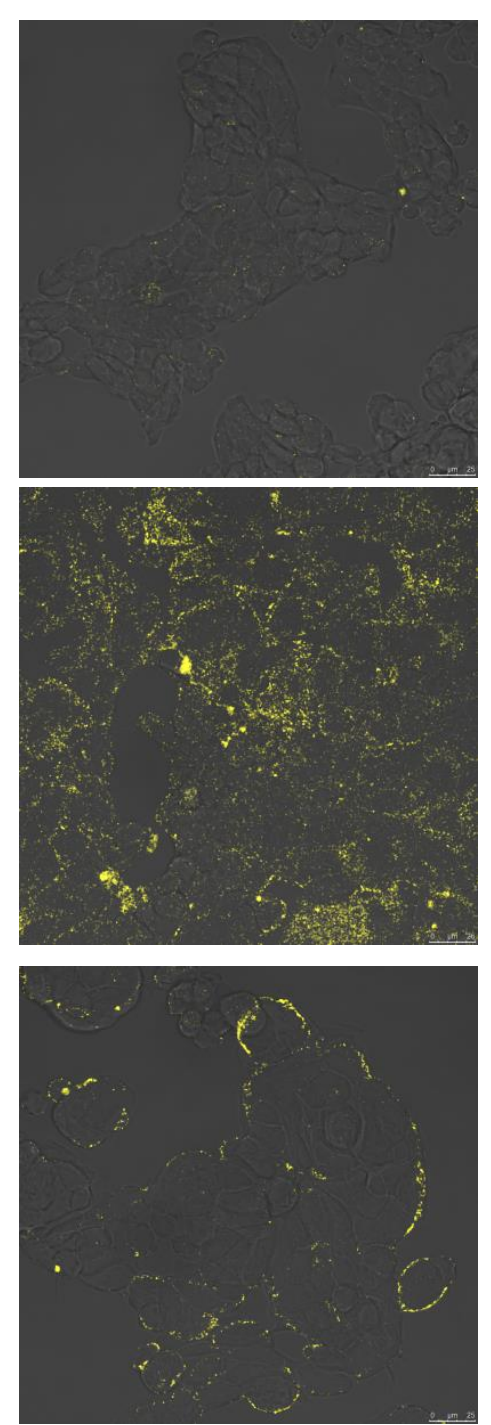

Supplementary Fig. 15. Characterization of PMA1-expressing cells by ICC staining (non-permeabilized) DAPI (blue), WGA (green), PMA1 (Alexa Fluor 594 red) 


\section{Supplementary Fig. 16}

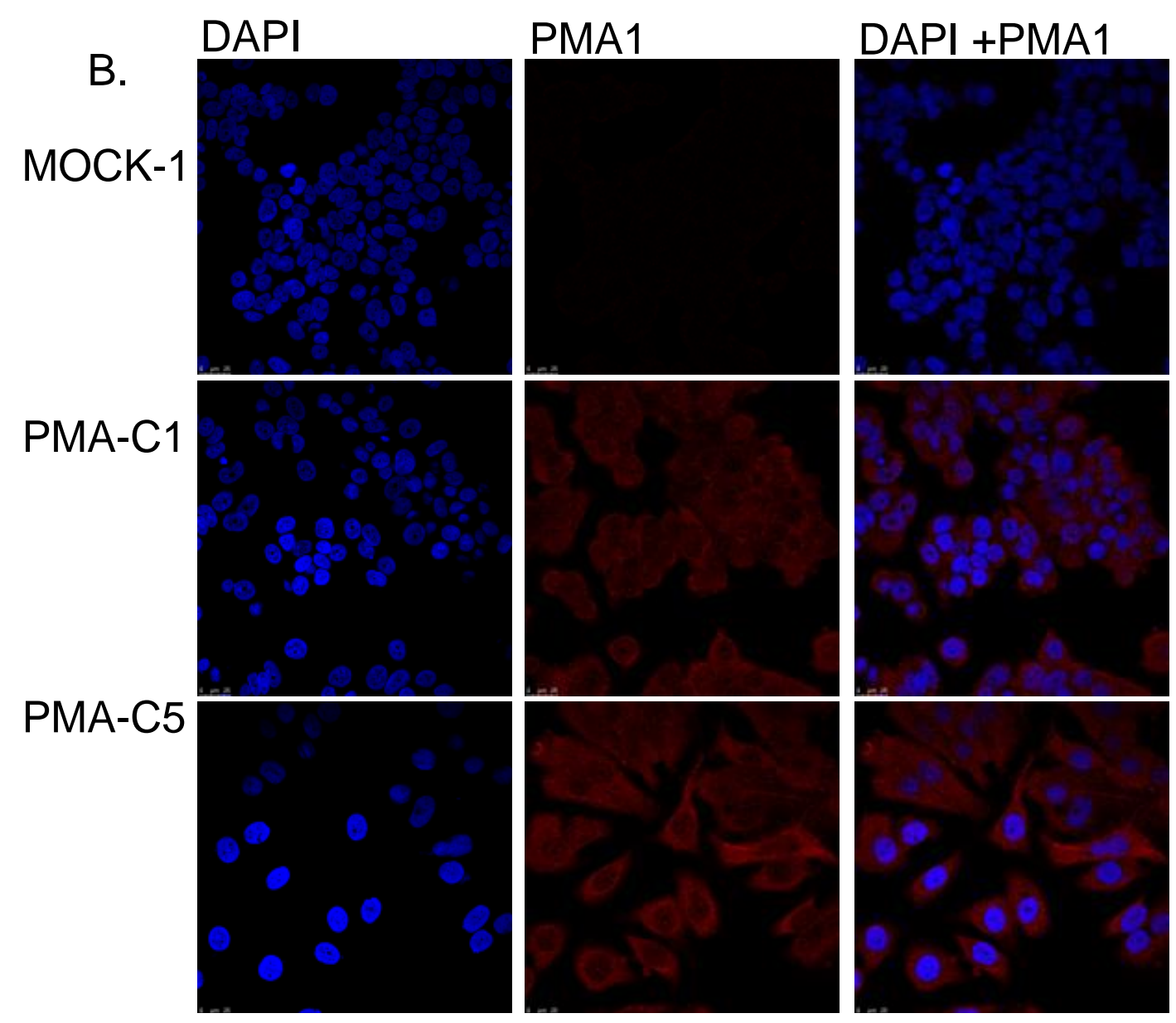

Supplementary Fig. 16. ICC of permeabilized cells staining for PMA1. PMA in red and Nuclear stain DAPI in blue. 


\section{Supplementary Fig. 17}

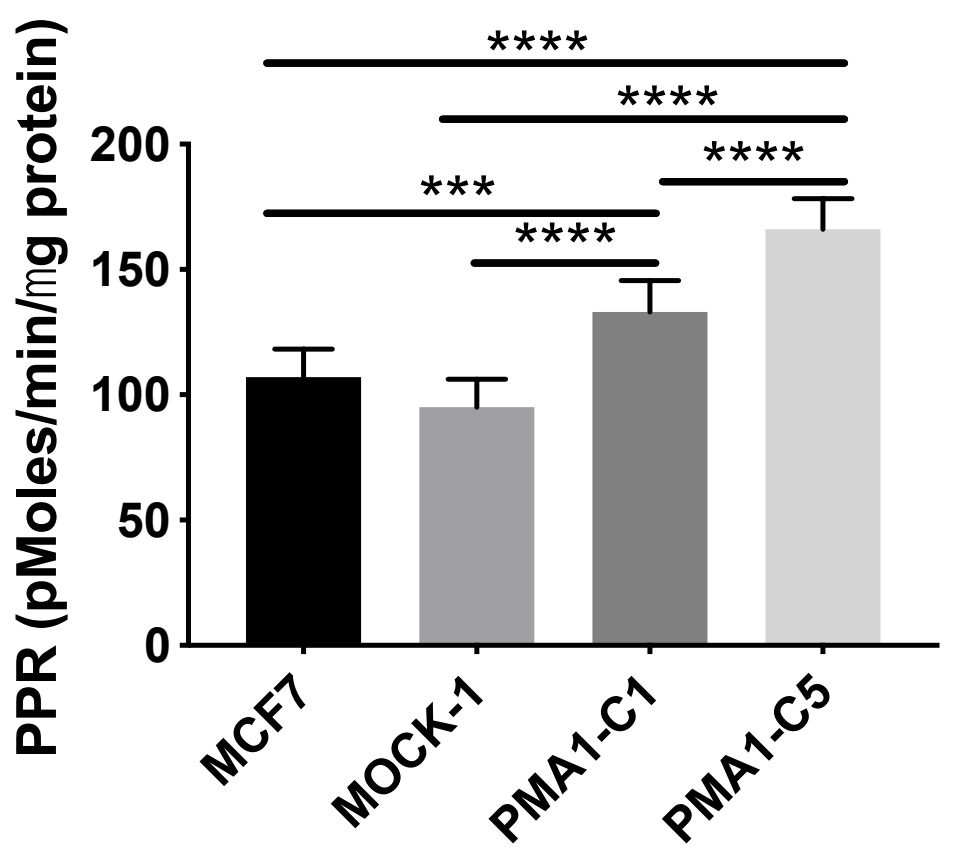

Supplementary Fig. 17. Glycolytic reserve measured by glycolysis stress test with XFe96 Seahorse assay. Reserve is determined by difference in glucosestimulated proton production rate (PPR) and addition of oligomycin which inhibits mitochondrial energy production. Average \pm SD. (Ordinary one-way ANOVA. $\left.p<0.0005^{\star \star *}, p<0.0001^{\star \star \star \star}\right)$ 


\section{Supplementary Fig. 18}

MOCK-1
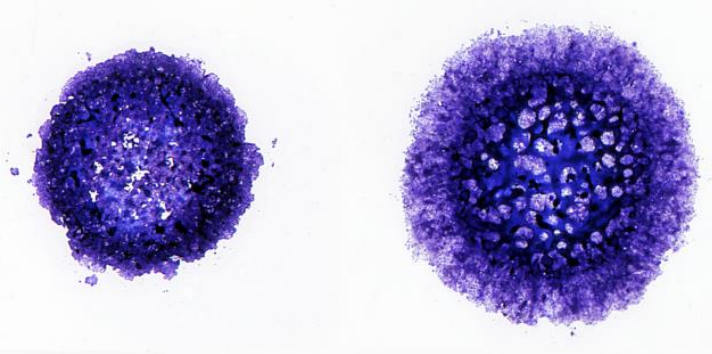

PMA1-C5

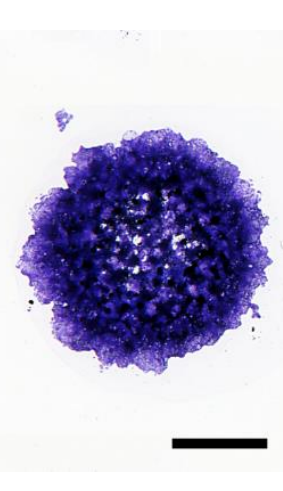

Raw Gel Escape

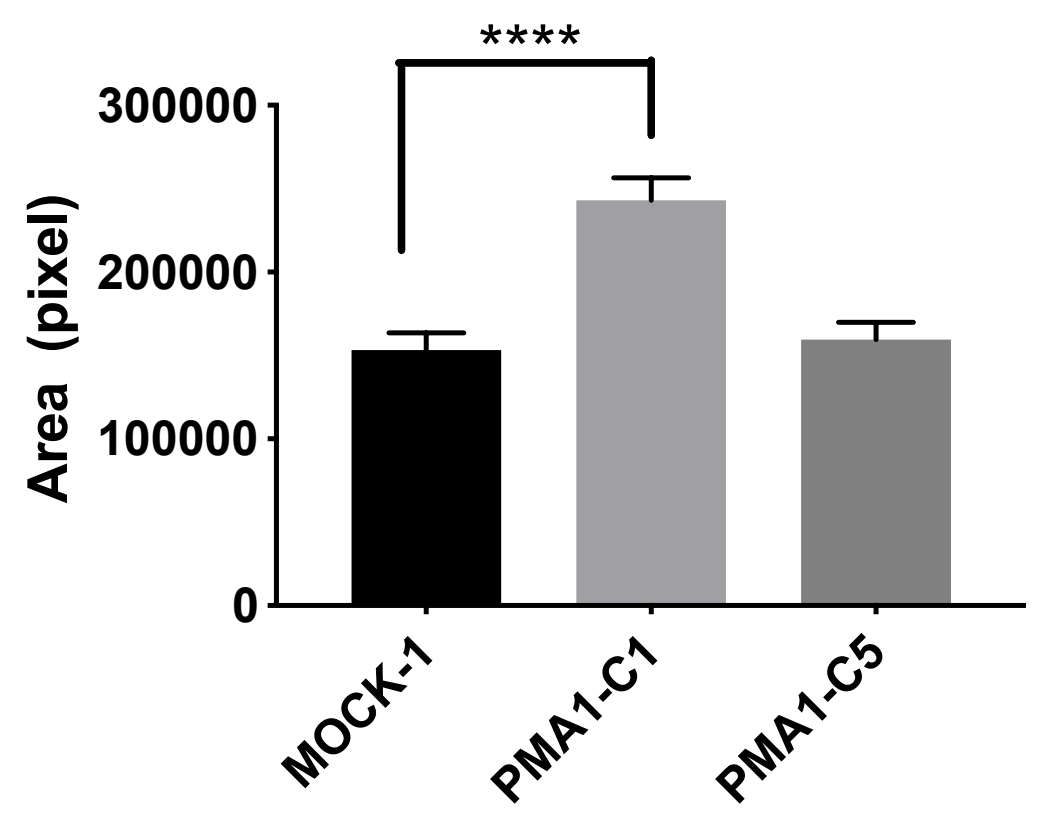

Supplementary Fig. 18. Raw data of gel escape assay and corresponding images, prior to normalization by growth rate. $\mathrm{N}=4$ biological replicates, average \pm SD. (Ordinary one-way ANOVA, $p<0.0001^{* * * *}$ ) 


\section{Supplementary Fig. 19}

MOCK-1

PMA1-C1

PMA1-C5
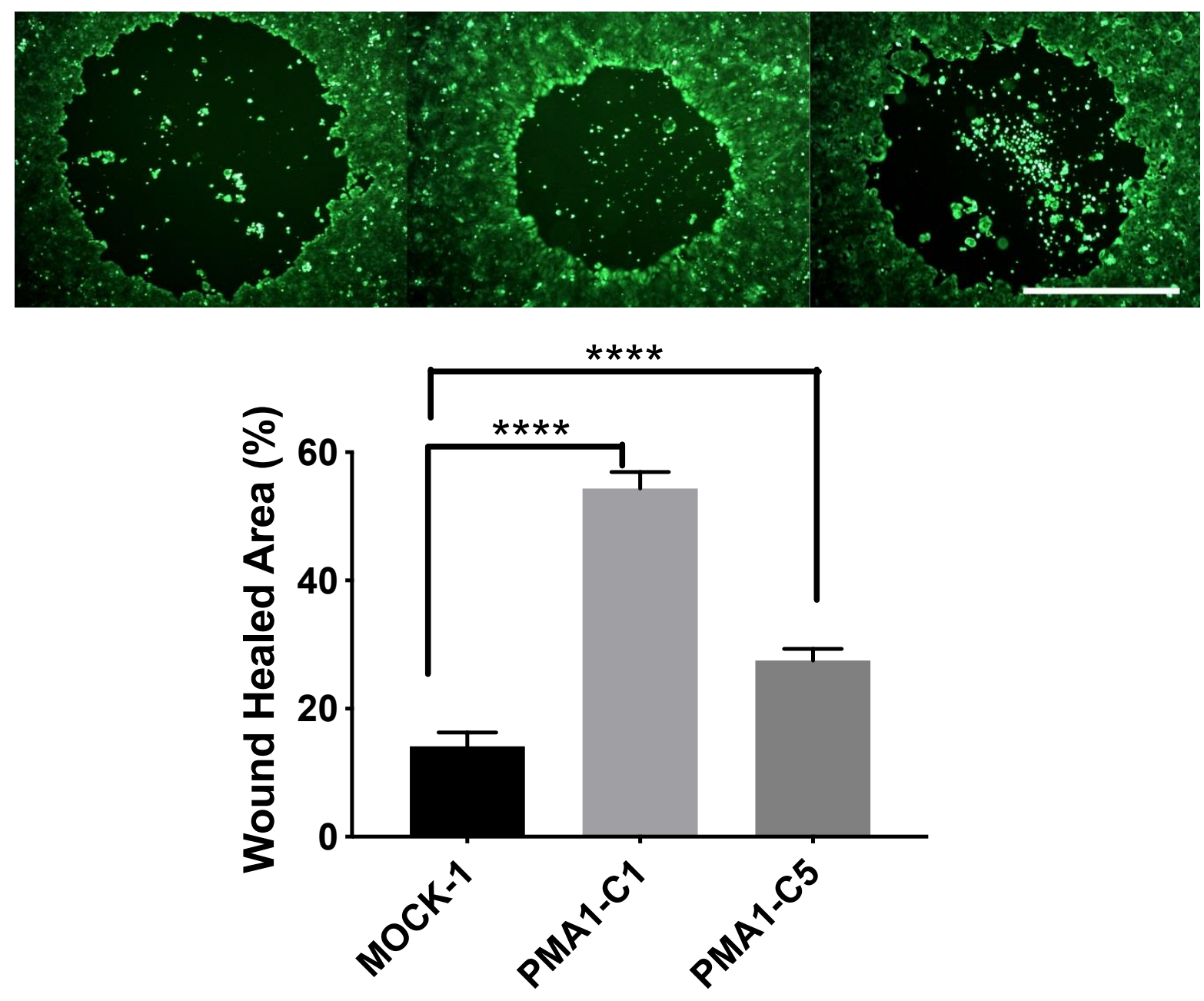

Supplementary Fig. 19. Raw data of circular wound healing assay and corresponding images, prior to normalization by growth rate. $\mathrm{N}=4$ biological replicates, average \pm SD. (Ordinary one-way ANOVA, $p<0.0001^{* * * *}$ ) 


\section{Supplementary Fig. 20}

MOCK

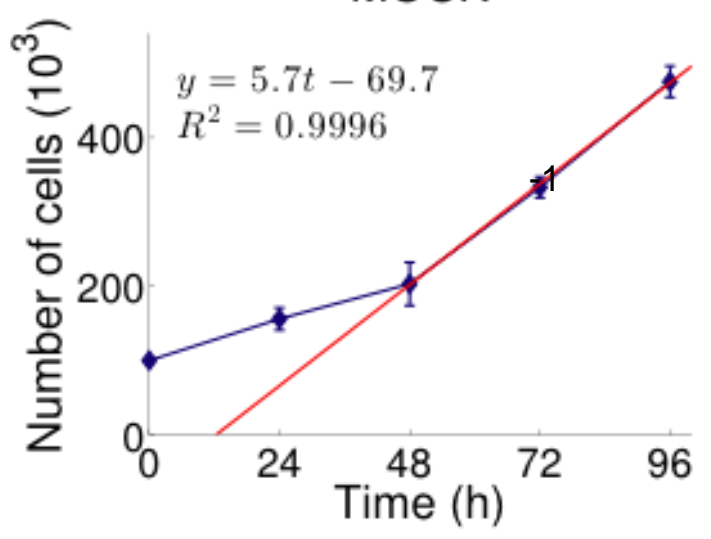

PMA1-C1

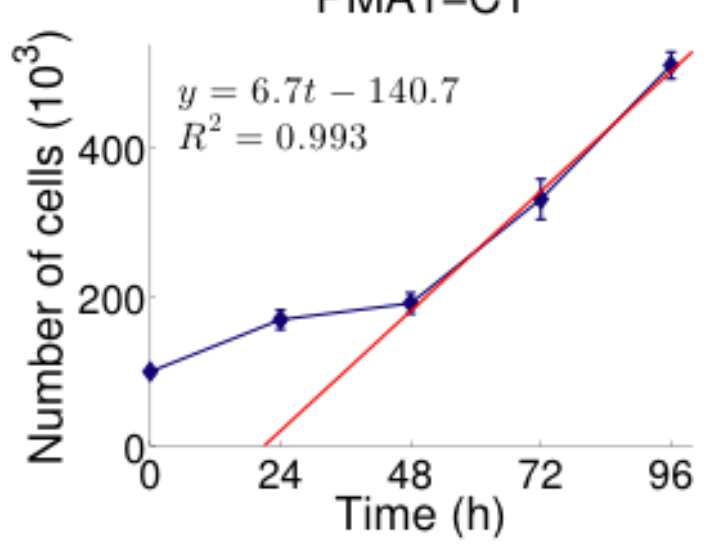

MCF7

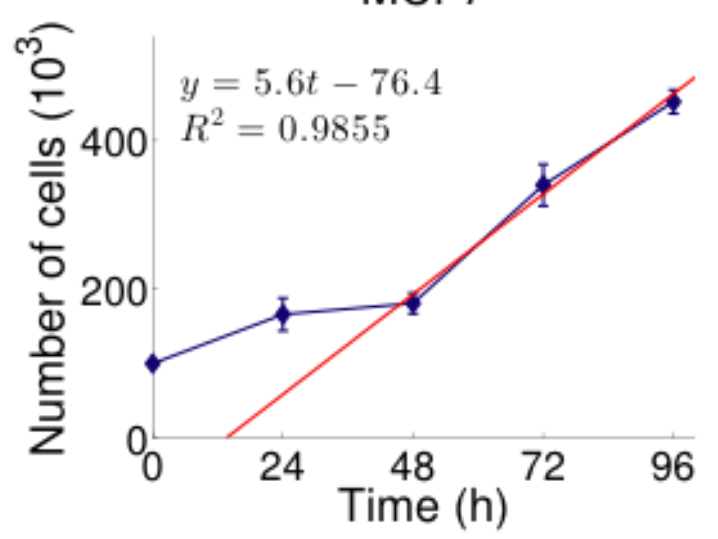

PMA1-C5

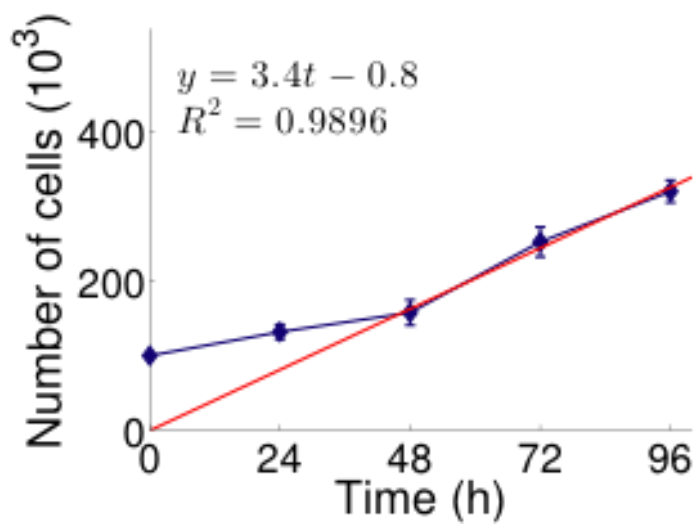

Supplementary Fig. 20. Cellular growth rate was determined by number of cells over time and calculated by a linear fit of cell growth for normalization of invasion and migration assays 


\section{Supplementary Fig. 21 FFPE Lung Tissue}

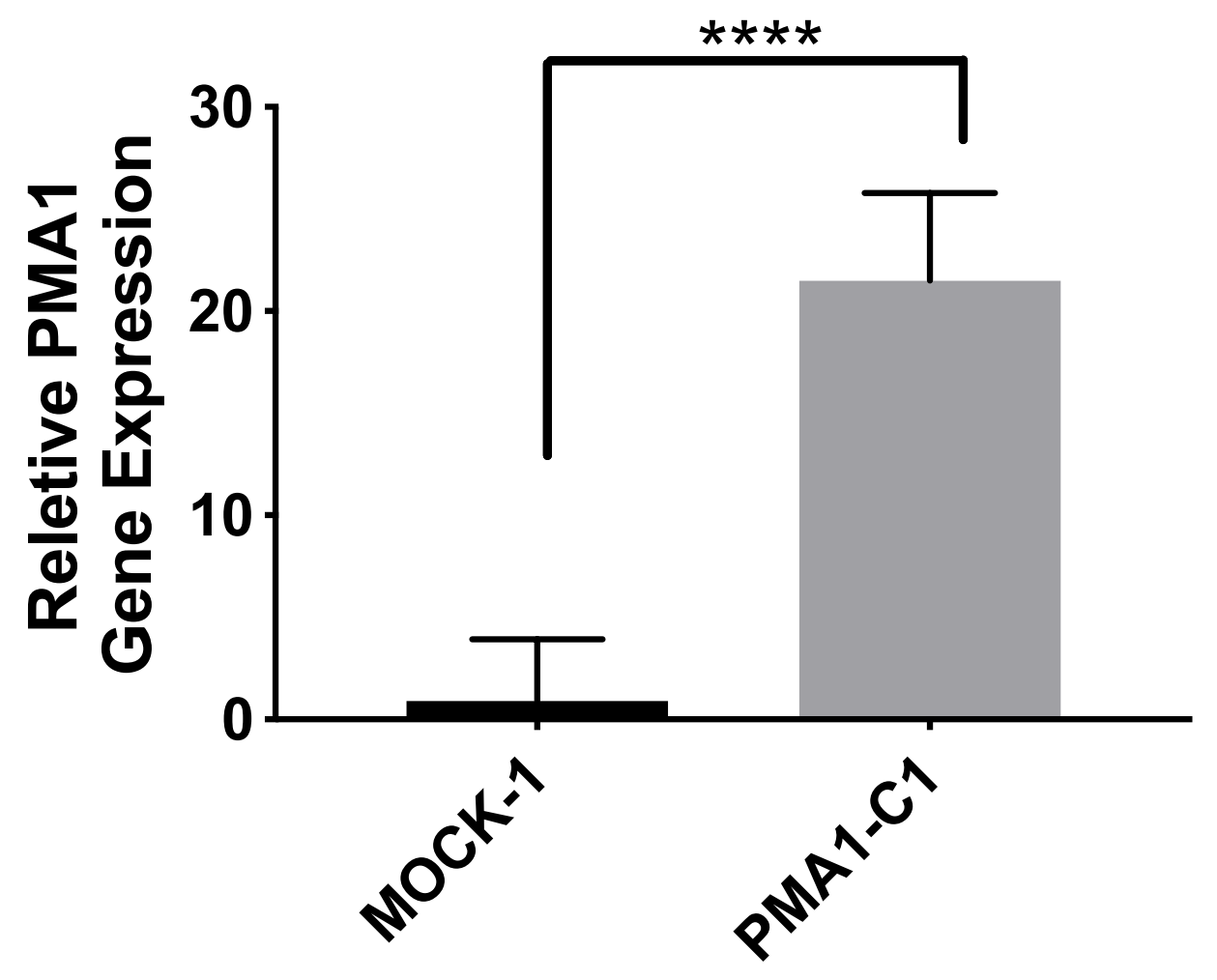

Supplementary Fig. 21. Relative PMA1 gene expression in lung micrometatases. Average relative gene expression $\pm \mathrm{SD}$, unpaired t-test $p<0.0001$. 


\section{Supplementary Fig. 22}

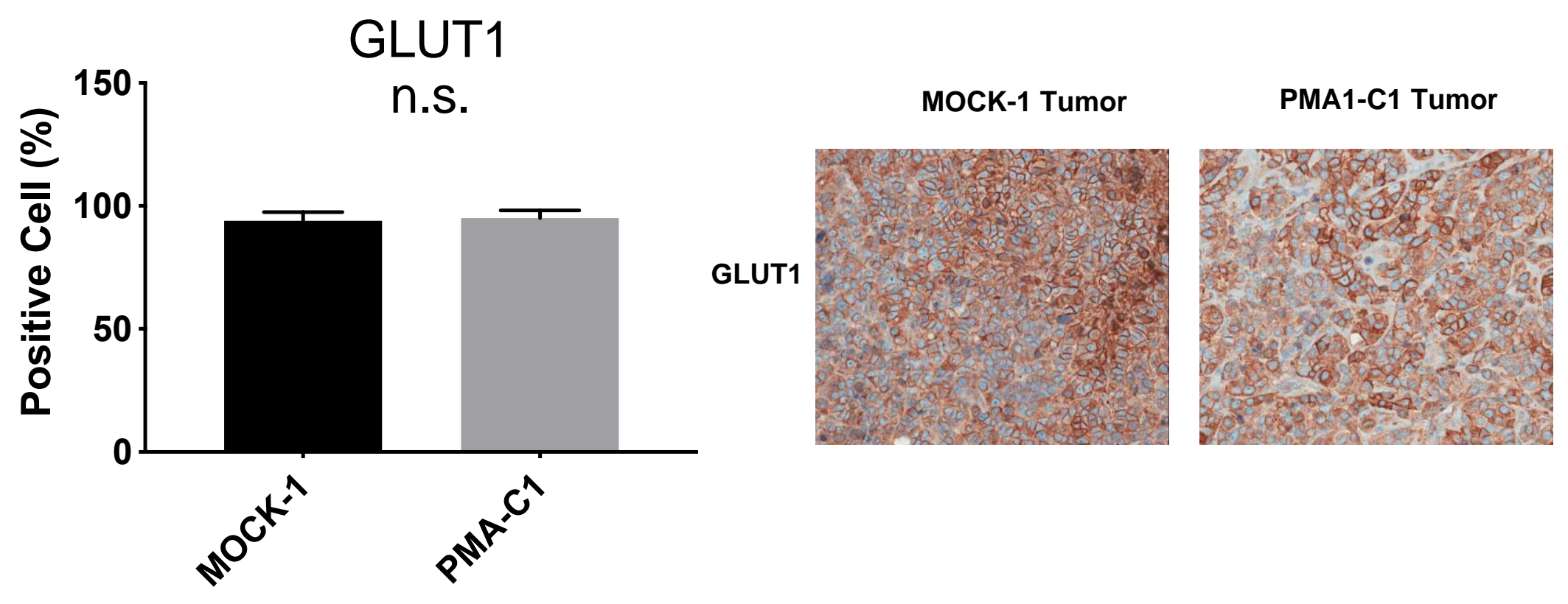

Supplementary Fig. 22. Quantification of GLUT1 protein staining in IHC samples of resected primary tumors and representative images. $\mathrm{N}=9-10$, Average $\pm \mathrm{SD}$, unpaired t-test n.s. 


\section{Supplementary Fig. 23}

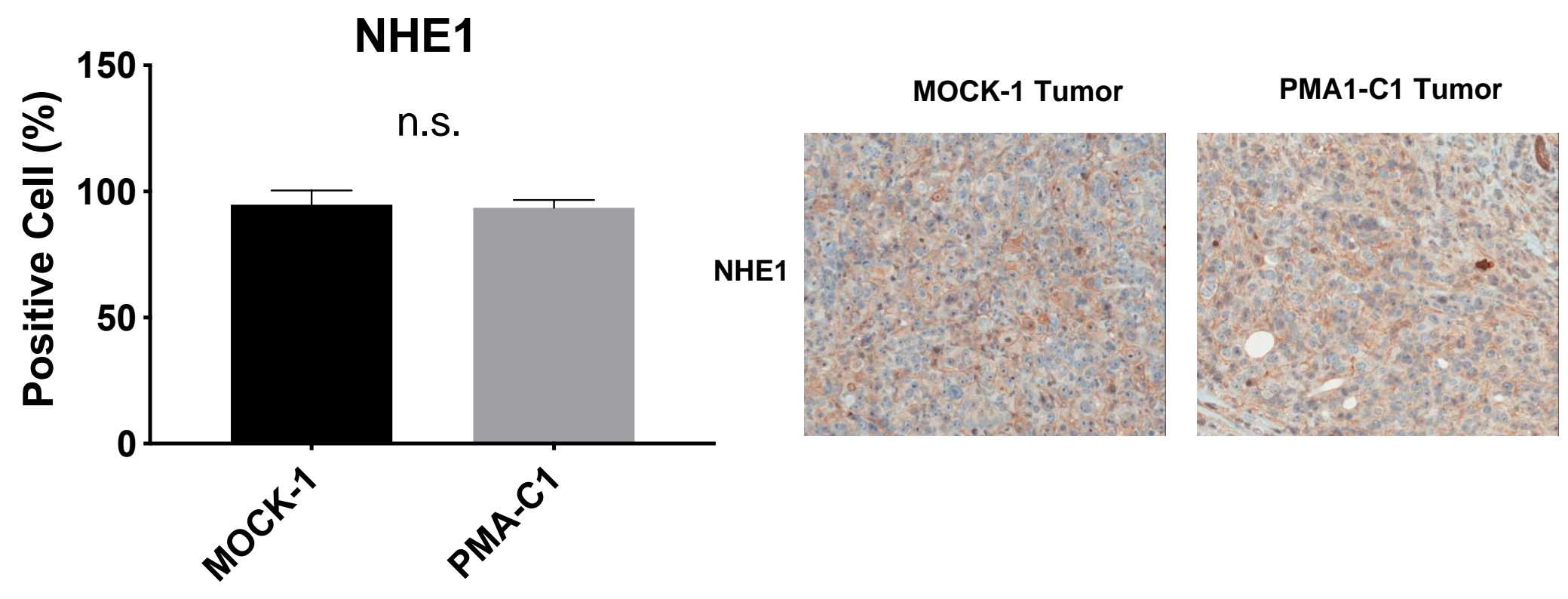

Supplementary Fig. 23. Quantification of NHE1 protein staining in IHC samples of resected primary tumors and representative images, $n=8-9$ Average \pm SD, unpaired t-test n.s. 


\section{Supplementary Fig. 24}

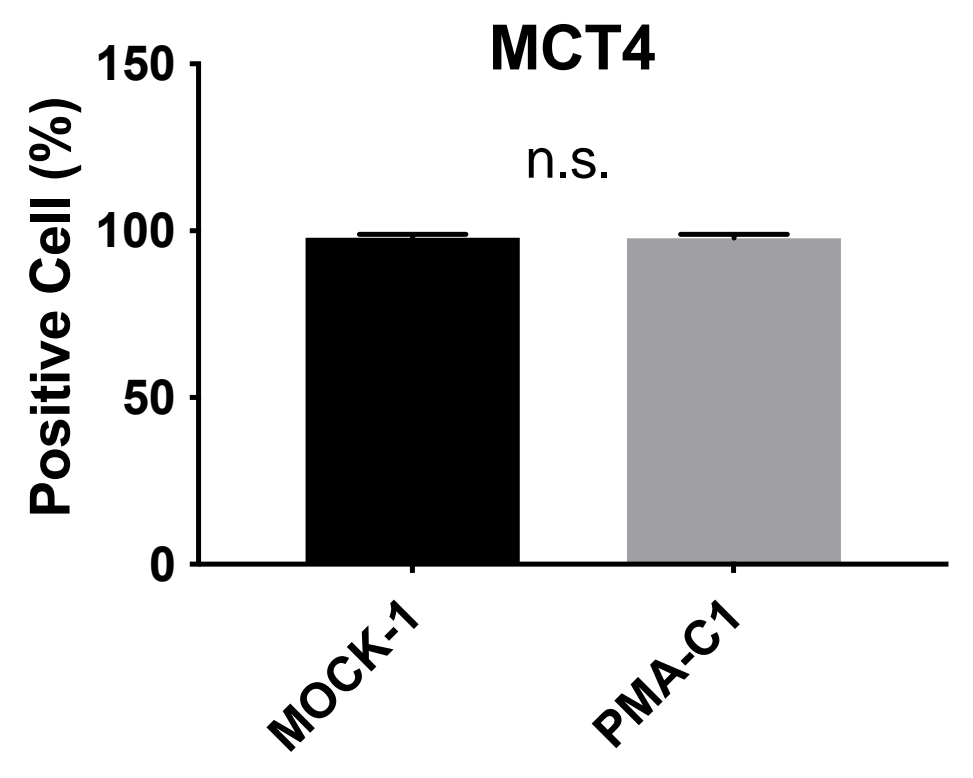

Supplementary Fig. 24. Quantification of MCT4 protein staining in IHC samples of resected primary tumors and representative images, $n=8-9$ Average \pm SD, unpaired t-test n.s. 


\section{Raw western blots}

$\underline{\text { Ladder mcf7 }} \underline{\text { Mck-2 }} \underline{\mathrm{m} 1 \mathrm{~m} 6} \underline{\mathrm{m} 6}$

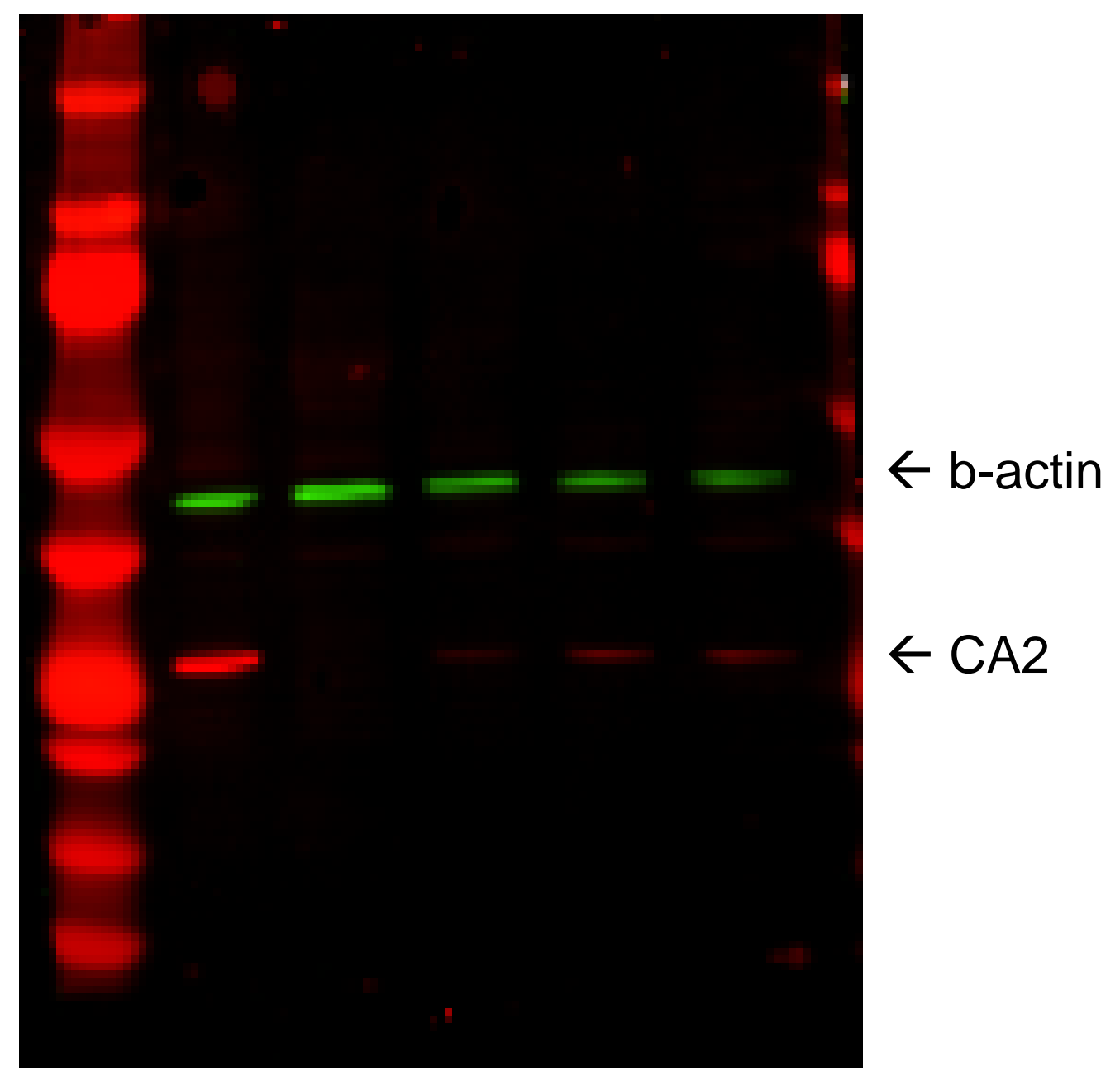




\section{Raw western}

$\underline{\text { Ladder mcf7 }} \underline{\text { Mck-2 }}$ m1 m6 m6

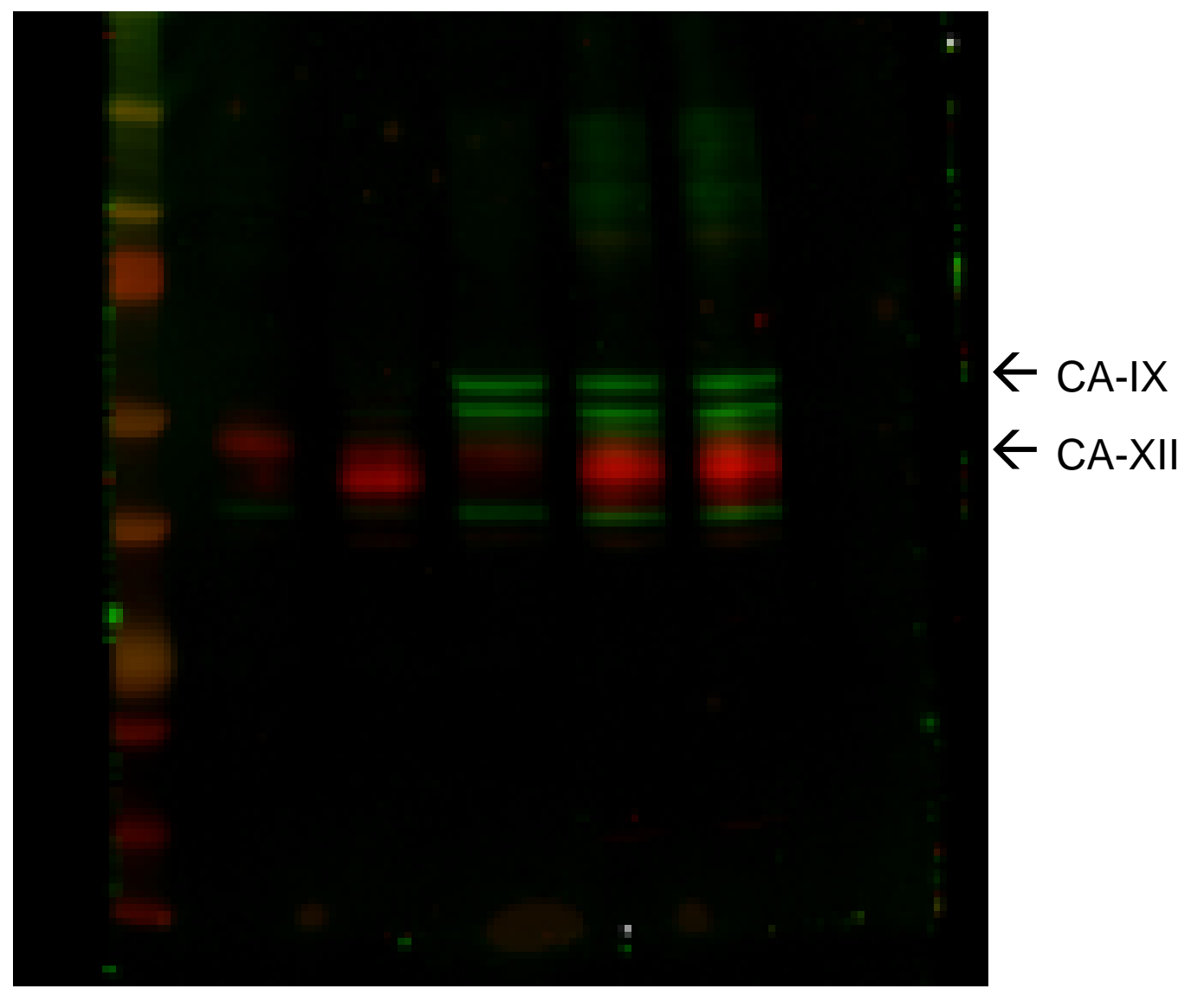

green - caix red- caxii 


\section{Raw western u2OS CA-IX}

red-caix

Green-gapdh

order of gel (left to right)

ladder

U2-os

U2-os Mock

U2-os C2 CA-IX

U2-os C11 CA-IX

U2-os C15 CA-IX 


\section{Raw western - HEK293 CA-IX}

red-caix

Green-gapdh

order of gel (left to right)

ladder

Hek 293

Hek mock-2

Hek caix c2

Hek caix c3

Hek caix c7 


\section{Raw western - PMA1}

PMA1 (100KDa)

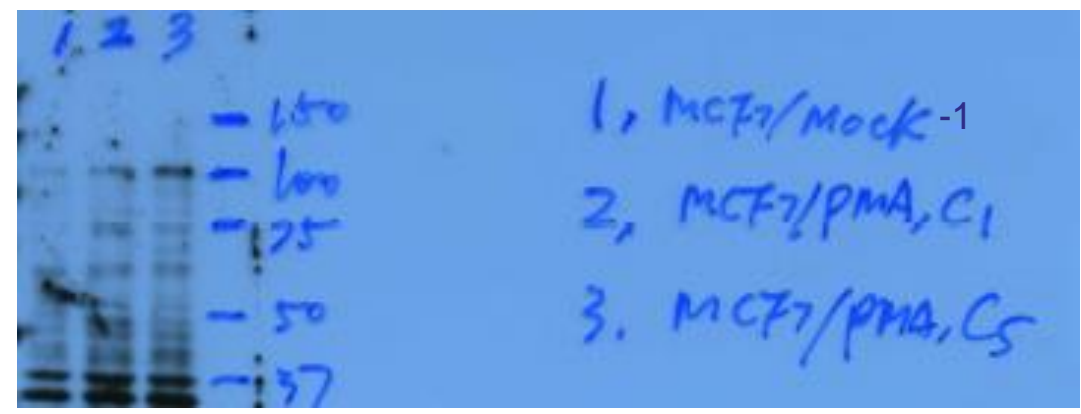

GAPDH (37KDa)

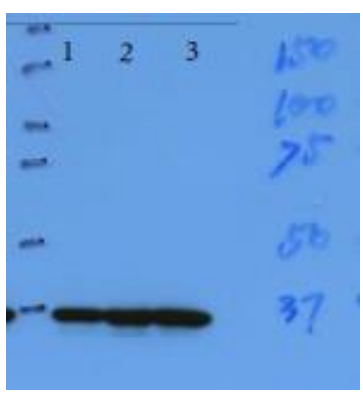




\section{Matlab code}

clear all

\& growth rates

GR_MOCK $=5.65773801$;

GR_PMA1_C1 $=6.71474358$;

H_C $5=3 . \overline{4} 0938755$;

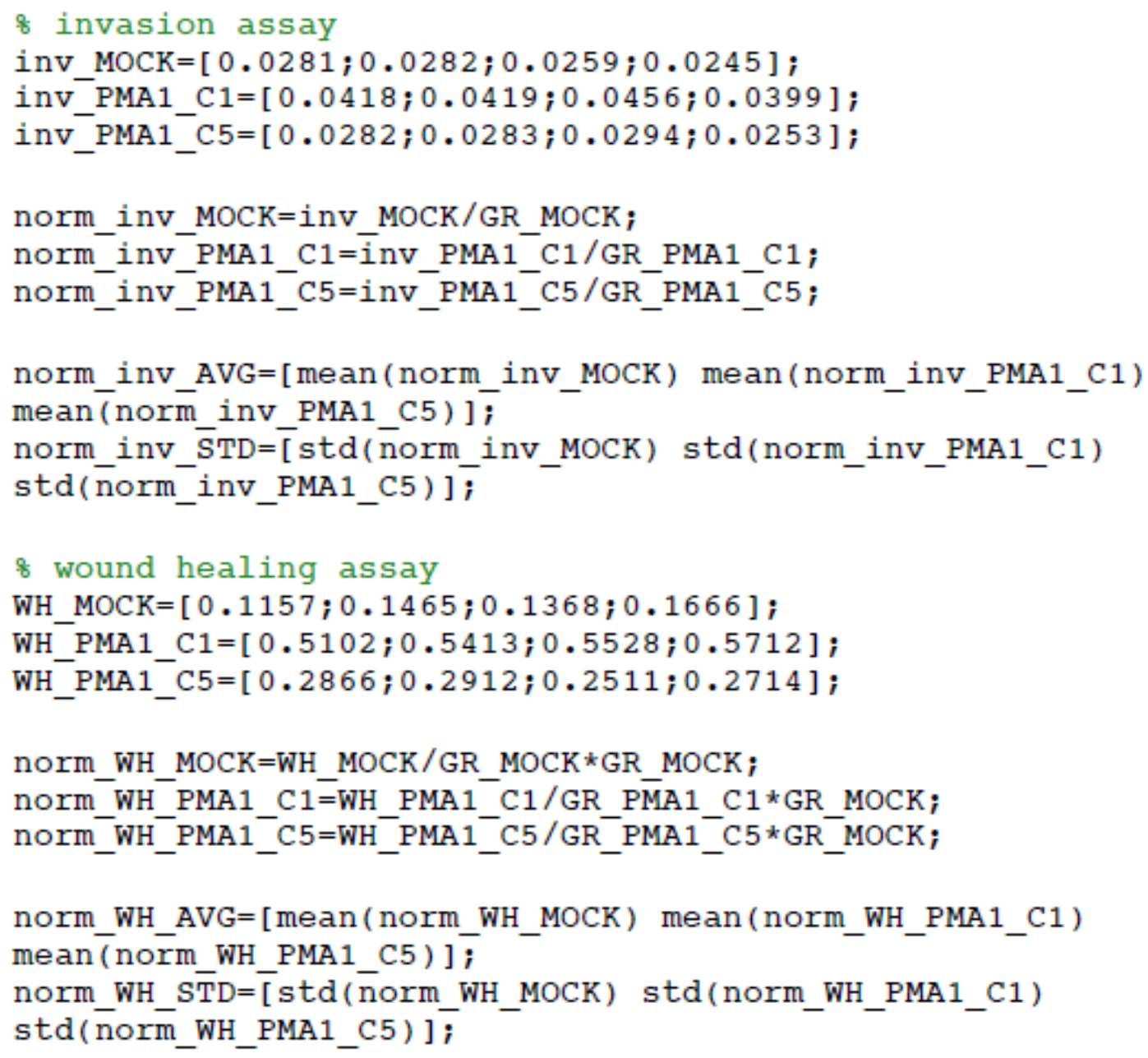

